\title{
Development of Emission Factors (EFs) Model for Coal Train Loading Operations
}

\author{
Bisleshana Brahma Prakash
}

Follow this and additional works at: https://researchrepository.wvu.edu/etd

\section{Recommended Citation}

Prakash, Bisleshana Brahma, "Development of Emission Factors (EFs) Model for Coal Train Loading Operations" (2016). Graduate Theses, Dissertations, and Problem Reports. 6448.

https://researchrepository.wvu.edu/etd/6448

This Thesis is protected by copyright and/or related rights. It has been brought to you by the The Research Repository @ WVU with permission from the rights-holder(s). You are free to use this Thesis in any way that is permitted by the copyright and related rights legislation that applies to your use. For other uses you must obtain permission from the rights-holder(s) directly, unless additional rights are indicated by a Creative Commons license in the record and/ or on the work itself. This Thesis has been accepted for inclusion in WVU Graduate Theses, Dissertations, and Problem Reports collection by an authorized administrator of The Research Repository @ WVU. For more information, please contact researchrepository@mail.wvu.edu. 


\title{
Development of Emission Factors (EFs) Model for Coal Train Loading Operations
}

\author{
Bisleshana Brahma Prakash
}

Thesis submitted to the

\author{
Benjamin M. Statler College of Engineering and Mineral Resources \\ at West Virginia University \\ in partial fulfillment of the requirements \\ for the degree of \\ Master of Science \\ in \\ Mining Engineering
}

\author{
Vladislav Kecojevic, Ph.D., Chair \\ Brijes Mishra, Ph.D. \\ Ashish Nimbarte, Ph.D.
}

Department of Mining Engineering

Morgantown, West Virginia

2016

Keywords: dust emission; coal train; emission factor; loading facilities; environmental impact

Copyright 2016 Bisleshana Brahma Prakash 


\begin{abstract}
Development of Dust Emission Factors (EFs) Model for Coal Train Loading Operations
\end{abstract}

\author{
Bisleshana Brahma Prakash
}

The objectives of this research were to conduct an analysis of dust emission and to develop a dust emission factors (EFs) model for coal train loading operations. To achieve these objectives, field measurements and data collection were carried out at a facility operating along with a coal mine in West Virginia, U.S. The dust emission for the train loading point was determined by two methods: (i) the EPA AP-42 emission factor estimation equations (AP-42 Dust Emission Estimation), and (ii) the methodology used in the development of AP-42 equations (Type-2 Dust Emission Estimation). The analysis of dust emission revealed that dust emission obtained by the former method exceeded the field-based emission determined by the Type-2 Dust Emission Estimation method for this particular loading facility. Based on the data analysis, reconsideration of EFs for train loading operations and development of improved methods for estimation of EFs was suggested. A new model for estimating EF equations for train loading operations was developed based on multiple regression analysis. The development of new EFs was based on the use of on-site meteorological data, i.e., temperature, wind speed, moisture content of coal, and humidity. The wind speed and moisture content of coal were found to be statistically significant and were included in the final model. Though the temperature and humidity had some effect on the EFs, they were excluded from the final model due to statistical insignificance. This research may assist mining and environmental professionals in quantifying dust emission at train loading facilities and developing strategies for reducing its health and environmental impacts. 


\title{
Development of Emission Factors (EFs) Model for Coal Train Loading Operations
}

\author{
Bisleshana Brahma Prakash \\ Thesis submitted to the \\ Benjamin M. Statler College of Engineering and Mineral Resources \\ at West Virginia University \\ in partial fulfillment of the requirements \\ for the degree of \\ Master of Science \\ in \\ Mining Engineering
}

Department of Mining Engineering

APPROVAL OF THE EXAMINING COMMITTEE

Vladislav Kecojevic, Ph.D., Chair

Brijes Mishra, Ph.D.

Date

Ashish Nimbarte, Ph.D. 


\section{TABLE OF CONTENTS}

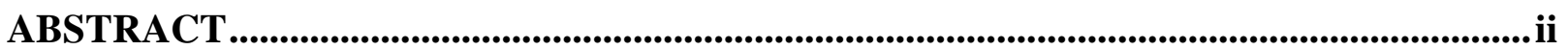

LIST OF TABLES

LIST OF FIGURES ......................................................................................................

LIST OF ABBREVIATIONS ......................................................................................................... viii

ACKNOWLEDGEMENT .....................................................................................................ix

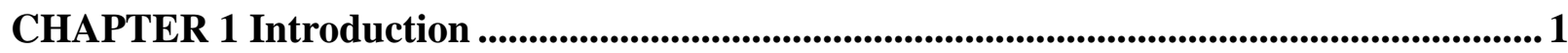

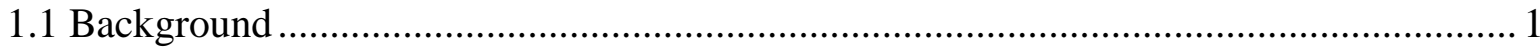

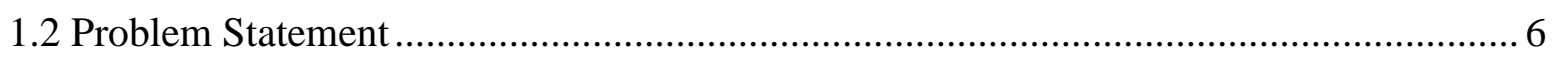

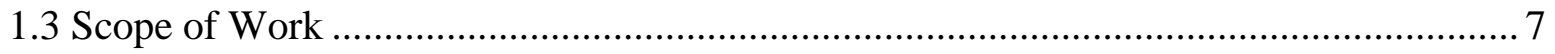

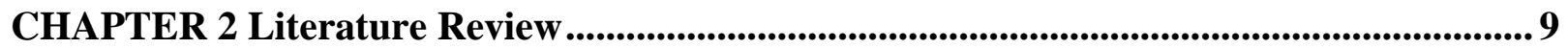

CHAPTER 3 Methodology.................................................................................................................. 18

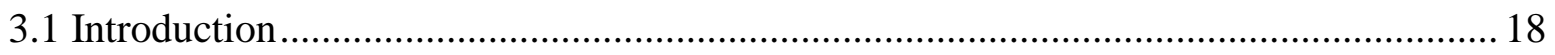

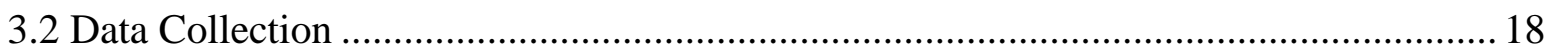

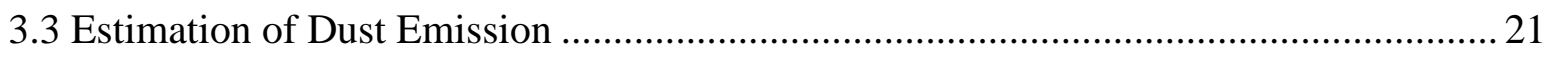

3.4 Factors that affect Dust Emission and Suspension ......................................................... 30

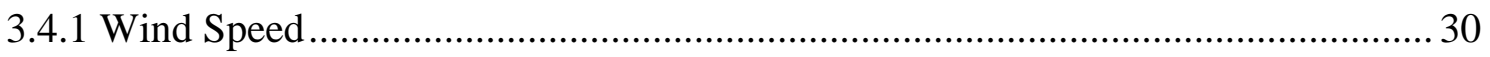

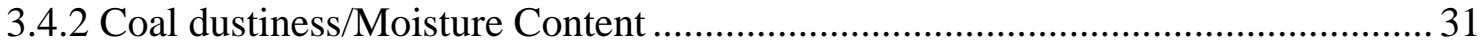

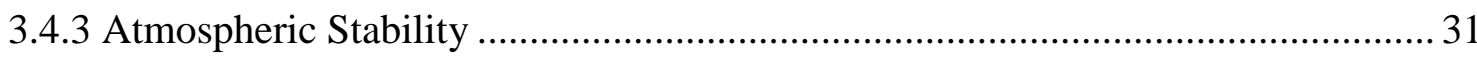

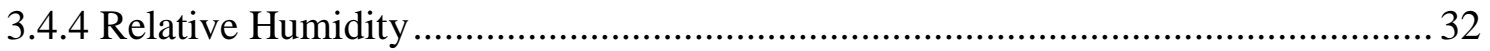

3.5 Development of Emission Factor Model …………………..............................................33

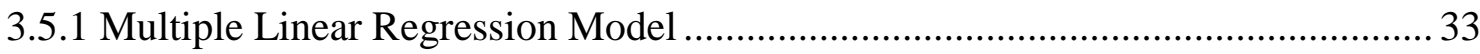




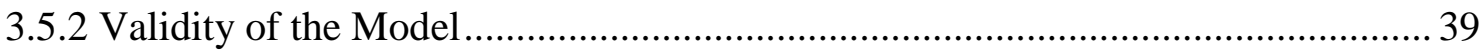

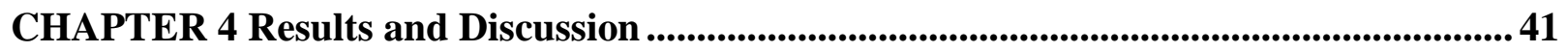

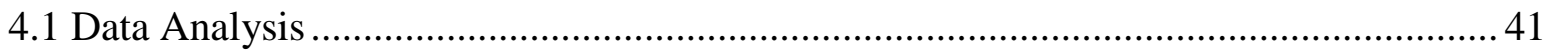

4.2 Multiple Regression Model.......................................................................... 60

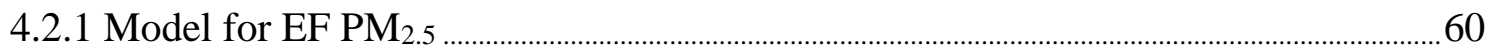

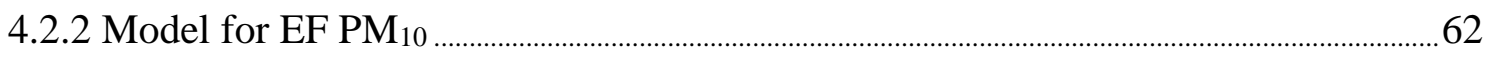

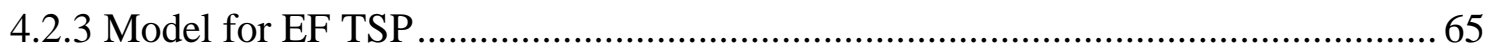

CHAPTER 5 Summary, Conclusions, Limitations, and Scope for Future Research ........ 69

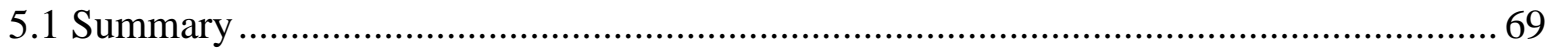

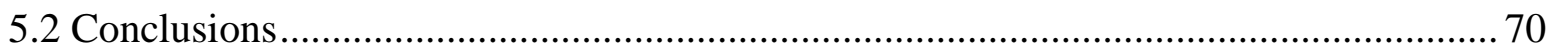

5.3 Limitations and Scope for Future Research................................................... 72

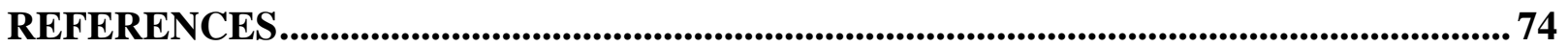




\section{LIST OF TABLES}

Table 1.1. U.S. occupational exposure limits ................................................................ 4

Table 1.2 Atmospheric lifetime and potential travel distance for particles of various size

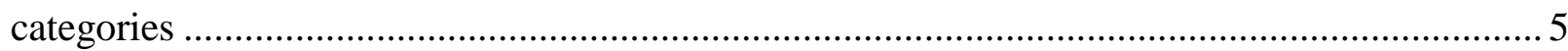

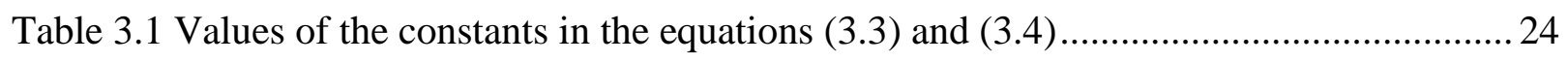

Table 3.2 Parameters used to calculate Pasquill-Gifford, ' $\sigma_{\mathrm{y}}$ ' in equation (3.5) and (3.7)........ 25

Table 3.3 Parameters used to calculate Pasquill-Gifford, ' $\sigma_{z}$ ' in equation (3.7) ................25-26

Table 3.4 Values of the wind profile exponent in the equation (3.9) .....................................2 27

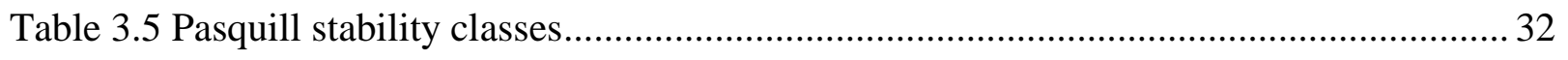

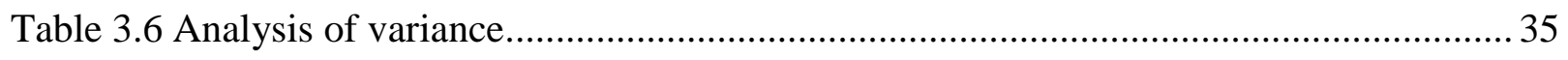

Table 4.1 Calculation of AP-42 dust emissions based on equations (3.1) and (3.2) ...........44-47

Table 4.2 Calculation of Type-2 dust emissions based on equation (3.3) and (3.4)............48-50

Table 4.3 Calculation of Type-2 dust emissions based on equation (3.5) and (3.7)............51-53

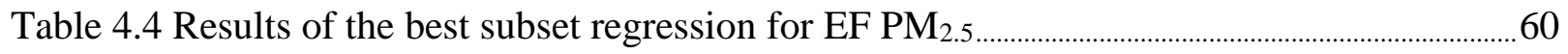

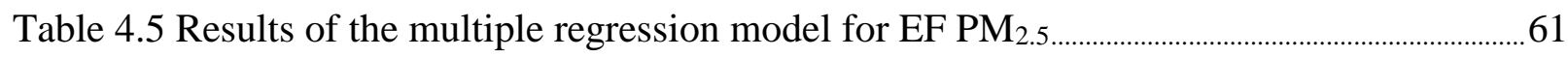

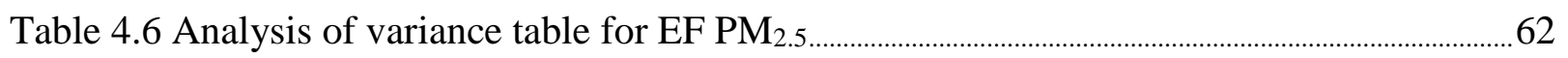

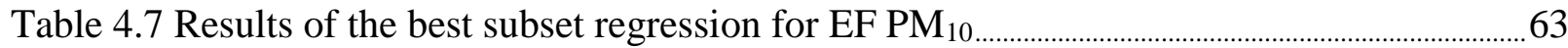

Table 4.8 Results of the multiple regression model for EF PM $10 \ldots \ldots \ldots \ldots \ldots \ldots \ldots \ldots \ldots \ldots \ldots \ldots \ldots \ldots \ldots \ldots \ldots \ldots \ldots \ldots \ldots \ldots \ldots . . .64$

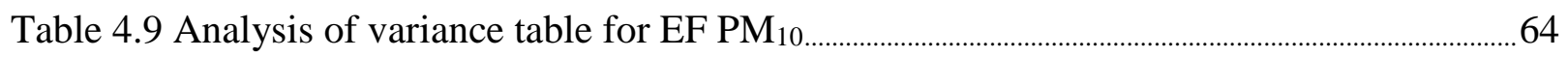

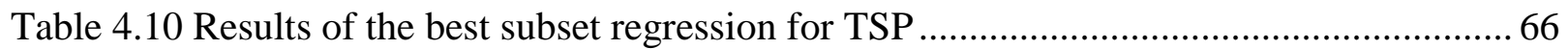

Table 4.11 Results of the multiple regression model for TSP ...........................................67 67

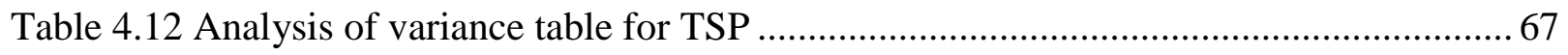




\section{LIST OF FIGURES}

Figure 1.1 Approach to emission estimation ................................................................. 3

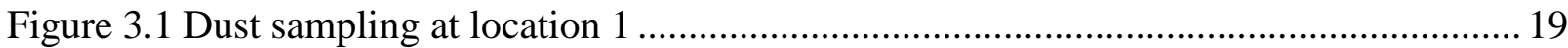

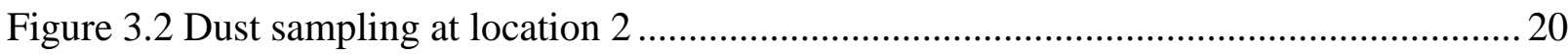

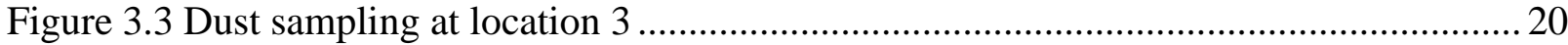

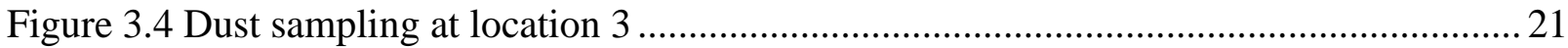

Figure 4.1 Dust concentration for a 47-min period of coal train loading at Location 1 ............42

Figure 4.2 Dust concentration for an 8-min period of coal train loading at Location 2 ............42

Figure 4.3 Dust concentration for a 120-min period of coal train loading at Location 3 ..........43

Figure 4.4 Comparison of $\mathrm{PM}_{2.5}$ emissions at coal train loading point (using equation (3.3)

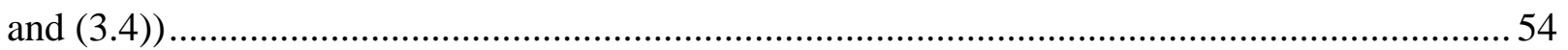

Figure 4.5 Comparison of $\mathrm{PM}_{2.5}$ emissions at coal train loading point (using equation (3.5)

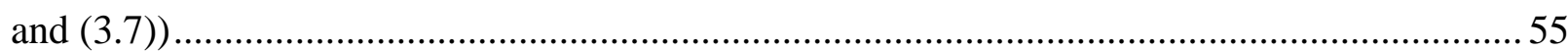

Figure 4.6 Comparison of $\mathrm{PM}_{10}$ emissions at coal train loading point (using equation (3.3)

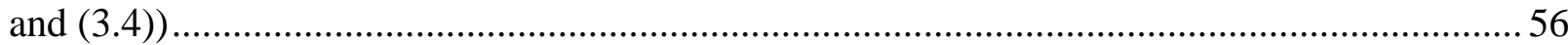

Figure 4.7 Comparison of $\mathrm{PM}_{10}$ emissions at coal train loading point (using equation (3.5)

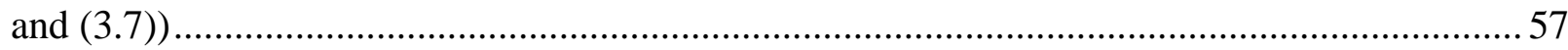

Figure 4.8 Comparison of TSP emissions at coal train loading point (using equation (3.3)

And (3.4))

Figure 4.9 Comparison of TSP emissions at coal train loading point (using equation (3.5)

and (3.7)) 


\section{LIST OF ABBREVIATIONS}

ARTC Australian Rail Track Corporation

CAC Criteria Air Contaminants

CRG Columbia River Gorge

DCP Dynamic Component Program

DEM Dust Extinction Moisture

DLMM Door Loss Measurement Mechanism

DPM Diesel Particulate Matter

DSITIA Department of Science, Information Technology, Innovation and the Arts

EDS Emission Factor Development Study

EF Emission Factor

EFIG Emission Factor and Inventory Group

EPA Environmental Protection Agency

EPCRA Emergency Planning And Community Right-To-Know Act

FRM Federal Reference Method

HAP Hazardous Air Pollutant

$\mathrm{MS}_{\mathrm{E}} \quad$ Mean Square Error

NSW New South Wales

OAQPS Office of Air Quality Planning and Standards

OEL Occupational Exposure Limit

$\mathrm{SS}_{\mathrm{E}} \quad$ Sum of squares considering error

$\mathrm{SS}_{\mathrm{R}} \quad$ Sum of squares considering regression

TSP Total Suspended Particulate

VIF Variance Inflation Factor 


\section{Acknowledgement}

My heart is filled with gratitude for all those who helped me in the completion of this project.

First and foremost, I would like to express my most sincere appreciation and indebtedness to Dr. Vladislav Kecojevic for allowing me to pursue the present topic, "Development of Emission Factors (EFs) Model for Coal Train Loading Operations," and later for his inspiring guidance, constructive criticism, and valuable suggestions throughout this project. I am very thankful to him for his able guidance and painstaking efforts to improve my understanding of this project and expand my knowledge as a graduate student.

I would further like to thank my committee members, Dr. Brijes Mishra and Dr. Ashish Nimbarte, for their valuable time spent for reviewing my thesis.

I also would like to thank the coal mining industry for providing data for this research and for financial assistance.

Finally, I extend my sincere thanks to my parents, colleagues, and all my friends who provided me with unconditional support and guidance throughout my graduate studies. 


\section{Chapter 1}

\section{Introduction}

\subsection{Background}

Coal dust is a pollutant that can result from train loading operations. It can have an adverse effect on human health and the surrounding environment. Coal dust is a complex and heterogeneous mixture containing more than 50 different elements and their oxides (NIOSH, 1995). The mineral content varies with the particulate size of the dust and with the coal seam. Common minerals associated with coal dust include quartz (crystalline silica), kaolinite, illite, calcite, pyrite, and sulfur varying from $0.5 \%$ (by weight) to more than $10 \%$. Exposure to respirable dust containing crystalline silica causes the death of more than 250 workers in the U.S. each year (Reed, 2005). Quartz in respirable dust can cause lung emphysema and cancer (Inyang and Bae, 2006). The effects of dust on the agriculture and ecology of an area depend on the size distribution, deposition rate, and concentration of dust particles in the ambient air. A thick coating of dust on vegetation can abrade plant surfaces and bury organisms and photosynthetic organs (Grantz et al., 2003). Therefore, estimating coal dust emission at train loading facilities, and developing mitigation strategies is critical.

Particulate matter is a term used to define solid or liquid particles that may be suspended in the atmosphere (Katestone, 2014). Particulate matter is a generic term that is commonly used interchangeably with other terms such as soot, haze, smoke, and dust (including coal dust). The potential effect of particulate matter on human health, vegetation, and the environment depends 
on the size of the particles, the concentration of particulate matter in the atmosphere, and the rate of deposition. According to the size of the component particles, dust is classified as follows: total suspended particulate (TSP), inhalable dust $\left(\mathrm{PM}_{10}\right)$, respirable dust $\left(\mathrm{PM}_{4}\right)$, and particulate matter $2.5\left(\mathrm{PM}_{2.5}\right)$. TSP refers to particles ranging in size from 0.1 micrometer to about 30 micrometers in diameter (EPA, 1998). Inhalable particles $\left(\mathrm{PM}_{10}\right)$ refers to particulate matters with a diameter of 10 micrometers collected with $50 \%$ efficiency by a $\mathrm{PM}_{10}$ sampling collection device. The particulate matters with a diameter of 2.5 micrometers collected with $50 \%$ efficiency by a $\mathrm{PM}_{2.5}$ sampling collection device are called fine particles $\left(\mathrm{PM}_{2.5}\right)$. The particles less than 1 micrometer in diameter are referred to as $\mathrm{PM}_{1}$.

Emission estimates are critical for determining the applicability of permitting and control programs, ascertaining the effects of sources and appropriate mitigation strategies, developing emission control strategies, and other related applications. Emission estimates are used by an array of users, including federal, state, and local agencies, consultants, and industry. Various approaches to emission estimation are available.

Figure 1.1 shows the various approaches to emission estimation, in a hierarchy of requirements and levels of sophistication one must consider while trading off between the quality of the resulting estimates and cost of the estimates (EPA, 2015a). When the risks of adverse environmental effects are high, more costly and sophisticated methods of emission may be necessary. However, if the risks of using a poor estimate are low, then cheaper estimation methods such as emission models and emission factors may be both satisfactory and appropriate. Selection of appropriate method to estimate source-specific emissions may warrant a case-by-case analysis considering the costs and associated risks in the particular situation. 


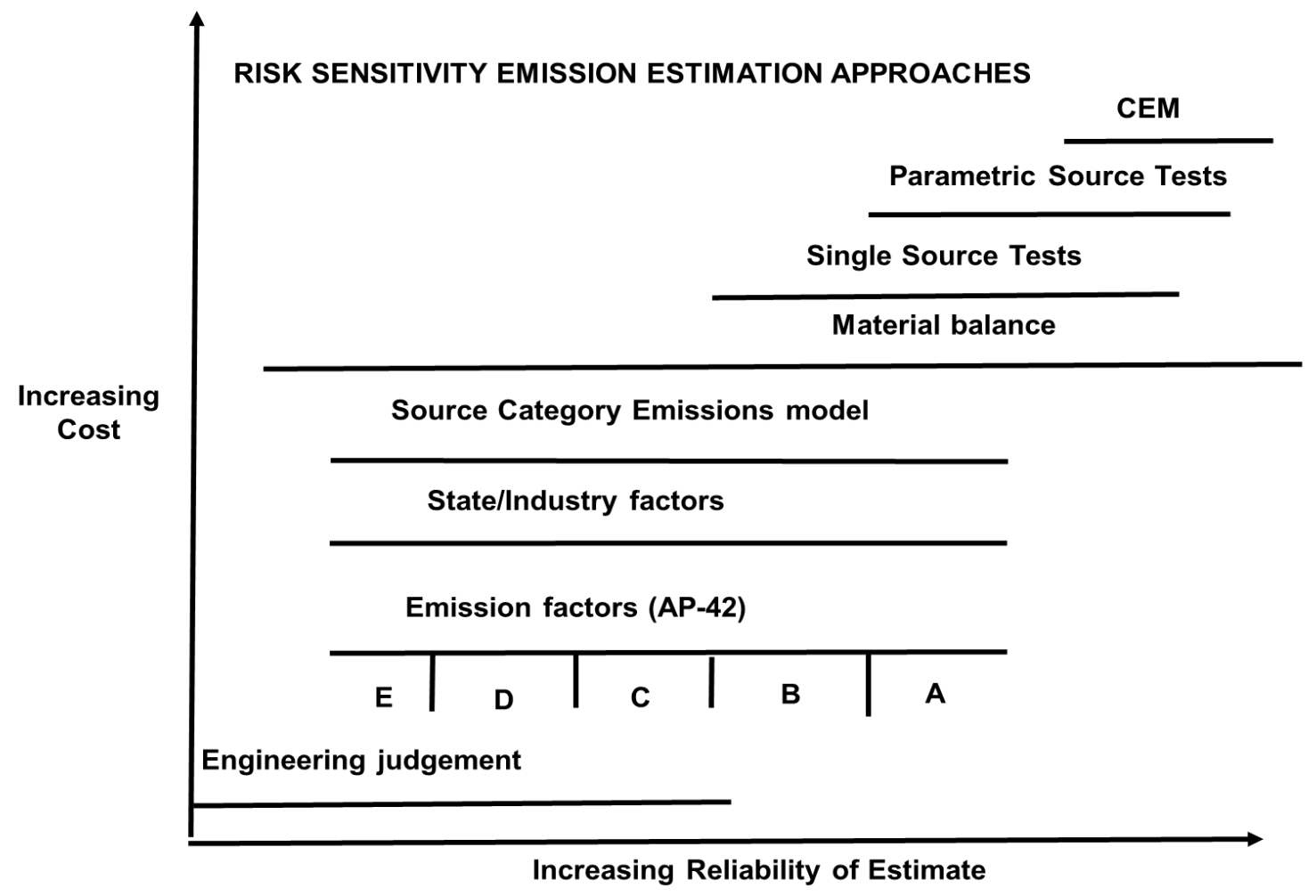

Figure 1.1 Approach to emission estimation (EPA, 2015a)

An emission factor $(\mathrm{EF})$ is a representative value that attempts to relate the quantity of a pollutant released to the atmosphere with an activity associated with the release of that pollutant. Emission factors are usually expressed as the weight of pollutant divided by a unit weight, distance, volume, or duration of the activity emitting the pollutant (e. g., kilograms of particulate emitted per mega gram of coal burned). Emission factors facilitate the estimation of emissions from various sources of air pollution. Average emissions differ significantly from source to source as well as similar individual sources depending upon the process, control system, and type of pollutant. Thus, emission factors may not provide sufficient estimates of the average emissions for a specific source. The extent of variability that exists causes some of the emission factors derived from tests to vary by an order of magnitude or more. Despite their limitations, emission factors are frequently used for estimating emissions (EPA, 2015a). 
The preferred methods of estimating a source's emission are source-specific tests or continuous emission monitors, as the data generated from these methods provide the best representation of the tested source's conditions. However, test data from individual sources are not always available. Also, the test data may not reflect the variability of actual emissions over longer periods of time (e.g. yearly or typical day) (EPA, 2015a).

Two legislative acts regulate air quality from mining operations: (i) the Federal Mine Safety and Health (MSHA) Act of 1977 (NIOSH, 1995), which regulates the amount of dust allowable in the air for health and safety purposes, and (ii) the Clean Air Act of 1970, further amended in 1977 and 1990 (Schnelle and Dey, 2000), which regulates air quality from facilities from an environmental perspective. Table 1.1 summarizes occupational exposure limits in the U.S. by various organizations. The need for Hazardous Air Pollutant (HAP) and criteria emission factors and inventories have increased greatly due to Clean Air Act Amendments of 1990 (CAAA) and the Emergency Planning And Community Right-To-Know Act (EPCRA) of 1986 (EPA, 2015a). The Emission Factor and Inventory Group (EFIG) in the U.S. Environmental Protection Agency's (EPA) Office of Air Quality Planning and Standards (OAQPS), develops and maintains emission estimating tools for air quality management.

Table: 1.1. U.S. occupational exposure limits (OEL) (OSHA, 2015)

\begin{tabular}{cc}
\hline Organization and OEL type & Quartz-TWA \\
\hline OSHA PEL/ MSHA PEL & $\frac{10 \mathrm{mg} / \mathrm{m}^{3}}{\% \mathrm{SiO}_{2}+2}$ \\
NIOSH PEL & $0.05 \mathrm{mg} / \mathrm{m}^{3}$ \\
ACGIH TLV & $0.025 \mathrm{mg} / \mathrm{m}^{3}$ \\
\hline
\end{tabular}


Previously, TSP was regulated by the U.S. Environmental Protection Agency (EPA), but in the past few years the focus has shifted to fine and inhalable particles, as inhalable particles pose the biggest threat due to their longer atmospheric lifetime and their tendency to get deep into the lungs and sometimes the bloodstream (EPA, 1998). The atmospheric lifetime of particulate matter refers to the duration of time the particle is airborne and depends on the size of the particle. Coarse (large) particulate matter tends to deposit quickly and in relative proximity to its original point of source emission while fine particulate matter may remain suspended in the atmosphere for many days and travel many hundreds of kilometers. Table 1.2 summarizes the atmospheric lifetimes of particles and potential travel distances based on particle size (EPA, 1996).

Table 1.2 Atmospheric lifetime and potential travel distance for particles of various size categories (EPA, 1996)

\begin{tabular}{ccl}
\hline $\begin{array}{c}\text { Particle } \\
\text { Size }\end{array}$ & Atmospheric & \multicolumn{1}{c}{ Travel Distance } \\
\hline TSP & Minutes to hours & Typically deposits within the proximate area downwind of \\
& & the point of emission \\
PM10 & Days & Up to 100 kilometers or more \\
$\mathbf{P M}_{2.5}$ & Days to week & Hundreds to thousands of kilometers \\
\hline
\end{tabular}

Sources of air pollutants are primarily categorized into point sources and fugitive sources (IFC, 2007). Point source emissions refer to discrete, stationary, identifiable sources of emissions that release pollutants into the atmosphere. There may be several individual 'emission points' within a given point source. Emission points refer to a specific stack, vent, or other discrete point of pollution release. Fugitive source air emissions are distributed spatially over a wide area and not confined to a specific discharge point. They are generated in operations where exhausts are not 
captured and passed through a stack. Mobile sources include all nonstationary sources, such as automobiles, trucks, aircraft, trains, and construction and farm equipment, and are a subcategory of area sources (EPA, 2001).

\subsection{Problem Statement}

EPA has created a list of approved equations that attempt to quantify the amount of pollutants that include dust generated from specific operations at various industries. A listing of the equations primarily used to estimate emission, called emissions factors, can be found in the Compilation of Air Pollutant Emission Factors (AP-42) published by EPA (2015b). The AP-42 document is based on data collected from western surface coal mines and also includes equations for train loading facilities. This document contains a number of equations used to determine fugitive dust EFs as well as process information for more than 200 classes of air pollution sources. These equations are based on the observations of dust concentrations from specific industrial operations and can be used to determine the amount of dust produced by particular operations. In section 9 of chapter 11 of the EPA's AP-42, information regarding western U.S. surface coal mining is provided. This section includes EF estimation equations for blasting, truck loading, bulldozing, dragline, grading, aggregates handling, storage piles, and train loading facilities. The dust-specific equations quantify dust in the size range of 30 microns and below.

Lashgari and Kecojevic (2015) conducted a comparative analysis of dust emission of digging and loading equipment in surface coal mining, specifically front-end wheel loader and cable shovel. The authors compared the dust emissions by the EPA AP-42 EF estimation equations (AP-42 dust emission estimation) vs. field study and found the EPA AP-42 emission factor method over-predicted dust emission for overburden loading operations in a specific surface coal mine. 
The results indicated a need for the development of improved methods for EF estimation and use of on-site meteorological data where the estimation of dust concentration is required for digging and loading operations for a particular site.

The literature survey reveals that the Emission Factor Development Study (EDS) conducted in 1978 and 1979 (Shearer et. al., 1981) to develop Particulate Matter emission factors was the latest research in this area; no further studies have been found for the estimation of dust emission for coal loading facilities. Over the years several changes have taken place, particularly in the technology used in coal loading facilities. This research gap provides impetus for research on dust emission for coal train loading facilities. The EDS forms one of the bases of EPA (2015a)published Compilation of Air Pollutant Emission Factors (AP-42 documents).

\subsection{Objective and Scope of work}

Based on the research gap identified, the study has the following objectives:

a) To conduct an analysis of dust emission for a coal train loading facility; and

b) To develop dust emission factors (EFs) model for coal train loading operations.

The first objective was determined by two methods: (i) the EPA AP-42 emission factor estimation equations (AP-42 Dust Emission Estimation), and (ii) the methodology used in the development of AP-42 equations (Type-2 Dust Emission Estimation). By this analysis, new EF equations for train loading operations using multiple regression analysis were used to develop the model for the second objective. The development of new EFs is based on the use of on-site meteorological data where the estimation of dust particulate concentration for train loading operations for a particular site. 
In order to solve the problem, the research goals are to:

a) Compare dust emission for a coal train loading facility using two methods: (i) the EPA AP42 emission factor estimation equations (AP-42 Dust Emission Estimation), and (ii) the methodology used in development of AP-42 equations (Type-2 Dust Emission Estimation);

b) Develop a regression model to determine which of the available measured parameters influence the EF;

c) Find the preferences for parameters that affect the EF estimation the most;

d) Construct a logical and easy to use model to provide the estimation of EF for train loading operations based on previously defined preferences.

This thesis is separated into five chapters, each presenting a necessary step required to accomplish the overall project objectives. The brief outline of the thesis can be presented as follows: (i) Chapter 1 includes a short introduction to the impact of dust emissions and an overview of the scope of work; (ii) Chapter 2 includes a review of literature relating to already existing methodologies and models for dust emission for a coal train loading facility; (iii) Chapter 3 includes the methodology used for the analysis of dust emission for a coal train loading facility and creation of a new model that attempts to correct the over-prediction of AP-42 equations; (iv) Chapter 4 includes results and discussion of the applied methodology and compares the results of field study to the results of the AP-42 equations and new model; and (v) Chapter 5 states and summarizes the conclusions from the research, limitations, and scope for future work related to the topic. 


\section{Chapter 2}

\section{Literature Review}

There are a number of studies related to the estimation of the emission rate of dust from coal trains at rail corridors, however, a very limited number of them at coal train loading points.

Szabo (1978) studied the primary and secondary environmental impacts resulting from transportation of coal by slurry pipeline, railroad, barge, truck, and conveyor. Also, the impacts from coal preparation and associated activities, such as loading and unloading and energy efficiencies of the transport modes were analyzed. The loss of particulates in transit varies with the type of coal shipped, moisture and fine content of coal, speed of the train, condition of the cars, and wind speed. The author suggested a focus on research aimed at developing sprays that will hold coal fines in place at a reasonable cost.

Norfolk Southern Rail Company (NS) conducted studies to quantify the amount of coal dust generated during rail transport of coal and to determine the effects of several dust suppression techniques, including load shaping, water spraying, and surfactant spraying. (Commonwealth of Virginia, 1997). The studies found that the average material losses from untreated cars were estimated at 0.36 tonnes and 0.20 tonnes for unshaped and shaped wagons respectively. Chemical treatment combined with load shaping reduced fugitive dust emissions by up to $95 \%$. Also, water spray at the mine was only effective for the first two to three hours of each trip. Moreover, tunnels, trestles, topographic interfaces, and trains accelerating from $24-48 \mathrm{~km} / \mathrm{hr}$ and passing oncoming trains were associated with an increase in fugitive dust. 
Cope and Bhattacharyya (2001) conducted a study to estimate fugitive coal dust emissions for various coal mining operations, from mine to end-use facility. A significant portion of the investigation focused on fugitive coal dust emission related to the transport of coal by rail in Canada, as the present emission factors (EFs) for estimating fugitive coal dust from unit trains were questioned. The emission factors to quantify coal dust emissions were developed in the late 1970s and early 1980s. Also, the emission factors were based on studies that suggested that, for uncontrolled trains travelling over a distance of $1100 \mathrm{~km}$ on rough terrain during dry conditions, the maximum potential coal losses (in the form of TSP) were estimated to be in the range from $0.5 \%$ to $3.0 \%$ of the total coal load. This is equivalent to a rate of $0.0045 \mathrm{~kg} / \mathrm{tonne} / \mathrm{km}$ to 0.027 $\mathrm{kg} /$ tonne $/ \mathrm{km}$. Emission rates of $\mathrm{PM}_{10}$ can be calculated by multiplying the TSP emission factor by 0.5. The basic Environment Canada's National Criteria Air Contaminants (CAC) inventory was modified using new $\mathrm{PM}_{10}$ and $\mathrm{PM}_{2.5}$ scaling factors, precipitation factor, adjusted dust control factor of 99\%, and linear distance factor to prorate emissions.

Kotchenruther (2013) estimated coal train fugitive dust impacts in Tacoma, Washington, U.S. The author looked into rail routes from Powder River Basin to proposed U.S. Pacific Northwest Coal Terminals and found that the number of coal trains per day on rail routes would significantly increase if these terminals are built. The yearly emission of $\mathrm{PM}_{2.5}$ for Tacoma was calculated based on Canadian Emission factor as reported by Cope and Bhattacharyya (2001).

Connell Hatch (2008) conducted an environmental evaluation for Queensland Rail Limited to identify, quantify, and assess risk, and propose mitigation measures relating to fugitive dust emissions from coal trains. Connell Hatch found that around $80 \%$ of coal dust emissions from moving trains occur from the surface of the wagon. The other major factors were spilled coal (9\%), and door leakage $(6 \%)$. The key factor that contributes to the emission rate of coal dust from 
wagons is the speed of the air passing over the coal surface that in turn is influenced by train speed and ambient wind speed. Also, TSP monitored did not exceed the guideline of $150 \mu \mathrm{g} / \mathrm{m}^{3}$ provided by Queensland Environmental Protection (Air) Policy (EPP, 2008) over the monitoring period for each site.

Burlington Northern Santa Fe Railway (BNSF, 2010) conducted Super Trial in Powder River Basin to develop and provide information on coal dust suppression technologies that help coal shippers implement effective coal dust control measures. The 'Super Trial' involved treatment of 1,633 trains with either a 'body treatment' or a 'topical treatment'. In a body treatment, the chemical agent used for suppressing coal dust emissions from loaded trains was applied to the coal before the coal was loaded into the railcars. The chemical was also applied to the coal after it was loaded into railcars. The trial showed that treatment of loaded coal substantially reduces coal dust emissions with trains while those that were body treated showed only a limited reduction. However, there was potential for inconsistency in both load shaping and application of the dust suppression treatment, thereby reducing the effectiveness of the treatment.

Jaffe et al. (2015) examined the emissions of coal dust and diesel particulate matter (DPM) from both freight and coal trains in the Columbia River Gorge (CRG) in the state of Washington, U.S. The authors found a diesel PM mean value of $1.2 \mathrm{gm} / \mathrm{kg}$ fuel, which was in conjunction with U.S. EPA projection for 2013. Nearly all coal trains appeared to generate some degree of coal dust $\left(\mathrm{PM}_{2.5}\right)$. 4 out of the 74 coal trains (5.4\%) were "Super Dusters;" i.e., these trains were responsible for massive clouds of visible coal dust and high $\mathrm{PM}_{2.5}\left(50-250 \mu \mathrm{g} / \mathrm{m}^{3}\right)$ and $\mathrm{PM}_{10}$. They also concluded that a significant increase in rail traffic would put the locations (Seattle and Bellingham) at risk of exceeding air quality standards. 
Ferreira et al. (2003) conducted full-scale tests on coal wagons in Portugal to evaluate the effectiveness of two different types of partial covers. The authors observed that coal cars equipped with even partial covers emitted much less coal dust than those without covers. The wagons tested had partial covers with a gap of $1 \mathrm{~m}$. Ferreira and Vaz (2004) used scale model trains in a wind tunnel to show that more than 80 percent reduction in dust emissions can be achieved by covering coal wagons. The reduction was achieved in the semi-cover system, despite the existence of a $1 \mathrm{~m}$ wide gap along the upper part of the wagon.

Aurecon Hatch (2009) conducted a study in the Queensland region to identify variables that could influence whether and how much coal would be lost from doors. Some of the variables included coal type and rank, metrological conditions, washed/unwashed content, moisture, proportions of fines, track geometry and condition, and wagon design, condition, and maintenance. During the study, they used an innovative Door Loss Measurement Mechanism (DLMM) to capture losses for both loaded and unloaded coal trains through Kwik-Drop doors. In DLMM design, four overlapping trays housed in a frame attached to the bottom of the wagon are incorporated. It was concluded that no significant correlation between coal loss and door clearance measurements could be established.

The Queensland Department of Science, Information Technology, Innovation, and the Arts (DSITIA) conducted Tennyson Dust Monitoring Investigation (DSITIA, 2012) in the Brisbane suburb of Tennyson to study Particulate levels $\left(\mathrm{PM}_{10}\right)$ and dust deposition in or near the rail corridor and also the contribution of coal particles in deposited dust. The study found the average $\mathrm{PM}_{10}$ level was $26.6 \mu \mathrm{g} / \mathrm{m}^{3}$ at the Tennyson station site and did not exceed the Queensland Environmental Protection (Air) Policy 2008 (EPP) 24-hour average air quality objective (50 $\mu \mathrm{g} / \mathrm{m}^{3}$ ) during the study period. The primary depositional component was Mineral dust (crushed 
soil and rock particles) and coal dust accounting for $10-20 \%$ of the deposited samples at each of the sites.

The Coal Train Pollution Signature Study (2013) was conducted in the New South Wales (NSW) region to investigate the particulate signatures and increases in particulate levels from passing coal trains for residential areas close to a rail corridor (Higginbotham et al., 2013). Approximately $81 \%$ of the coal trains produced a recognizable pollution signature. The result focused on eight signatures (of 73 measured train passings), showing that $\mathrm{PM}_{10}$ levels rose between $94 \%$ and $427 \%$ for loaded coal trains; $1210 \%$ for unloaded coal trains. Also, the particulate pollution increased up to thirteen times when coal trains passed; however, freight trains showed much lower values.

Kane (2015) undertook a study to monitor particle pollution at several sites along the West Moreton rail line in Queensland to determine the pollution signatures from passing coal trains, both loaded and unloaded, in response to residents long-term pollution and health concerns. For the eight signatures reported, the loaded coal trains showed increases of $500 \%-1,000 \%$ over ambient levels of $\mathrm{PM}_{10}$ before the train passing, and 500\% - 900\% for unloaded. There was a significant difference in the intensity of the peak between different coal trains. Also, the data collected after rain events showed little or no signature. During train passings, areas adjacent to the coal corridor experienced intense PM pollution between 5-9 times pre-passing levels. Also, the trains were assumed to be veneered, thereby questioning the effectiveness of veneering in suppressing dust.

AECOM (2015) conducted a study to investigate black dust deposition in the Lower Hunter Region, NSW. The study was focused on larger dust particles likely to deposit in areas located along the railway corridors, and involved 12 months of monitoring. Three trends - long-term 
deposition (over about 30 days), short-term deposition (over period of less than three days), and composition were examined during sampling. The interim six months report suggested the greatest proportions of samples with an average of $73 \%$ comprising soil or rock dust. Also, the coal comprised on average $6.2 \%$ of the samples. From these six months of data, no conclusion has been drawn.

The Australian Rail Track Corporation (ARTC) implemented a pilot monitoring air quality program to find whether coal trains and rail transport contribute to ambient particulate levels along the Hunter Valley rail network (Environ, 2012). For this purpose, two sites, Mayfield and Metford, were selected. The analysis showed that the loaded coal trains had increased levels of TSP, PM10, and $\mathrm{PM}_{2.5}$ in both sites, the rail corridor data set as compared to no train. Also, the loaded coal, freight, and unloaded coal trains had statistically different, but only marginally higher $\mathrm{PM}_{2.5}$ concentrations, compared to passenger trains.

Ryan and Wand (2014) re-analyzed ARTC's data on particle emissions from coal and other trains. They concluded that trains operating on the Hunter Valley rail network were associated with elevated particulate matter concentrations, as significant increases in all four particle types including TSP, $\mathrm{PM}_{10}, \mathrm{PM}_{2.5}$, and $\mathrm{PM}_{1}$ - were observed when a train passed by the monitoring station. There was no evidence that loaded coal trains produce more dust compared to unloaded coal trains or freight trains. The findings also suggested that other contaminants such as diesel may be of more concern than coal dust.

Ryan and Malecki (2015) further extended the analysis of data from the ARTC on particle emissions from coal and other trains in the Hunter rail corridor based on the release of more data in the form of the number of locomotives pulling each train and precipitation records. The analysis 
suggested that the number of locomotives may have little influence on increased particulate levels associated with various types of trains passing (loaded and unloaded coal trains and freight trains). Rainfall data for two areas, Maitland and Cessnock, were taken into account. It was observed that particulate levels were significantly influenced by whether or not it had rained the previous day in Maitland; however, once Maitland rainfall was taken into account, Cessnock rain had no significant influence on particulate levels.

Katestone (2012) conducted a study to identify dust emissions from rail transport between Duralie and Stratford coal mines in NSW. The most significant source of rail-generated dust was found to be the coal surface of the wagons of coal-laden trains. The continued use of the two-stage water spray system at the rail loadout facility, which was reported to be $98 \%$ effective in controlling dust liftoff, was the recommended method for control of emissions from wagons. Veneering was not recommended as it was found to be only slightly more effective than water.

Katestone (2014) focused on current literature surrounding coal train dust management practices and measures relevant to the Hunter Valley rail corridor and other coal rail corridors in NSW. Irrespective of the type of train - loaded, unloaded, freight, and passenger - the dust levels increased near the rail corridor. Water or veneer suppressant were found to reduce top-of-wagon emissions by $50-99 \%$. Wagon lids were estimated to reduce dust off the top of the wagons by $99 \%$ but have significant disadvantages. The veneering costs for NSW were estimated at $\$ 0.02-0.04$ per tonne and water at $\$ 0.005$ per tonne.

NSW EPA (2014) completed a compliance audit program of eleven loadout facilities and four unloading facilities in NSW. In coal loading facilities, the audits examined management practices that could minimize primary sources of coal dust emissions from loaded coal trains 
during rail transport. The coal loading facilities that were fully automated and equipped with loading chutes achieved a consistent load profile height, shape, and distribution, and reduced dust emissions during transport. Monitoring ensured that the wagon doors were firmly closed before the train departed the loading station, thereby ensuring that coal was not spilled from the bottom of loaded wagons during transit. Also, at coal unloading facilities, the audits examined management practices to help minimize coal dust emissions from unloaded coal trains during rail transport. Closed circuit television cameras at unloading facilities automatically identified large quantities of 'hung up' coal in unloaded wagons. Also, controls were present to ensure wagon doors were closed after unloading. Coal overflows were identified by high hopper alarms, preventing coal being transferred into adjacent ballast or building up on the wagon wheels and axles.

Planner (ACARP, 2012) reviewed the current best practice in dust control techniques across the coal industry, from mine to port. The focus was on controlling the moisture content of the coal. Some of the suggested measures included are: (i) keeping coal above its DEM level during transport and handling, (ii) applying a veneer chemical treatment to coal surface for long distance rail travel, (iii) installing moisture monitoring equipment at rail discharge facilities, (iv) using water sprays at rail discharge facilities when needed, and (v) establishing minimum discharge height for stacking.

In the review of available literature, it can be observed that most studies were conducted on the effects of coal transportation by trains on surrounding area and recommended control strategies to address the problem. The EDS study to develop Particulate Matter emission factors carried out in 1978, and 1979 (Shearer et. al., 1981) was limited in scope to the western U.S.; so the model developed may not work in the other regions (EPA, 1998). This was the latest research, 
and as such, no further studies so far have been found for the estimation of dust emission for coal loading facilities. The other studies that have been conducted show that fugitive dust emissions depend on surface conditions, wind speed, and atmospheric and surface moisture. The emission rates developed from the EDS study concentrated on three factors - wind speed, moisture, and silt content of the material. However, other on-site metrological parameters, such as surface temperature and humidity, were not taken into account. With this background, the present research project was developed to achieve the defined objectives. 


\section{Chapter 3}

\section{Methodology}

\subsection{Introduction}

To achieve the objectives of this research, dust emission for the train loading facility was determined by two methods: (i) the EPA AP-42 emission factor estimation equations (AP-42 Dust Emission Estimation), and (ii) the methodology used in the development of AP-42 equations (Type-2 Dust Emission Estimation). Based on the analysis of the data, a new model for estimating EF equations for train loading operations was developed. The EF model was derived using a multiple regression analysis. A detailed explanation of the methodology is explained in the following chapter.

\subsection{Data}

Data on dust emission was collected at a loading facility that operates in conjunction with a coal mine in West Virginia. Train cars are loaded through the surge bin at the production rate of 3,265 t/hr. The time to load a train car is approximately 90 seconds. A total of 131 cars were loaded during the collection period on the first day, and a total of 130 cars were loaded during the second day. Dust concentrations at different distances and locations were collected during the field trip (Figures 3.1-3.4). TSI DustTrak DRX 8534 real-time aerosol monitoring instrument was used for collecting real-time measurements of dust concentration. The instruments provide particle matter concentrations in five size ranges - TSP, $\mathrm{PM}_{10}, \mathrm{PM}_{4}$ (Respirable), $\mathrm{PM}_{2.5}$, and $\mathrm{PM}_{1}$. The Kestrel 
4500 Weather Meter was used to collect necessary weather parameters required for the study such as wind speed, wind direction, temperature, humidity, and atmospheric pressure. The loading point for trains had enclosures and fluid was being sprayed into the empty train cars before being loaded. Overcast conditions were present on the first day, and the data was collected at night, while on the second day, the data was gathered in the afternoon and the sky was clear.

The mine provided the coal properties such as silt content and moisture content. After the field measurements had been completed, dust emission for the train loading point was estimated based on two methods: (a) emission determined directly using the EPA AP-42 EF estimation equations (AP-42 dust emission estimation), and (b) emission estimated based on the methodology used in the development of AP-42 equations (Type-2 dust emission estimation). Once the emission rates were calculated by the EPA AP-42 method (equation (3.2)) and by the Type-2 estimation method (equation (3.11)), a comparative analysis was conducted.

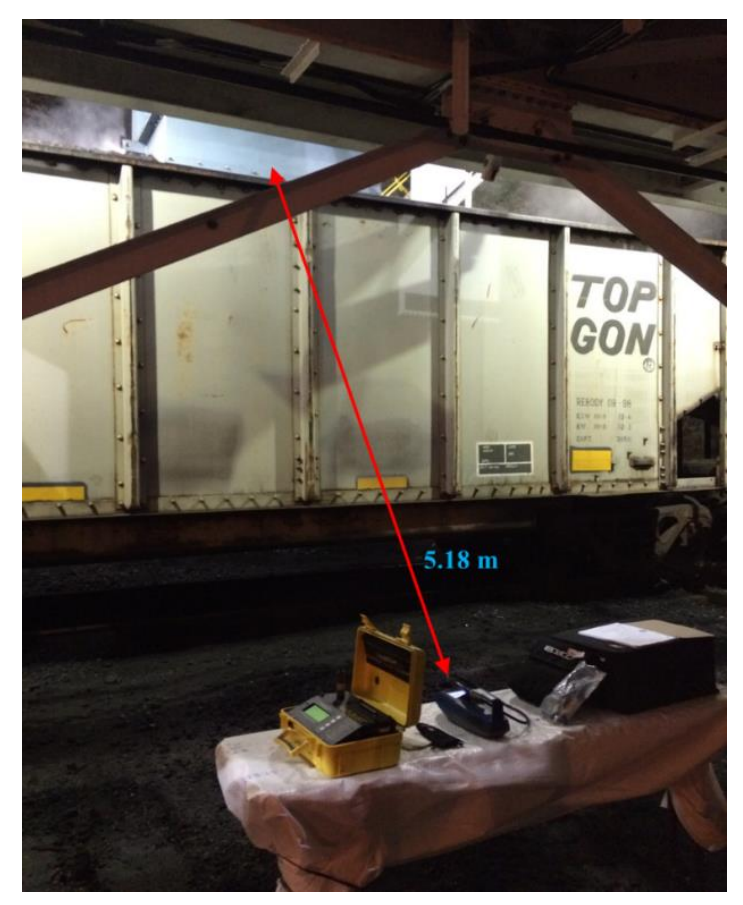

Figure 3.1. Dust sampling at location $1(5.18 \mathrm{~m}$ away from the source) 


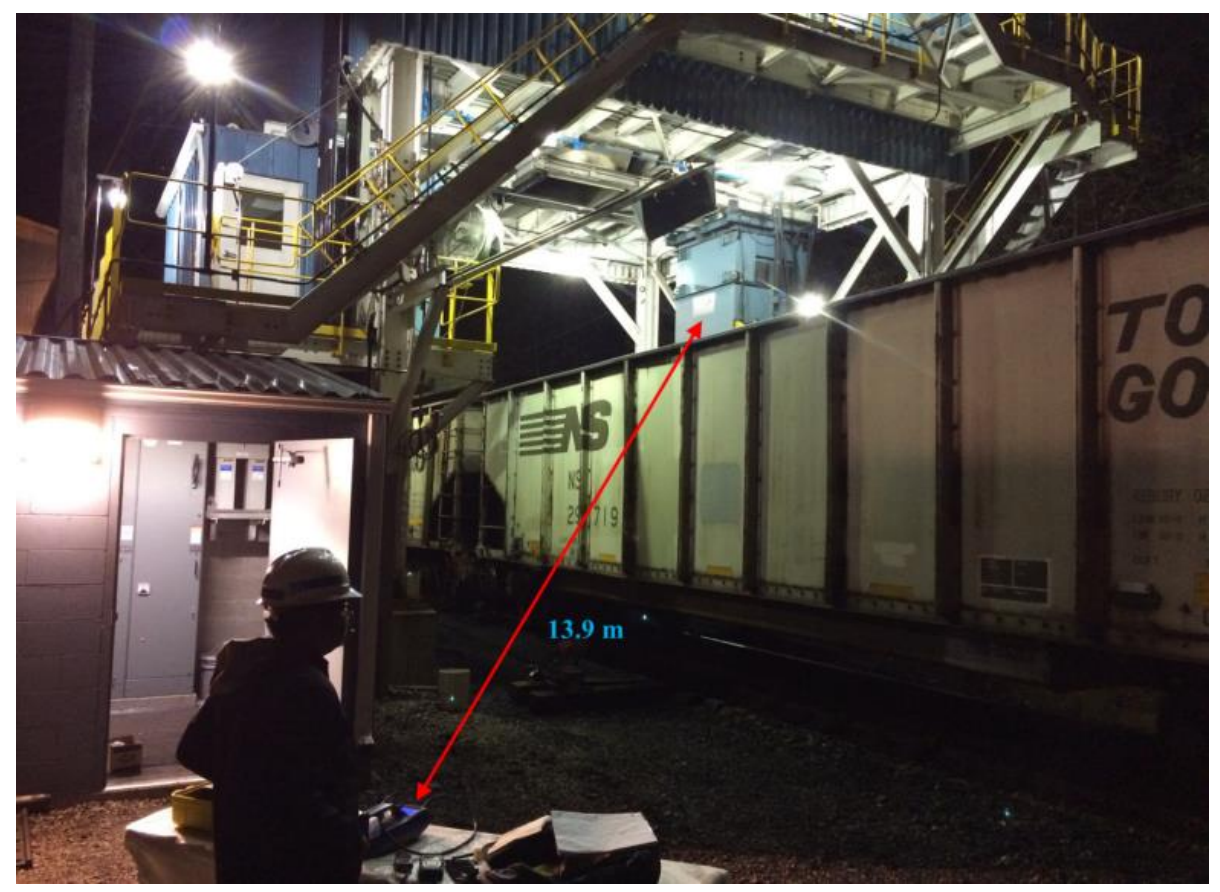

Figure 3.2. Dust sampling at location 2 (13.9m away from the source)

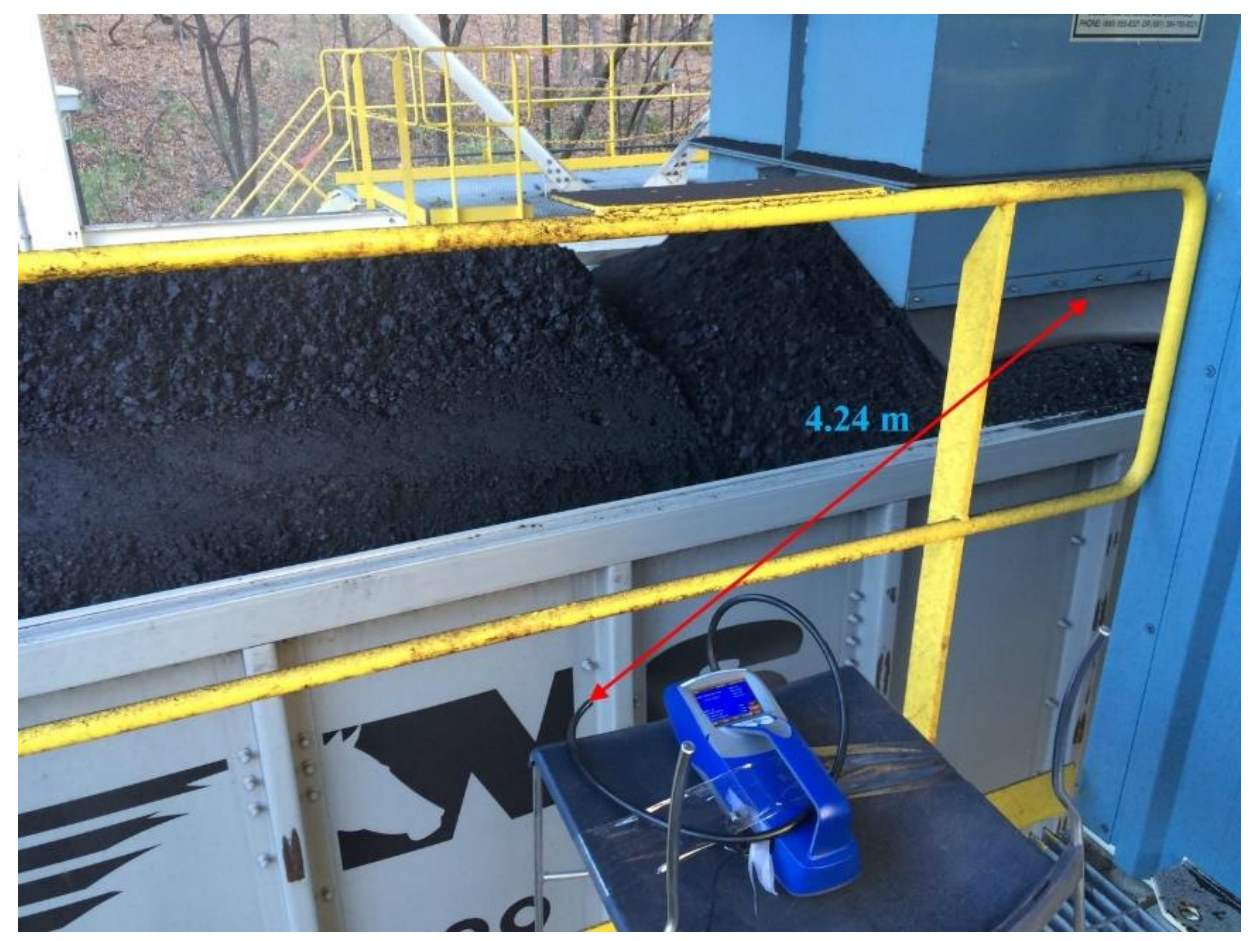

Figure 3.3. Dust sampling at location 3 (4.24m away from the source) 


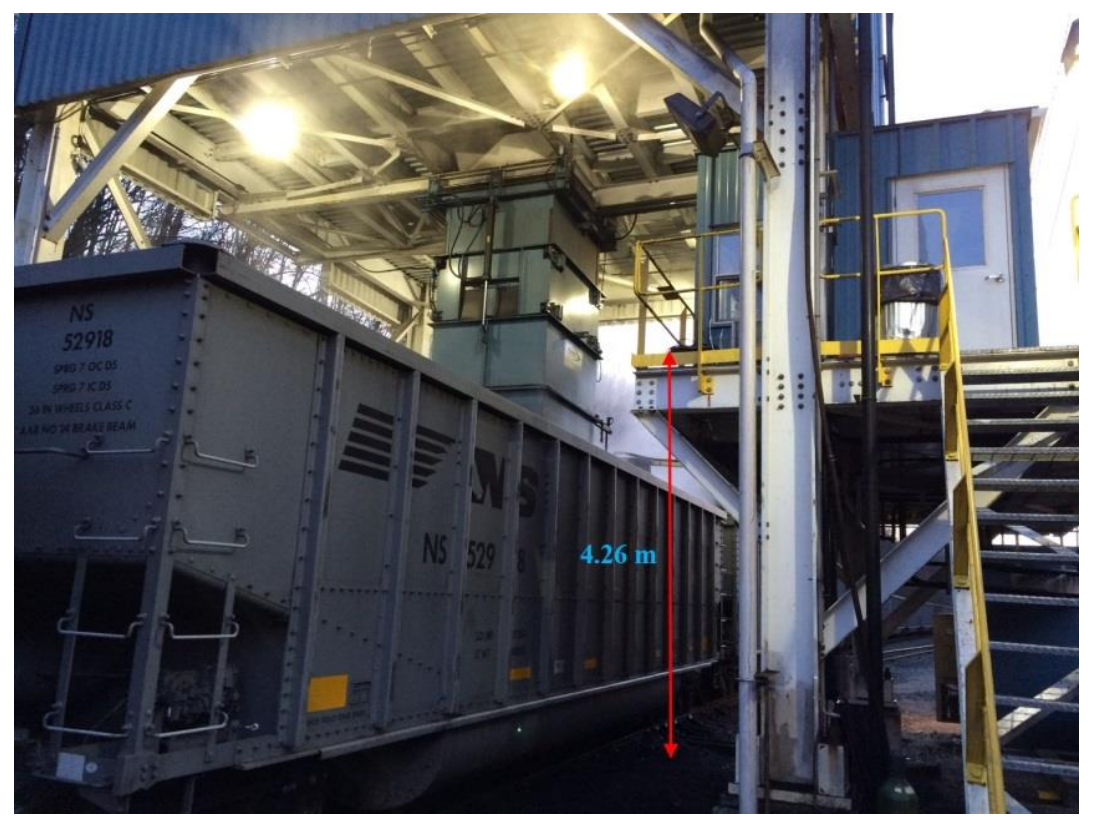

Figure 3.4. Dust sampling at location $3(4.26 \mathrm{~m}$ from the ground level)

\subsection{Estimation of dust emission}

For the determination of air emissions from non-stack sources, the most commonly used method is based on multiplication of the activity rate (in units of weight, volume, distance, or duration per unit of time) by the appropriate emission factors (EFs) (EPA 2015a). It can be expressed as:

$$
E_{i}=A \times E F_{i} \times\left(1-\frac{C E_{i}}{100}\right)
$$

where $E_{i}$ is emission rate of pollutant $\mathrm{i}(\mathrm{kg} / \mathrm{hr}), \mathrm{A}$ is production rate $(\mathrm{t} / \mathrm{hr}), \mathrm{EF}_{\mathrm{i}}$ is uncontrolled emission factor of pollutant $\mathrm{i}(\mathrm{kg} / \mathrm{t}), \mathrm{CE}_{\mathrm{i}}$ is overall emission reduction efficiency of pollutant $\mathrm{i}(\%)$, and $\mathrm{PM}_{2.5}, \mathrm{PM}_{10}$, and TSP are pollutants i.

The overall emission reduction efficiency of a pollutant for loading of trains is $70 \%$ for the enclosure, $99 \%$ for enclosure and use of fabric filters, and 90\% control allowed for water sprays 
with chemicals (NPI, 2012). Also, the reduction efficiency when using surge bins and loadout bins is greater than $99 \%$ (Todoroski, 2012).

EPA (2015a) published the Compilation of Air Pollutant Emission Factors (AP-42), which is primarily used to estimate emission rates. The AP-42 document is based on data collected from western surface coal mines and also includes equations for train loading facilities. This document contains a number of equations to determine fugitive dust EFs as well as process information for more than 200 classes of air pollution sources. These equations are based on the observations of dust concentrations from specific industrial operations and can be used to determine the amount of dust produced by a particular operation. In section 9 of chapter 11 of the EPA's AP-42, information regarding western U.S. surface coal mining is provided. This section includes EF estimation equations for blasting, truck loading, bulldozing, dragline, grading, aggregate handling, storage piles, and train loading facilities.

Fugitive dust emissions are expected from the loading of coal into trains. The empirical EF estimation equation of particulate emissions generated by either type of drop operation for loading of aggregate onto storage piles (batch or continuous drop operations) is provided in section 2.4 of chapter 13 in the AP-42 document (AP-42 13.2.4). The emission estimations from the loading of coal into trains uses the same equations as that used for emissions generated by either type of drop operation for loading of aggregate onto storage piles (EPA, 2015b). The quantity of dust emissions from the loading of aggregate onto storage piles varies with the volume of aggregate passing through the storage cycle. The emission factor for the amount of emissions per quantity of material is estimated using the following equation:

$$
\mathrm{EF}_{\mathrm{i}}=\mathrm{K} \times 0.0016 \times\left(\frac{\mathrm{U}}{2.2}\right)^{1.3} \times\left(\frac{\mathrm{M}}{2}\right)^{-1.4}
$$


where $\mathrm{EF}_{\mathrm{i}}$ is uncontrolled emission factor of pollutant $\mathrm{i}(\mathrm{kg} / \mathrm{t}), \mathrm{U}$ is mean wind speed $(\mathrm{m} / \mathrm{s})$, and $\mathrm{M}$ is material moisture content (\%), and $\mathrm{K}$ for TSP, $\mathrm{PM}_{10}$, and $\mathrm{PM}_{2.5}$ are $0.74,0.35$, and 0.053 , respectively.

The ranges of source conditions used in developing equation (3.2) include silt content of $0.44-19 \%$, wind speed of $0.6-6.7 \mathrm{~m} / \mathrm{s}$, and moisture content of $0.25-4.8 \%$. Thus, the AP-42 dust emission estimation method used in the methodology calculates dust emission based on the equation (3.2) proposed in the EPA AP-42.

The EPA employed stability classes along with Pasquill-Gifford (P-G) dispersion curves to determine vertical and horizontal measures of plume spread $\left(\sigma_{\mathrm{y}}\right.$ and $\left.\sigma_{\mathrm{z}}\right)$ in the development of the AP-42 11.9 equations. The stability classes provide a qualitative approach to determine atmospheric stability. The Pasquill stability class refers to the stability of air layers near the ground. It is based on wind speed and insolation (incoming solar radiation). Insolation is the rate of radiation from the sun received per unit of earth's surface (Schnelle and Dey 2000). The six categories of Pasquill stability classes are given in Schnelle and Dey (2000).

After the computation of the stability class, the plume spread $\left(\sigma_{\mathrm{y}}\right.$ and $\left.\sigma_{\mathrm{z}}\right)$ used in the development of AP-42 11.9 equations can be computed at a certain downwind distance $\mathrm{x}$ by choosing one of several available equations:

a) The plume spread $\left(\sigma_{\mathrm{y}}\right.$ and $\left.\sigma_{\mathrm{z}}\right)$ is presented in an analytical form by Green et.al (1980) as

$$
\begin{aligned}
& \sigma_{y}(x)=\frac{K_{1} x}{\left[1+\left(\frac{x}{K_{2}}\right)\right]^{K_{3}}} \\
& \sigma_{z}(x)=\frac{K_{4} x}{\left[1+\left(\frac{x}{K_{2}}\right)\right]^{K_{5}}}
\end{aligned}
$$


where the constants $\mathrm{K}_{1}, \mathrm{~K}_{2}, \mathrm{~K}_{3}, \mathrm{~K}_{4}$, and $\mathrm{K}_{5}$ for various stability classes are given in Table 3.1 (Green et.al., 1980) and the downwind distance $\mathrm{x}$ is in meters.

The above $\sigma_{\mathrm{y}}, \sigma_{\mathrm{z}}$ values were derived (Gifford, 1976) primarily from a diffusion experiment in flat terrain, where a non-buoyant tracer gas was released near the surface and measured (3-min averages) downwind up to a distance of $800 \mathrm{~m}$ from the source.

Table 3.1 Values of the constants in the equations (3.3 and 3.4) (Green et.al, 1980)

\begin{tabular}{cccccc}
\hline $\begin{array}{c}\text { Stability } \\
\text { Class }\end{array}$ & $\mathbf{K}_{\mathbf{1}}$ & $\mathbf{K}_{\mathbf{2}}$ & $\mathbf{K}_{\mathbf{3}}$ & $\mathbf{K}_{\mathbf{4}}$ & $\mathbf{K}_{\mathbf{5}}$ \\
\hline $\mathbf{A}$ & 0.250 & 927 & 0.189 & 0.1020 & -1.918 \\
$\mathbf{B}$ & 0.202 & 370 & 0.162 & 0.0962 & -0.101 \\
$\mathbf{C}$ & 0.134 & 283 & 0.134 & 0.0722 & 0.102 \\
$\mathbf{D}$ & 0.0787 & 707 & 0.135 & 0.0475 & 0.465 \\
$\mathbf{E}$ & 0.0566 & 1070 & 0.137 & 0.0335 & 0.624 \\
$\mathbf{F}$ & 0.0370 & 1070 & 0.134 & 0.0220 & 0.700 \\
\hline
\end{tabular}

b) A second set of equations that approximately fit the Pasquill-Gifford curves (Turner, 1970) are used to calculate $\sigma_{\mathrm{y}}$ and $\sigma_{\mathrm{z}}$ (in meters) for the rural mode. These equations are being used in EPA's Industrial Source Complex (ISC3) model.

$$
\sigma_{\mathrm{y}}=465.11628(\mathrm{x}) \tan (\mathrm{TH})
$$

where

$$
\mathrm{TH}=0.017453293[\mathrm{c}-\mathrm{d} \ln (\mathrm{x})]
$$

In Equations (3.5) and (3.6) the downwind distance $\mathrm{x}$ is in kilometers, and the coefficients $\mathrm{c}$ and $\mathrm{d}$ for various Pasquill Stability Categories are given in Table 3.2 (EPA, 1995b). 
The equation used to calculate $\sigma_{\mathrm{z}}$ is of the form:

$$
\sigma_{\mathrm{z}}=\mathrm{ax}^{\mathrm{b}}
$$

where the downwind distance $\mathrm{x}$ is in kilometers and $\sigma_{\mathrm{z}}$ is in meters. The coefficients a and $\mathrm{b}$ for various Pasquill Stability Categories are given in Table 3.3 (EPA, 1995b).

Table 3.2 Parameters used to calculate Pasquill-Gifford, $\sigma_{y}$ in equation (3.5) and (3.6) (EPA, 1995b)

\begin{tabular}{ccc}
\hline Pasquill Stability Category & c & d \\
\hline A & 24.167 & 2.5334 \\
B & 18.333 & 1.8096 \\
C & 12.500 & 1.0857 \\
D & 8.333 & 0.72382 \\
E & 6.250 & 0.054287 \\
F & 4.1667 & 0.36191 \\
\hline
\end{tabular}

Table 3.3 Parameters used to calculate Pasquill-Gifford, $\sigma_{z}$ in equation (3.7) (EPA, 1995b)

\begin{tabular}{cccc}
\hline $\begin{array}{c}\text { Pasquill Stability } \\
\text { Category }\end{array}$ & $\mathbf{x}(\mathbf{k m})$ & $\mathbf{a}$ & $\mathbf{b}$ \\
\hline & $<0.10$ & 122.800 & 0.94470 \\
$0.01-0.015$ & 158.080 & 1.05420 \\
$0.16-0.20$ & 170.220 & 1.09320 \\
$0.21-0.25$ & 179.520 & 1.12620 \\
$\mathbf{A}$ & $0.26-0.30$ & 217.410 & 1.26440 \\
& $0.31-0.40$ & 258.890 & 1.40940 \\
& $0.41-0.50$ & 346.750 & 1.72830 \\
& $0.51-3.11$ & 453.850 & 2.11660 \\
\hline
\end{tabular}


Table 3.3 Parameters used to calculate Pasquill-Gifford, $\sigma_{z}$ in equation (3.7) (Continued)

\begin{tabular}{|c|c|c|c|}
\hline \multirow{3}{*}{ B } & $<0.20$ & 90.673 & 0.93198 \\
\hline & $0.21-0.40$ & 98.483 & 0.98332 \\
\hline & $>0.40$ & 109.300 & 1.09710 \\
\hline $\mathbf{C}$ & All & 61.141 & 0.91465 \\
\hline \multirow{6}{*}{ D } & $<0.30$ & 34.459 & 0.86974 \\
\hline & $0.31-1.00$ & 32.093 & 0.81066 \\
\hline & $1.01-3.00$ & 32.093 & 0.64403 \\
\hline & $3.01-10.00$ & 33.504 & 0.60486 \\
\hline & $10.01-30.00$ & 36.650 & 0.56589 \\
\hline & $>30.00$ & 44.053 & 0.51179 \\
\hline \multirow{8}{*}{$\mathbf{E}$} & $<0.10$ & 24.260 & 0.83660 \\
\hline & $0.10-0.30$ & 23.331 & 0.81956 \\
\hline & $0.31-1.00$ & 21.628 & 0.75660 \\
\hline & $1.01-2.00$ & 21.628 & 0.63077 \\
\hline & $2.01-4.00$ & 22.534 & 0.57154 \\
\hline & $4.01-10.00$ & 24.703 & 0.50527 \\
\hline & $10.01-20.00$ & 26.970 & 0.46713 \\
\hline & $20.01-40.00$ & 35.420 & 0.37615 \\
\hline \multirow{11}{*}{$\mathbf{F}$} & $>40.00$ & 47.618 & 0.29592 \\
\hline & $<0.20$ & 15.209 & 0.81558 \\
\hline & $0.21-0.70$ & 14.457 & 0.78407 \\
\hline & $0.71-1.00$ & 13.953 & 0.68227 \\
\hline & $1.01-2.00$ & 13.953 & 0.63227 \\
\hline & $2.01-3.00$ & 14.823 & 0.54503 \\
\hline & $3.01-7.00$ & 16.187 & 0.46490 \\
\hline & $7.01-15.00$ & 17.836 & 0.41507 \\
\hline & $15.01-30.00$ & 22.651 & 0.32681 \\
\hline & $30.01-60.00$ & 27.074 & 0.27436 \\
\hline & $>60.00$ & 34.219 & 0.21716 \\
\hline
\end{tabular}


The ISC3 model is based on the Gaussian equation (3.8) for point source emissions, which is given as the following for the ISC3 model (EPA, 1995b):

$$
\chi=\frac{\mathrm{QKVD}}{2 \pi \mathrm{u}_{\mathrm{s}} \sigma_{\mathrm{y}} \sigma_{\mathrm{z}}} \exp \left[-0.5\left(\frac{\mathrm{y}}{\sigma_{\mathrm{y}}}\right)^{2}\right]
$$

where $\mathrm{Q}$ is pollutant emission rate $(\mathrm{g} / \mathrm{sec}) ; \mathrm{K}$ is scaling coefficient to convert calculated concentrations to desired units (default value of $1 \times 10^{6}$ ); $\mathrm{V}$ is vertical term (dimensionless); $\mathrm{D}$ is decay term (dimensionless); $\mathrm{u}_{\mathrm{s}}$ is mean wind speed at release height $(\mathrm{m} / \mathrm{sec}) ; \sigma_{\mathrm{y}}$ and $\sigma_{\mathrm{z}}$ are standard deviation of lateral and vertical concentration distribution $(\mathrm{m}) ; \chi$ is hourly concentration at downwind distance $\mathrm{x}\left(\mu \mathrm{g} / \mathrm{m}^{3}\right)$; and $\mathrm{y}$ is crosswind distance from source to receptor $(\mathrm{m})$.

Mean wind speed $u_{s}$ at release height $(\mathrm{m} / \mathrm{sec})$ is

$$
\mathrm{u}_{\mathrm{s}}=\mathrm{u}_{\mathrm{ref}}\left(\frac{\mathrm{h}_{\mathrm{s}}}{\mathrm{z}_{\mathrm{ref}}}\right)^{\mathrm{p}}
$$

where $\mathrm{u}_{\mathrm{ref}}$ is observed wind from a measured reference height $\left(\mathrm{z}_{\mathrm{ref}}\right)(\mathrm{m} / \mathrm{sec}) ; \mathrm{h}_{\mathrm{s}}$ is stack height $(\mathrm{m})$; $\mathrm{p}$ is wind profile exponent (dimensionless), and given by EPA (1995b) for various stability categories; and $\mathrm{z}_{\mathrm{ref}}$ is measured reference height for wind speed (m).

Table 3.4 Values of the wind profile exponent in the equation (3.9) (EPA, 1995b)

\begin{tabular}{ccc}
\hline Stability category & Rural exponent & Urban exponent \\
\hline A & 0.07 & 0.15 \\
B & 0.07 & 0.15 \\
C & 0.10 & 0.20 \\
D & 0.15 & 0.25 \\
E & 0.35 & 0.30 \\
F & 0.55 & 0.30 \\
\hline
\end{tabular}


EPA completed a three-phase study at a surface coal mine in Wyoming in 1994-1995 to review the entire mining operation for dust dispersion and validate ISC3 (EPA, 1994 and EPA, 1995a). The amount of emissions from the operation was determined using the emissions factors equations from the EPA's AP-42 document. These calculated emissions were used as input for the ISC3 model to complete dispersion modeling. Field testing was completed by placing six $\mathrm{PM}_{10}$ sampling stations throughout the surface mining operation to validate the ISC3 model. According to the study, there is significant over-prediction of $\mathrm{PM}_{10}$ emissions from surface coal mining operation by the ISC3 model (EPA, 1995a). Also, the study showed an over-prediction of more than a factor of 2 at a single site where modeled versus measured results were compared (EPA, 1994). In the above EPA study, no attempt was made to determine the source of the over-prediction of $\mathrm{PM}_{10}$. Consequently, it is not known whether the over-prediction was caused by the emission estimation methods (AP-42), by the dispersion model, or both.

Cole and Zapert (1995) completed a study and concluded that ISC3 model over-predicted the actual $\mathrm{PM}_{10}$ concentrations ranging from a factor of less than 1 (87\% over-prediction) to a factor of 5. Authors found two reasons of over-prediction - (i) the model failed to account any deposition of the particulates, and (ii) the emission factor for unpaved roads over-predicted the amount of emissions from haul trucks. Reed et al. (2001) also completed a study on the ISC3 model using a theoretical rock quarry and concluded that the majority of $\mathrm{PM}_{10}$ concentrations is caused by hauling operations and the haul truck emissions factors may be part of the cause of the over-prediction of $\mathrm{PM}_{10}$ concentrations by the ISC3 model. Reed (2003) described a model called the Dynamic Component Program (DCP) based on a Gaussian equation similar to that used by the ISC3 model for predicting dust dispersion from haul trucks.

$$
\chi=\frac{\mathrm{QK}}{2 \pi \mathrm{u}_{\mathrm{s}} \sigma_{\mathrm{y}} \sigma_{\mathrm{z}}} \exp \left[-0.5\left(\frac{\mathrm{y}}{\sigma_{\mathrm{y}}}\right)^{2}\right]
$$


where $\mathrm{Q}$ is pollutant emission rate $(\mathrm{g} / \mathrm{sec}) ; \mathrm{K}$ is scaling coefficient to convert calculated concentrations to desired units (default value of $1 \times 10^{6}$ ); $\mathrm{u}_{\mathrm{s}}$ is mean wind speed at release height $(\mathrm{m} / \mathrm{sec}) ; \sigma_{\mathrm{y}}$ and $\sigma_{\mathrm{z}}$ are standard deviation of lateral and vertical concentration distribution $(\mathrm{m}) ; \chi$ is hourly concentration at downwind distance $\mathrm{x}\left(\mu \mathrm{g} / \mathrm{m}^{3}\right)$; and $\mathrm{y}$ is crosswind distance from source to receptor (m).

The main difference between the DCP and the ISC3 model is the methodology of applying the source emissions when predicting dust dispersion from that source (Reed, 2003). In the DCP, the use of the vertical and the decay terms are eliminated. The decay term $\mathrm{D}$ is assumed to be one as the default value of decay coefficient is zero. The vertical term $\mathrm{V}$ is calculated using stack or emission height, receptor height, and mechanical mixing height. As receptor height and emission height for haul trucks are nearly equal, and also the emission of the haul trucks will never be above the mechanical mixing height, V can be eliminated (Reed, 2003). Similarly, in the loading of trains using surge bins, emission height and receptor height are nearly equal. So, the equations used in the development of DCP can be used. For the Type-2 Dust Emission Estimation method, emission factors are determined based on data collected from the mine. This method uses the conversion of concentration values into emission rates using the P-G dispersion curves and the backward Gaussian dispersion model (equation 3.11)

$$
\mathrm{Q}=\frac{2 \pi \mathrm{u}_{\mathrm{s}} \sigma_{\mathrm{y}} \sigma_{\mathrm{z}} X}{\operatorname{Kexp}\left[-0.5\left(\frac{\mathrm{y}}{\sigma_{\mathrm{y}}}\right)^{2}\right]}
$$

This is the same approach that was employed by EPA in the conversion of concentration values into emission rates. 


\subsection{Factors that affect dust emission and suspension}

Fugitive dust emissions depend on wind speed, moisture content of material, surface temperature, and humidity. Emission rates and control measures are also closely related to these properties.

\subsubsection{Wind speed}

The energy needed to suspend loose particle from the surface by high wind speeds, and the turbulence associated with these winds, elevates particles to high altitudes where they can be transported over long distances (Prospero et al., 1970; Prospero and Carlson, 1972; Duce et al., 1980; Gillete et al., 1972; and Gillete and Blifford, 1971). Chepil and Woodruff (1963) and Gillette and Hanson (1989) showed that the amount of dust suspended by the wind depends on wind speed at the surface, particle size distribution, surface roughness, relative amount of erodible material ( $<2 \mathrm{~mm}$ diameter) and non-erodible material ( $>2 \mathrm{~mm}$ diameter), and the cohesion of the particles among them. The values for each of these variables affect other variables. For example, a higher moisture content increases the cohesion among particles. Also, the agglomeration of smaller particles decreases the wind speed at the surface by increasing surface roughness.

Particles suspended in the atmosphere are acted upon by atmospheric resistance in an upward direction and by gravity in a downward direction. Equilibrium is attained between these forces for each particle at its terminal settling velocity. The settling velocity increases with the square of the particle diameter, and linearly with particle density (Friedlander, 1999). Small particles remain suspended for a long time because turbulent air movements counter the gravitational settling velocity (Sehmel, 1980 and Slinn, 1982). Factors affecting transport distance are initial elevation of the particle above ground level, horizontal wind velocity component, and gravitational settling velocity. 


\subsubsection{Coal dustiness/Moisture Content}

The dustiness of coal varies from mine to mine and is a function of the chemical composition, density, hydrophilic/hydrophobic nature, and particle size distribution of the specific coal type (Connell Hatch, 2008). Water sticking to the particle increases its mass and surface tension, thereby reducing suspension and transport. Due to the formation of aggregates and surface crusts, the cohesion of wetted particles persists even after evaporation of water.

In coal handling (transfers and drop operations), there is a direct relation between moisture content and dustiness of a particular coal, which can be expressed in terms of a dust extinction moisture level (DEM). DEM can be determined using a laboratory test procedure, as detailed in International Standard ISO 20905:2004, Coal Preparation: Determination of dust/moisture relationship for coal (ISO, 2004). It is possible to determine DEM for each coal type using this procedure. Keeping the moisture content of coal at or above DEM will minimize dust emissions associated with coal handling.

\subsubsection{Atmospheric stability}

The vertical movement of particles in the atmosphere is influenced by atmospheric stability and by the temperature effect of the air (Cora and Hung, 2003). Atmospheric stability is defined as the atmospheric tendency to resist or enhance vertical motion or to suppress or augment existing turbulence (Zoras et al., 2006). Pasquill developed a method of estimating atmospheric stability accounting for both mechanical and thermal turbulence (Schnelle and Dey, 2000). Atmospheric stability was classified into six classes ranging from A (very unstable) to F (very stable).

The classes were developed based on wind speed, solar radiation (daytime), and cloud cover (at night). Strong insulation leads to the heating of the ground, thereby increasing the 
temperature of the lower part of the atmosphere and creating an unstable condition. If wind speed increases, vertical mechanical mixing becomes stronger than buoyancy effects and leads to neutral stability. During the night, the ground cools, creating stable conditions (Colls, 2002). Table 3.5 shows the stability classes developed by Pasquill (Schnelle and Dey, 2000).

Table 3.5 Pasquill stability classes (Schnelle and Dey, 2000)

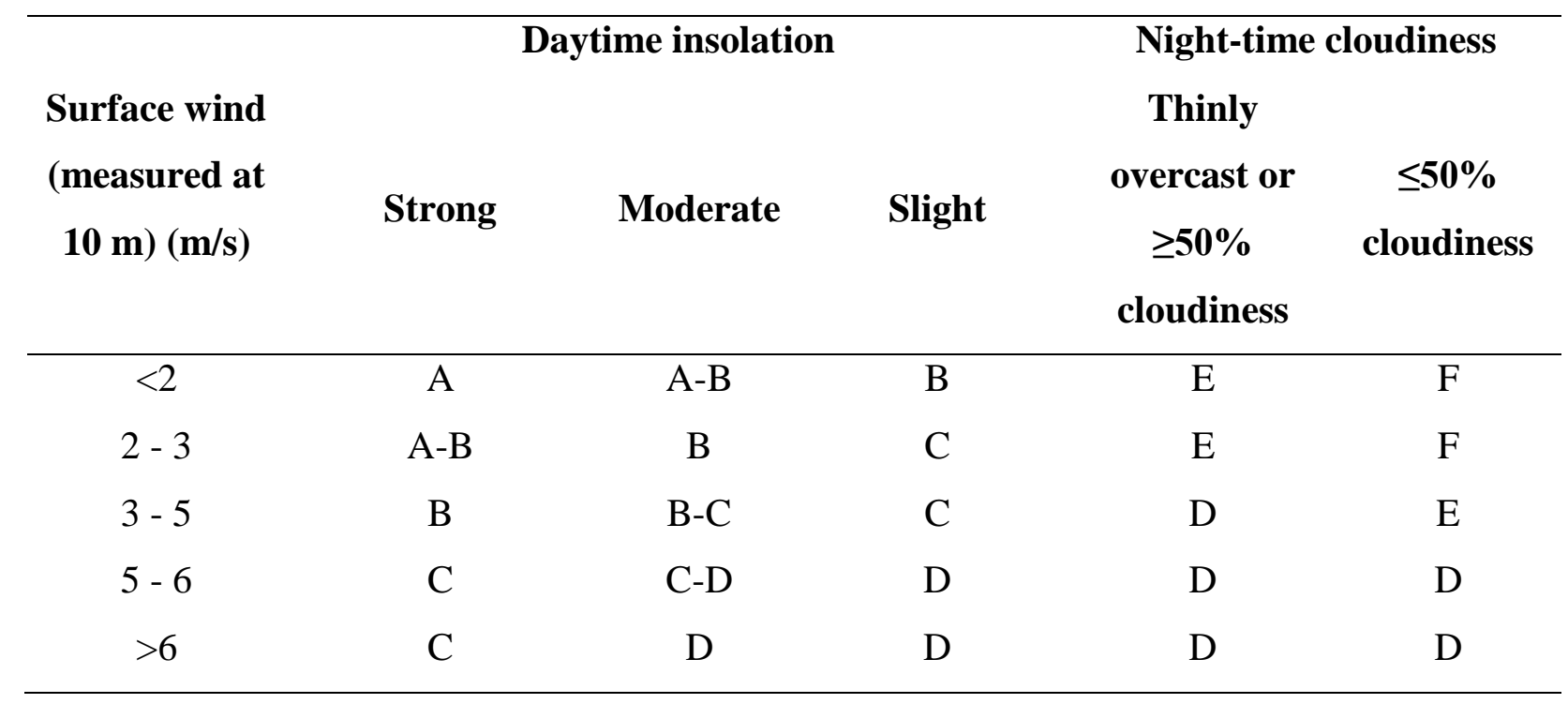

Note: A - Extremely unstable; B - Moderately unstable; C - Lightly unstable; D - Neutral; E - Slightly stable; F Moderately stable. Strong insolation corresponds to sunny midday in summer. Slight insolation corresponds to similar conditions in winter. For A-B, B-C, and C-D, average values are taken. Night refers to $1 \mathrm{hr}$ before sunset to $1 \mathrm{hr}$ after dawn. Regardless of wind speed, the neutral category D should be assumed for overcast conditions during day or night, and for any sky conditions during the hour preceding or the following night.

\subsubsection{Relative humidity}

The relative humidity has counteracting effects on aerosol particulate concentrations through various processes such as evaporation, condensation, and nucleation (Hussein et. al., 2006). These effects are only observed in the diurnal variations of aerosol particulate concentrations and substantially depend on the chemical composition of particulates. 


\subsection{Development of Emission Factor Model}

Based on the analysis of the data collected at the coal train loading facility, there is a need for the development of new EF equations for train loading operations. To develop the function of EF, relationships and significant variables were defined by statistical tests. Multiple linear regression modeling was used for developing this model. Measured variables were used as independent ones (regressors) and included in the model development. These variables are wind speed $(\mathrm{m} / \mathrm{s})$, moisture content $(\%)$, temperature $\left({ }^{\circ} \mathrm{C}\right)$, and humidity $(\%)$.

\subsubsection{Multiple linear regression models}

Regression analysis is a statistical technique used for examining the relationships between two or more variables. Either observational or experimental data can be used in regression modeling. The general linear regression model is mathematically expressed by the following equation (Kutner et al. 2004):

$$
Y_{i}=\beta_{0}+\beta_{1} X_{i 1}+\beta_{2} X_{i 2}+\cdots+\beta_{p-1} X_{i, p-1}+\varepsilon_{i}
$$

and

$$
\begin{gathered}
\mathrm{E}(\mathrm{Y})=\beta_{0}+\beta_{1} \mathrm{X}_{1}+\beta_{2} \mathrm{X}_{2}+\cdots+\beta_{\mathrm{p}-1} \mathrm{X}_{\mathrm{p}-1} \\
\text { for } \mathrm{X}_{\mathrm{i} 0}=1, \text { and } \mathrm{E}\left(\varepsilon_{\mathrm{i}}\right)=0
\end{gathered}
$$

where:

$\beta_{0}, \beta_{1}, \ldots, \beta_{\mathrm{p}-1}$ are regression parameters,

$\mathrm{X}_{\mathrm{i} 1}, \ldots, \mathrm{X}_{\mathrm{i}, \mathrm{p}-1}$ are variables (regressors) in the model,

$\varepsilon_{\mathrm{i}}$ is a normal error term, which has to be independent and normally distributed with mean zero and variance $\sigma^{2}$, for appropriate adequacy of the model, 
$\mathrm{E}(\mathrm{Y})$ is the expected value of the response variable $\mathrm{Y}$.

Models having curvilinear and complex response functions are still cases of general linear regression models. Linearity can be obtained by suitable transformation of the $\mathrm{Y}$, Xi variables or both. The model of EF is the model, where the natural logarithm transformation of the response variable $\mathrm{Y}$ was performed.

The general regression model with normal error terms shows that the observations Yi are independent normal variables, with mean $\mathrm{E}\left(\mathrm{Y}_{\mathrm{i}}\right)$ and constant variance $\sigma^{2}$. A statistical model for linear regression corresponds to the population regression line and a description of the variation of Y about the line (Moore and McCabe 2006).

The linearity of the model means that it is linear in its parameters, and does not refer to the shape of the surface that is created. The method of least squares is used for the estimation of parameters. The analysis of variance provides an estimate of the variance of the error term $\sigma^{2}$ that is a significant step in the linear regression.

For estimation of model adequacy in multiple linear regression problems, some hypotheses tests are useful. The suitable hypotheses are (Montgomery and Runger 2003):

$$
\begin{aligned}
\mathrm{H}_{0}=\beta_{1}=\beta_{2}=\cdots \beta_{\mathrm{k}}=0 \\
\mathrm{H}_{1}: \beta_{\mathrm{j}} \neq 0 \text { for at least one } \mathrm{j}
\end{aligned}
$$

where:

$\mathrm{H}_{\mathrm{o}}$ represents the null hypothesis, $\mathrm{H}_{1}$ represents the alternative hypothesis. 
Rejection of the null hypothesis indicates that at least one of the regressor variables $\mathrm{x}_{1}, \mathrm{x}_{2}$, ..., $\mathrm{x}_{\mathrm{k}}$ benefits significantly to the model. The total sum of squares $\left(\mathrm{SS}_{\mathrm{T}}\right)$ is the summation of the sum of squares considering regression $\left(\mathrm{SS}_{\mathrm{R}}\right)$ and the sum of squares considering error $\left(\mathrm{SS}_{\mathrm{E}}\right)$. Test statistic for the null hypothesis defined with equation 3.14, is defined as the following (Montgomery and Runger 2003):

$$
\mathrm{F}_{0}=\frac{\mathrm{SS}_{\mathrm{R}} / \mathrm{p}}{\mathrm{SS}_{\mathrm{E}} /(\mathrm{n}-\mathrm{p}-1)}=\frac{\mathrm{MS}_{\mathrm{R}}}{\mathrm{MS}_{\mathrm{E}}}
$$

where:

$\mathrm{F}_{\mathrm{o}}$ represents test statistic,

p represents the number of regressor variables in the model,

$\mathrm{n}$ represents the number of data used for analysis,

$\mathrm{MS}_{\mathrm{R}}$ represents the mean square model, and

$M S_{E}$ represents the mean square error.

The procedure is summarized in the analysis of variance (Table 3.6). These computations were performed with the Minitab statistical software.

Table 3.6 Analysis of variance (Montgomery and Runger 2003)

\begin{tabular}{ccccc}
\hline $\begin{array}{c}\text { Source of } \\
\text { variation }\end{array}$ & Sum of Squares & $\begin{array}{c}\text { Degrees of } \\
\text { Freedom }\end{array}$ & Mean Square & Test statistic Fo \\
\hline Regression & $\mathrm{SS}_{\mathrm{R}}$ & $\mathrm{p}$ & $\mathrm{MS}_{\mathrm{R}}$ & $\mathrm{MS}_{\mathrm{R}} / \mathrm{MS}_{\mathrm{E}}$ \\
Error or residual & $\mathrm{SS}_{\mathrm{E}}$ & $\mathrm{n}-\mathrm{p}-1$ & $\mathrm{MS} \mathrm{E}_{\mathrm{E}}$ & \\
Total & $\mathrm{SS}_{\mathrm{T}}$ & $\mathrm{n}-1$ & & \\
\hline
\end{tabular}

Tests of the hypothesis on the individual regression coefficients contribute to the determination of the potential value of every regressor variable in the model. Thus, the 
effectiveness of the model can be better if one or more regressor variables are included in the model, or if one or more regressor variables are deleted from the model.

The same rules are valid for reject/failure to reject the null hypothesis as for the already defined hypothesis testing. The $\mathrm{t}$ statistic is the test statistic for individual regressors and is provided in the regression output in statistical software. Another test that can be used for the same purpose is partial F-statistic, which can be used for examining the best subset of regressor variables for the model.

The p-values for individual variables assess the statistical significance of a particular regressor. For the confidence interval of $95 \%$, the p-value should be less than $5 \%(0.005)$ to consider a particular variable significant.

To evaluate the fit of the model, coefficients of the multiple determination $\mathrm{R}^{2}$ or adjusted $\mathrm{R}^{2}$ are usually used (Montgomery and Runger 2003). The following equations can mathematically express them:

$$
\begin{gathered}
\mathrm{R}^{2}=\frac{\mathrm{SS_{ \textrm {R } }}}{\mathrm{SS_{ \textrm {T } }}} \\
\mathrm{R}_{\mathrm{adj}}^{2}=1-\frac{\mathrm{SS_{ \textrm {E } } / ( \mathrm { n } - \mathrm { p } )}}{\mathrm{SS_{ \textrm {T } } / ( \mathrm { n } - 1 )}}
\end{gathered}
$$

However, with the addition of the variable in the model, the value of $\mathrm{R}^{2}$ always increases, which can be somewhat problematic. On the other hand, $\mathrm{R}_{\mathrm{adj}}{ }^{2}$ will have higher value only if the newly added variable reduces the error mean square. It is a particularly useful parameter that limits the analyst in adding variables that are not helpful in explaining the variability of data. 
The first step that should be undertaken in model building is the correlation test between the independent variables. The correlation coefficient measures the linear relationship between variables and has the value range from minus one to one. The value of plus one shows the perfect positive correlation, while the value of minus one shows the perfect negative correlation. Minitab software was used to obtain the correlation among variables.

Next, one of the most important problems in regression analysis involves selecting the set of independent (regressor) variables to be used in the model.

Finally, the best subset analysis and stepwise regression analysis were used for determination of significant independent variables for development of the EF model. The selection of the "best" subset of the independent variables involves examining available variables to obtain the regression model. Therefore, to make a model easy to use, one's goal is to choose as few regressor variables as possible. For $\mathrm{K}$ regressors $\mathrm{x}_{1}, \mathrm{x}_{2}, \ldots, \mathrm{x}_{\mathrm{k}}$ and a single response variable $\mathrm{y}$, there are $2^{\mathrm{K}}$ total equations that should be analyzed (Montgomery and Runger 2003). For evaluating and comparing those different possible regression models, several criteria can be used (Kutner et al. 2004):

a) $\mathrm{R}_{\mathrm{adj}}{ }^{2}$ - The adjusted coefficient of determination $R_{a d j}{ }^{2}$ is one of the most commonly used criteria. As previously explained, the model maximizing this parameter also minimizes the mean square error. Thus, it is considered to be a suitable candidate for the best regression model.

b) $\mathrm{Cp}$ - Another criterion used for evaluation of regression models is $\mathrm{Cp}$ statistic. It is defined as the total mean square error for the regression model. Therefore, the best regression model should have a minimum $\mathrm{Cp}$ statistic. 
c) Press statistic - This parameter gives a measure of how well the model will perform while predicting new data, or data that are not used in the fitted regression model. Thus, it can be used for evaluating different regressor models.

Thus, the best subset analysis was performed on all regressors that are available, and parameters $R_{a d j}{ }^{2}$ and $C_{p}$ were used for evaluation of the most suitable model, which will be presented later in the thesis.

In addition to all possible regressor selection methods, the stepwise regression technique was performed. The stepwise regression method uses iterations to make a series of regression models by adding or removing variables at every step (Montgomery and Runger 2003). As previously mentioned, the criterion for addition or removal of variables is usually a partial F-test. The process of the backward stepwise selection method begins with inclusion of all variables in the model, then removing the least significant variable for each step.

The best subset selection is the recommended selection technique when the number of regressor variables are less (Montgomery and Runger 2003). Also, this technique is not affected by dependencies between regressor variables.

The variance inflation factors (VIF) are calculated for the variables in the model to check if multicollinearity exists. Multicollinearity represents dependency among the regressor variables, which has a high impact on coefficients of the regression as well as the appropriateness of the derived model. It is expressed with the Variance Inflation Factor (VIF), which has the following equation (Montgomery and Runger 2003):

$$
\mathrm{VIF}=\frac{1}{1-\mathrm{R}_{\mathrm{j}}^{2}} \quad \mathrm{j}=1,2,3 \ldots \mathrm{k}
$$


where:

$\mathrm{R}_{\mathrm{j}}^{2}$ is the coefficient of multiple determination that is the result of regressing $\mathrm{x}_{\mathrm{j}}$ on the other $\mathrm{k}_{\mathrm{j}}$ regressors.

The value of multicollinearity should not be more than 4 or 5 (Montgomery and Runger 2003). However, with VIF greater than 10, there is an indication for presence of multicollinearity (Statisticssolutions, 2015)

To check the validity of the developed model either of followed methods can be applied:

a) Collection of new data for checking model predictions;

b) Comparison of the prediction of models and coefficients with the theory;

c) Data splitting or Cross-validation where part of the data is used for model parameters estimation and the rest of data are used for determining the prediction accuracy of the model.

The mean squared predictor error (MSPR) is a means of measuring the actual predictive capability of the selected regression model by testing its effectiveness on another data set (Kutner et al. 2004). The MSPR for $\mathrm{n}^{*}$ data sets in the new (or validation) data set is

$$
\operatorname{MSPR}=\frac{\sum_{\mathrm{i}=1}^{\mathrm{n}^{*}}\left(\mathrm{Y}_{\mathrm{i}}-\mathrm{O}_{\mathrm{i}}\right)^{2}}{\mathrm{n}^{*}}
$$

where

$Y_{i}$ is the observed values from the new (or validation) data set

Oi is the values calculated by running the best model(s) variable(s) from the validation set as predicted values for new observations in the model building 
If the MSPR is fairly close to the $\mathrm{MS}_{\mathrm{E}}$ based on the regression fit to the original (or training) data set, then the error mean square $\mathrm{MS}_{\mathrm{E}}$ for the selected model is not seriously biased and gives an approximate indication of the predictive ability of the model. If the MSPR is much larger than the $\mathrm{MS}_{\mathrm{E}}$, one should rely on MSPR to determine how well the selected regression model will predict in the future (Kutner et al. 2004).

Applying all previously mentioned statistical procedures, the regression model for the EF was developed, and it is described in Chapter 4. 


\section{Chapter 4}

\section{Results and Discussion}

\subsection{Data Analysis}

Dust concentration data were collected for different size fractions, including $\mathrm{PM}_{1}, \mathrm{PM}_{2.5}, \mathrm{PM}_{4}$, $\mathrm{PM}_{10}$, and TSP. Figure 4.1 shows the concentration data for different dust size fractions collected for a 47-min period of coal train loading at Location 1. It can be observed that there was no significant change in the initial concentration of each size fraction. The initial concentrations of $\mathrm{PM}_{1}, \mathrm{PM}_{2.5}, \mathrm{PM}_{4}, \mathrm{PM}_{10}$, and TSP are $0.004 \mathrm{mg} / \mathrm{m}^{3}, 0.006 \mathrm{mg} / \mathrm{m}^{3}, 0.008 \mathrm{mg} / \mathrm{m}^{3}, 0.009 \mathrm{mg} / \mathrm{m}^{3}$ and $0.009 \mathrm{mg} / \mathrm{m}^{3}$, respectively. However, a few seconds after dumping coal into the train car, the concentrations increased rapidly followed by a decrease in concentration. After 90 seconds, the concentrations of $\mathrm{PM}_{1}, \mathrm{PM}_{2.5}, \mathrm{PM}_{4}, \mathrm{PM}_{10}$, and TSP increased to $0.003 \mathrm{mg} / \mathrm{m}^{3}, 0.007 \mathrm{mg} / \mathrm{m}^{3}, 0.01$ $\mathrm{mg} / \mathrm{m}^{3}, 0.024 \mathrm{mg} / \mathrm{m}^{3}$, and $0.024 \mathrm{mg} / \mathrm{m}^{3}$, respectively. Thus, a cycle of low concentration followed by high concentration and again low concentration was observed. The maximum concentration of TSP was $0.139 \mathrm{mg} / \mathrm{m}^{3}$ at 10:27:40 $\mathrm{pm}$ at Location 1. Figure 4.2 shows the concentration data for different dust size fractions collected for an 8-min period of coal train loading at Location 2. The maximum concentration of TSP was $0.049 \mathrm{mg} / \mathrm{m}^{3}$ at 10:46:30 pm at Location 2. In both Figures 4.1 and 4.2, the concentration of $\mathrm{PM}_{1}$ and $\mathrm{PM}_{2.5}$ did not change significantly. The value of $\mathrm{PM}_{1}$ in Figure 4.1 varies from $0.003 \mathrm{mg} / \mathrm{m}^{3}$ to $0.006 \mathrm{mg} / \mathrm{m}^{3}$ and in Figure 4.2 varies from $0.004 \mathrm{mg} / \mathrm{m}^{3}$ to $0.006 \mathrm{mg} / \mathrm{m}^{3}$. The value of $\mathrm{PM}_{2.5}$ in Figure 4.1 varies from $0.004 \mathrm{mg} / \mathrm{m}^{3}$ to $0.007 \mathrm{mg} / \mathrm{m}^{3}$ and in Figure 4.2 varies from $0.006 \mathrm{mg} / \mathrm{m}^{3}$ to $0.007 \mathrm{mg} / \mathrm{m}^{3}$. 


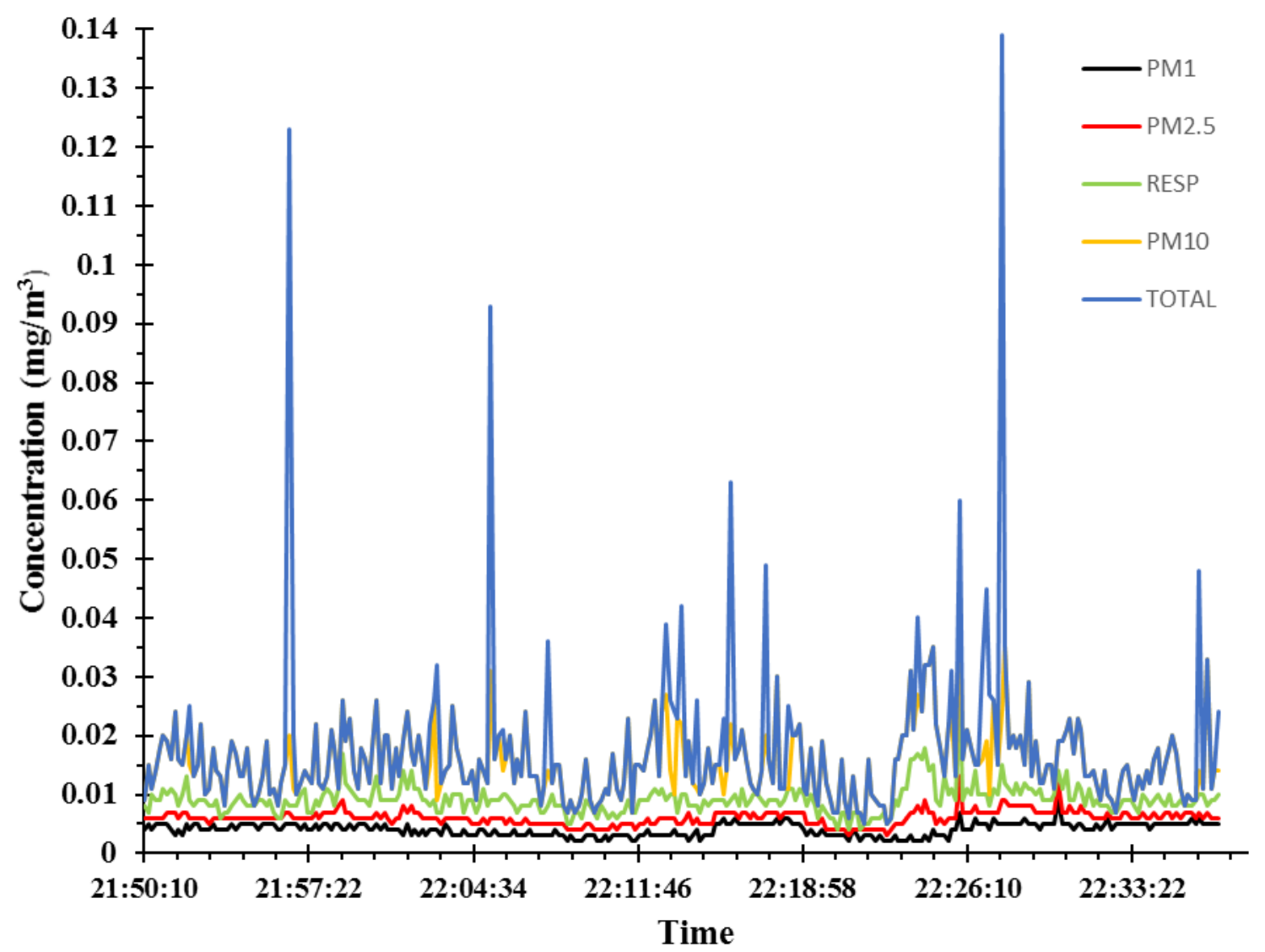

Figure 4.1 Dust concentration for a 47-min period of coal train loading at Location 1

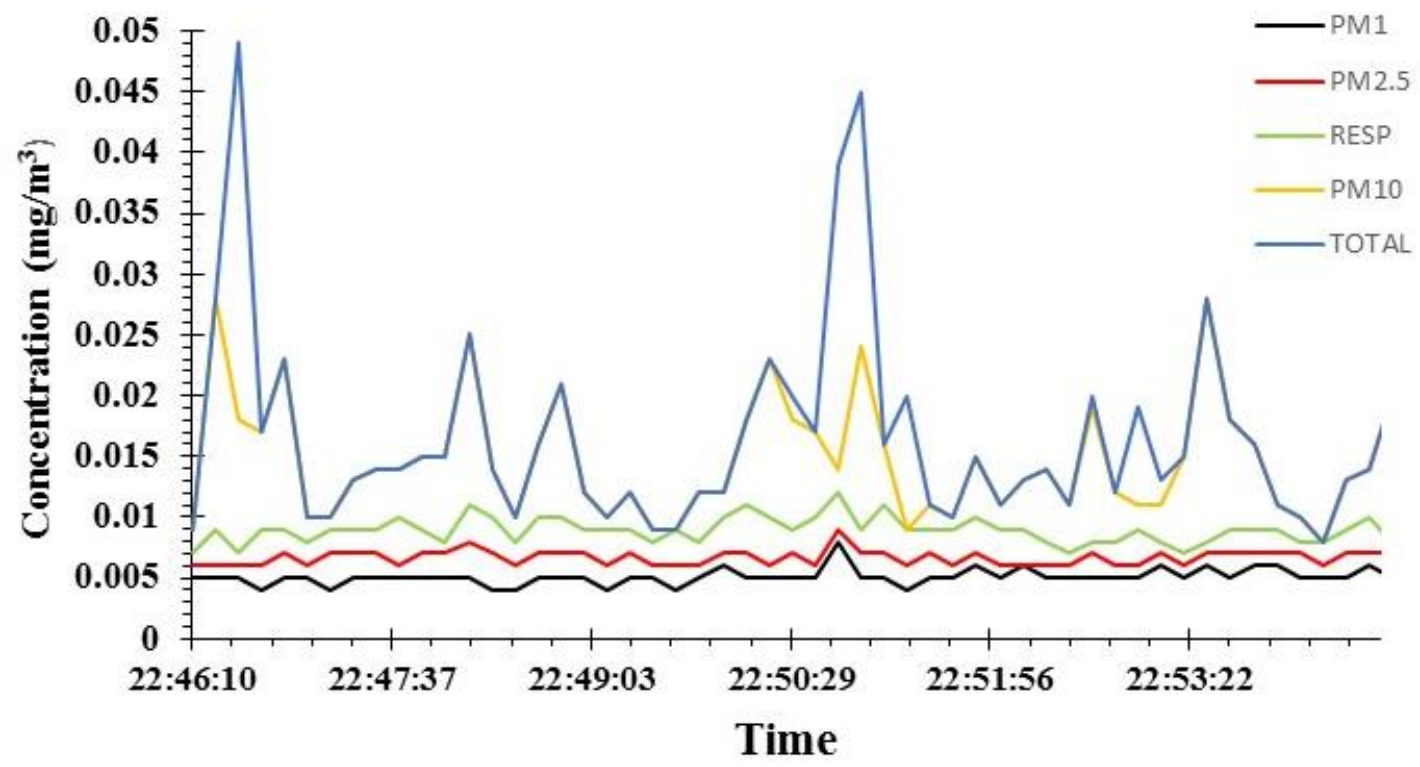

Figure 4.2 Dust concentration for an 8-min period of coal train loading at Location 2 


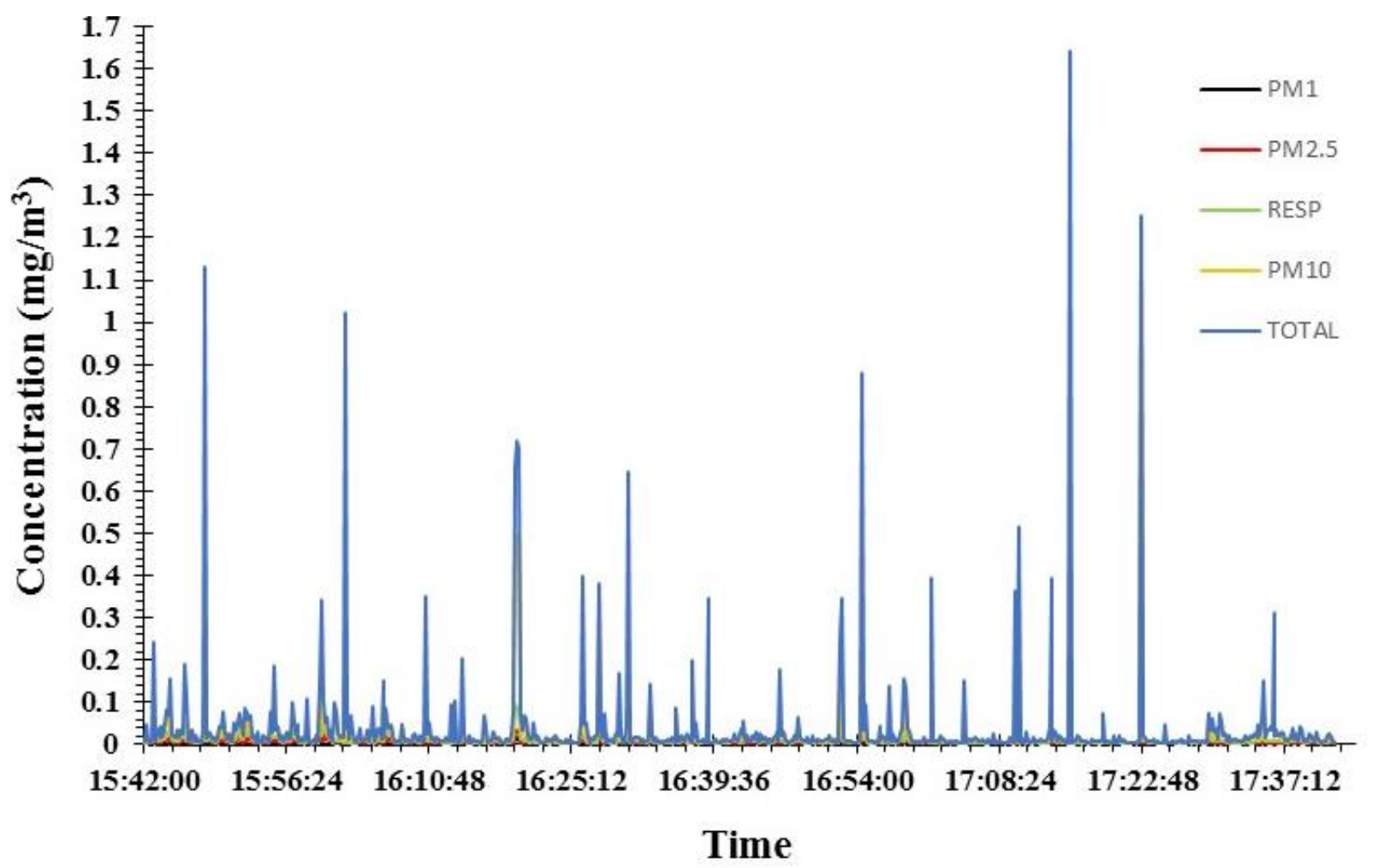

Figure 4.3 Dust concentration for a 120-min period of coal train loading at Location 3

The dust concentration for a 120-min period of train loading at Location 3 is shown in Figures 4.3. A cycle of low concentration followed by high concentration and again low concentration is observed. The value of $\mathrm{PM}_{1}$ in Figure 4.3 varied from $0 \mathrm{mg} / \mathrm{m}^{3}$ to $0.015 \mathrm{mg} / \mathrm{m}^{3}$, while $\mathrm{PM}_{2.5}$ varied from $0.002 \mathrm{mg} / \mathrm{m}^{3}$ to $0.026 \mathrm{mg} / \mathrm{m}^{3}$. The concentration of $\mathrm{PM}_{1}$ and $\mathrm{PM}_{2.5}$ does not significantly change. However, the concentration of TSP changed significantly. The maximum concentration of TSP was observed at 5:15:39 pm, which is $1.6 \mathrm{mg} / \mathrm{m}^{3}$ and the minimum observed value of TSP was $0.003 \mathrm{mg} / \mathrm{m}^{3}$.

The AP-42 Dust Emission Estimation method is based on the AP-42 EF estimation equations (3.1 and 3.2). The loading facility uses surge bin to load the train cars, so the reduction efficiency (CE) is 99\% (Todoroski, 2012). Table 4.1 shows the calculation of dust emissions using 
equation (3.1) and (3.2). The wind speeds at Locations 1 and 2 was $1.12 \mathrm{~m} / \mathrm{s}$ and $0.67 \mathrm{~m} / \mathrm{s}$ and the moisture content of coal was 5.9\%. The maximum emission rate of TSP, $\mathrm{PM}_{10}$, and $\mathrm{PM}_{2.5}$ at both location 1 and 2, based on the AP-42 estimation method, is $3.5 \times 10^{-3} \mathrm{~kg} / \mathrm{hr}, 1.7 \times 10^{-3} \mathrm{~kg} / \mathrm{hr}$, and $2.5 \times 10^{-4} \mathrm{~kg} / \mathrm{hr}$, respectively. The wind speed at Location 3 varied with time of data collection while the moisture content was $6.05 \%$. The wind speed at location ranges from $0.22 \mathrm{~m} / \mathrm{s}$ to $1.34 \mathrm{~m} / \mathrm{s}$. The emission rates of all particulates at Location 3 are relatively lower than other locations. The highest emission rate of TSP, $\mathrm{PM}_{10}$, and $\mathrm{PM}_{2.5}$ at location 3 based on the AP-42 estimation method is $4.3 \times 10^{-3} \mathrm{~kg} / \mathrm{hr}, 2.0 \times 10^{-3} \mathrm{~kg} / \mathrm{hr}$, and $3.0 \times 10^{-4} \mathrm{~kg} / \mathrm{hr}$, respectively. While the minimum emission rate of TSP, $\mathrm{PM}_{10}$, and $\mathrm{PM}_{2.5}$ at location 3 is $5.2 \times 10^{-5} \mathrm{~kg} / \mathrm{hr}, 2.4 \times 10^{-5} \mathrm{~kg} / \mathrm{hr}$, and $3.7 \times 10^{-6} \mathrm{~kg} / \mathrm{hr}$, respectively. The highest emission rate observed for all the three locations also has the highest wind speed, which plays a crucial role in dust emission and dispersion.

Table 4.1 Calculation of AP-42 dust emissions based on equations (3.1) and (3.2)

\begin{tabular}{|c|c|c|c|c|c|c|c|c|c|}
\hline & $\begin{array}{c}\text { Samp } \\
\text { le }\end{array}$ & $\begin{array}{c}\text { Locat } \\
\text { ion }\end{array}$ & $\mathbf{k}$ & $\begin{array}{c}M \\
(\%)\end{array}$ & $\begin{array}{c}\mathbf{u} \\
(\mathrm{m} / \mathrm{s})\end{array}$ & $\begin{array}{l}\text { EF }(\mathrm{kg} / \mathrm{t}) \\
(\operatorname{eqn} 3.2)\end{array}$ & $\begin{array}{l}\text { Producti } \\
\text { on }(\mathbf{t} / \mathbf{h r})\end{array}$ & $\begin{array}{l}\text { CE } \\
(\%)\end{array}$ & $\begin{array}{r}\mathrm{E}(\mathrm{kg} / \mathrm{hr}) \\
(\text { eqn } 3.1)\end{array}$ \\
\hline \multirow{7}{*}{$\mathbf{P M}_{2.5}$} & 1 & 1 & \multirow{7}{*}{0.053} & 5.9 & 1.12 & $7.7 \times 10^{-6}$ & \multirow{7}{*}{3265} & \multirow{7}{*}{99} & $2.5 \times 10^{-4}$ \\
\hline & 2 & 2 & & 5.9 & 1.12 & $7.7 \times 10^{-6}$ & & & $2.5 \times 10^{-4}$ \\
\hline & 3 & 3 & & 6.05 & 1.07 & $7.1 \times 10^{-6}$ & & & $2.4 \times 10^{-4}$ \\
\hline & 4 & 3 & & 6.05 & 1.29 & $9.1 \times 10^{-6}$ & & & $2.9 \times 10^{-4}$ \\
\hline & 5 & 3 & & 6.05 & 0.09 & $2.8 \times 10^{-7}$ & & & $9.1 \times 10^{-6}$ \\
\hline & 6 & 3 & & 6.05 & 0.36 & $1.7 \times 10^{-6}$ & & & $5.5 \times 10^{-5}$ \\
\hline & 7 & 3 & & 6.05 & 0.45 & $2.3 \times 10^{-6}$ & & & $7.4 \times 10^{-5}$ \\
\hline
\end{tabular}


Table 4.1 Calculation of AP-42 dust emissions based on equations (3.1) and (3.2) (Continued)

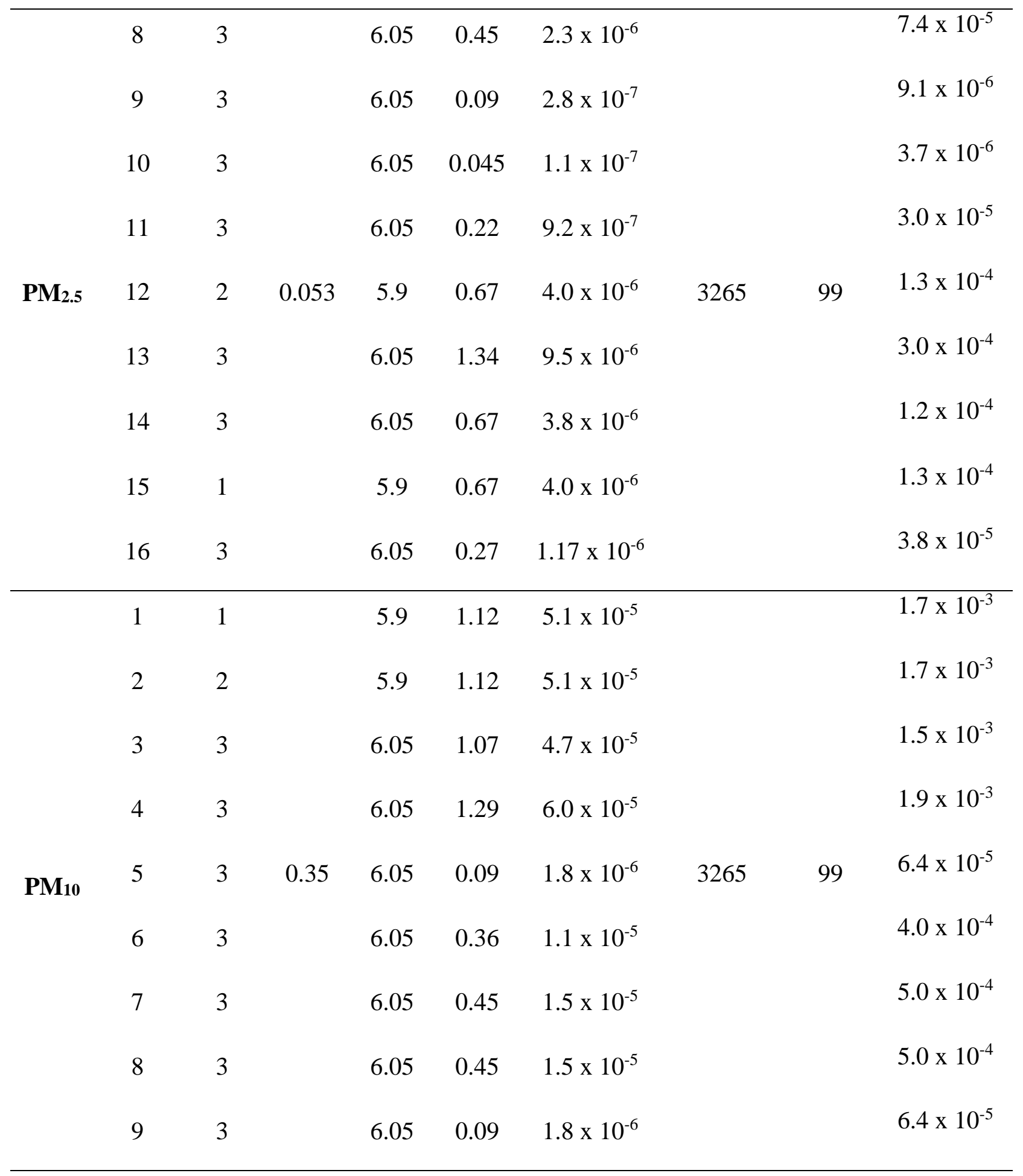


Table 4.1 Calculation of AP-42 dust emissions based on equations (3.1) and (3.2) (Continued)

\begin{tabular}{|c|c|c|c|c|c|c|c|c|c|}
\hline \multirow{7}{*}{$\mathrm{PM}_{10}$} & 10 & 3 & \multirow{7}{*}{0.35} & 6.05 & 0.045 & $7.5 \times 10^{-7}$ & \multirow{7}{*}{3265} & \multirow{7}{*}{99} & $2.4 \times 10^{-5}$ \\
\hline & 11 & 3 & & 6.05 & 0.22 & $6.1 \times 10^{-6}$ & & & $2.0 \times 10^{-4}$ \\
\hline & 12 & 2 & & 5.9 & 0.67 & $2.6 \times 10^{-5}$ & & & $8.6 \times 10^{-4}$ \\
\hline & 13 & 3 & & 6.05 & 1.34 & $6.4 \times 10^{-5}$ & & & $2.0 \times 10^{-3}$ \\
\hline & 14 & 3 & & 6.05 & 0.67 & $2.5 \times 10^{-5}$ & & & $8.3 \times 10^{-4}$ \\
\hline & 15 & 1 & & 5.9 & 0.67 & $2.6 \times 10^{-5}$ & & & $8.6 \times 10^{-4}$ \\
\hline & 16 & 3 & & 6.05 & 0.27 & $7.7 \times 10^{-6}$ & & & $2.5 \times 10^{-4}$ \\
\hline \multirow{11}{*}{ TSP } & 1 & 1 & \multirow{11}{*}{0.53} & 5.9 & 1.12 & $1.1 \times 10^{-4}$ & \multirow{11}{*}{3265} & \multirow{11}{*}{99} & $3.5 \times 10^{-3}$ \\
\hline & 2 & 2 & & 5.9 & 1.12 & $1.1 \times 10^{-4}$ & & & $3.5 \times 10^{-3}$ \\
\hline & 3 & 3 & & 6.05 & 1.07 & $9.9 \times 10^{-5}$ & & & $3.2 \times 10^{-3}$ \\
\hline & 4 & 3 & & 6.05 & 1.29 & $1.3 \times 10^{-4}$ & & & $4.1 \times 10^{-3}$ \\
\hline & 5 & 3 & & 6.05 & 0.09 & $3.9 \times 10^{-6}$ & & & $1.0 \times 10^{-4}$ \\
\hline & 6 & 3 & & 6.05 & 0.36 & $2.4 \times 10^{-4}$ & & & $8.0 \times 10^{-4}$ \\
\hline & 7 & 3 & & 6.05 & 0.45 & $3.2 \times 10^{-5}$ & & & $1.0 \times 10^{-3}$ \\
\hline & 8 & 3 & & 6.05 & 0.45 & $3.2 \times 10^{-5}$ & & & $1.0 \times 10^{-3}$ \\
\hline & 9 & 3 & & 6.05 & 0.09 & $3.9 \times 10^{-6}$ & & & $1.0 \times 10^{-4}$ \\
\hline & 10 & 3 & & 6.05 & 0.045 & $1.6 \times 10^{-6}$ & & & $5.2 \times 10^{-5}$ \\
\hline & 11 & 3 & & 6.05 & 0.22 & $1.3 \times 10^{-5}$ & & & $4.0 \times 10^{-4}$ \\
\hline
\end{tabular}


Table 4.1 Calculation of AP-42 dust emissions based on equations (3.1) and (3.2) (Continued)

\begin{tabular}{|c|c|c|c|c|c|c|c|c|c|}
\hline \multirow{5}{*}{ TSP } & 12 & 2 & \multirow{5}{*}{0.53} & 5.9 & 0.67 & $5.6 \times 10^{-5}$ & \multirow{5}{*}{3265} & \multirow{5}{*}{99} & $1.8 \times 10^{-3}$ \\
\hline & 13 & 3 & & 6.05 & 1.34 & $1.3 \times 10^{-4}$ & & & $4.3 \times 10^{-3}$ \\
\hline & 14 & 3 & & 6.05 & 0.67 & $5.4 \times 10^{-5}$ & & & $1.8 \times 10^{-3}$ \\
\hline & 15 & 1 & & 5.9 & 0.67 & $5.6 \times 10^{-5}$ & & & $1.9 \times 10^{-3}$ \\
\hline & 16 & 3 & & 6.05 & 0.27 & $1.6 \times 10^{-5}$ & & & $5.0 \times 10^{-4}$ \\
\hline
\end{tabular}

As the cloud cover was full on the first day of data collection, the stability class is D for locations 1 and 2. The stability class for location 3 was B as the cloud cover was nil, and the daytime insolation was slight. The plume spread $\sigma_{\mathrm{y}}$ and $\sigma_{\mathrm{z}}$ are calculated using equations (3.3) and (3.4). Table 4.2 shows the calculation of Type-2 dust emissions based on equation (3.3) and (3.4). The measured reference height for wind speed $\left(\mathrm{z}_{\mathrm{ref}}\right)$ is $1.6 \mathrm{~m}$, and the stack height $\left(\mathrm{h}_{\mathrm{s}}\right)$ is $4.34 \mathrm{~m}$ for Locations 1 and 2. For Location 3 the measured reference height for wind speed ( $\mathrm{z}_{\text {ref }}$ ) is 4.32 $\mathrm{m}$. The average concentration $\left(\chi \mathrm{in} \mathrm{mg} / \mathrm{m}^{3}\right)$ of respective particulate at a particular location is used in the calculations. The emission rate of $\mathrm{PM}_{2.5}$ using equation 3.11 at Locations 1 and 2 is $1.8 \times 10^{-}$ ${ }^{5} \mathrm{~kg} / \mathrm{hr}$ and $1.5 \times 10^{-4} \mathrm{~kg} / \mathrm{hr}$, respectively. The emission rate of $\mathrm{PM}_{10}$ at Locations 1 and 2 is $4.4 \times 10^{-}$ ${ }^{5} \mathrm{~kg} / \mathrm{hr}$ and $3.1 \times 10^{-4} \mathrm{~kg} / \mathrm{hr}$, respectively. Also, the emission rate of TSP at Locations 1 and 2 is $5.3 \times 10^{-5} \mathrm{~kg} / \mathrm{hr}$ and $4.0 \times 10^{-4} \mathrm{~kg} / \mathrm{hr}$, respectively. The emission rate of the particulates for Location 3 varies widely because of variation in the wind speed observed at different durations of the day. Among the twelve observations at Location 3, the maximum emission rate of $\mathrm{PM}_{2.5,}, \mathrm{PM}_{10}$, and TSP is $9.5 \times 10^{-5} \mathrm{~kg} / \mathrm{hr}, 4.5 \times 10^{-4} \mathrm{~kg} / \mathrm{hr}$, and $1.0 \times 10^{-3} \mathrm{~kg} / \mathrm{hr}$, respectively. The lowest emission rate of $\mathrm{PM}_{2.5}, \mathrm{PM}_{10}$, and TSP for location 3 is $1.1 \times 10^{-6} \mathrm{~kg} / \mathrm{hr}, 3.5 \times 10^{-6} \mathrm{~kg} / \mathrm{hr}$, and $1.1 \times 10^{-5} \mathrm{~kg} / \mathrm{hr}$, respectively. 
Table 4.2 Calculation of Type-2 dust emissions based on equation (3.3) and (3.4)

\begin{tabular}{|c|c|c|c|c|c|c|c|c|c|}
\hline & $\begin{array}{c}\text { Sampl } \\
\text { e }\end{array}$ & $\begin{array}{c}\text { Locat } \\
\text { ion }\end{array}$ & $\mathbf{x}(\mathbf{m})$ & $\begin{array}{c}\mathbf{u} \\
(\mathrm{m} / \mathbf{s})\end{array}$ & $\begin{array}{c}\sigma_{y}(\mathbf{m}) \\
(\mathbf{e q n} \\
3.3)\end{array}$ & $\begin{array}{c}\sigma_{z}(\mathbf{m}) \\
(\text { eqn 3.4) }\end{array}$ & $\begin{array}{c}\chi \\
(\mathrm{mg} / \mathrm{m} \\
3\end{array}$ & $\begin{array}{c}\mathbf{Q}(\mathrm{g} / \mathrm{s}) \\
(\mathrm{eqn} \\
3.11)\end{array}$ & $\begin{array}{c}\mathrm{Q} \\
(\mathrm{kg} / \mathrm{hr})\end{array}$ \\
\hline \multirow{16}{*}{$\mathbf{P M}_{2.5}$} & 1 & 1 & 5.18 & 1.12 & 0.40726 & 0.24522 & 0.006 & $4.9 \times 10^{-6}$ & $1.8 \times 10^{-5}$ \\
\hline & 2 & 2 & 13.9 & 1.12 & 1.09106 & 0.6543 & 0.007 & $4.1 \times 10^{-5}$ & $1.5 \times 10^{-4}$ \\
\hline & 3 & 3 & 4.24 & 1.07 & 0.8549 & 0.40858 & 0.008 & $1.9 \times 10^{-5}$ & $6.8 \times 10^{-5}$ \\
\hline & 4 & 3 & 4.24 & 1.29 & 0.8549 & 0.40858 & 0.007 & $2 \times 10^{-5}$ & $7.1 \times 10^{-5}$ \\
\hline & 5 & 3 & 4.24 & 0.09 & 0.8549 & 0.40858 & 0.006 & $1.2 \times 10^{-6}$ & $4.2 \times 10^{-6}$ \\
\hline & 6 & 3 & 4.24 & 0.36 & 0.8549 & 0.40858 & 0.005 & $3.9 \times 10^{-6}$ & $1.4 \times 10^{-5}$ \\
\hline & 7 & 3 & 4.24 & 0.45 & 0.8549 & 0.40858 & 0.005 & $4.9 \times 10^{-6}$ & $1.8 \times 10^{-5}$ \\
\hline & 8 & 3 & 4.24 & 0.45 & 0.8549 & 0.40858 & 0.008 & $7.9 \times 10^{-6}$ & $2.8 \times 10^{-5}$ \\
\hline & 9 & 3 & 4.24 & 0.09 & 0.8549 & 0.40858 & 0.004 & $7.9 \times 10^{-7}$ & $1.8 \times 10^{-6}$ \\
\hline & 10 & 3 & 4.24 & 0.045 & 0.8549 & 0.40858 & 0.003 & $2.9 \times 10^{-7}$ & $1.1 \times 10^{-6}$ \\
\hline & 11 & 3 & 4.24 & 0.22 & 0.8549 & 0.40858 & 0.004 & $1.8 \times 10^{-6}$ & $6.5 \times 10^{-6}$ \\
\hline & 12 & 2 & 3.9 & 10.67 & 1.09106 & 0.6543 & 0.006 & $1.8 \times 10^{-5}$ & $6.5 \times 10^{-5}$ \\
\hline & 13 & 3 & 4.24 & 1.34 & 0.8549 & 0.40858 & 0.009 & $2.6 \times 10^{-5}$ & $9.5 \times 10^{-5}$ \\
\hline & 14 & 3 & 4.24 & 0.67 & 0.8549 & 0.40858 & 0.008 & $1.2 \times 10^{-5}$ & $4.2 \times 10^{-5}$ \\
\hline & 15 & 1 & 5.18 & 0.67 & 0.40726 & 0.24522 & 0.006 & $2.5 \times 10^{-6}$ & $9.1 \times 10^{-6}$ \\
\hline & 16 & 3 & 4.24 & 0.27 & 0.8549 & 0.40858 & 0.005 & $3.0 \times 10^{-6}$ & $1.1 \times 10^{-5}$ \\
\hline
\end{tabular}


Table 4.2 Calculation of Type-2 dust emissions based on equation (3.3) and (3.4) (Continued)

\begin{tabular}{|c|c|c|c|c|c|c|c|c|c|}
\hline \multirow{16}{*}{ PM10 } & 1 & 1 & 5.18 & 1.12 & 0.40726 & 0.24522 & 0.015 & $1.2 \times 10^{-5}$ & $4.4 \times 10^{-5}$ \\
\hline & 2 & 2 & 13.9 & 1.12 & 1.09106 & 0.6543 & 0.015 & $8.7 \times 10^{-5}$ & $3.1 \times 10^{-4}$ \\
\hline & 3 & 3 & 4.24 & 1.07 & 0.8549 & 0.40858 & 0.037 & $8.7 \times 10^{-5}$ & $3.1 \times 10^{-4}$ \\
\hline & 4 & 3 & 4.24 & 1.29 & 0.8549 & 0.40858 & 0.044 & $1.2 \times 10^{-4}$ & $4.5 \times 10^{-4}$ \\
\hline & 5 & 3 & 4.24 & 0.09 & 0.8549 & 0.40858 & 0.025 & $4.9 \times 10^{-6}$ & $1.8 \times 10^{-5}$ \\
\hline & 6 & 3 & 4.24 & 0.36 & 0.8549 & 0.40858 & 0.022 & $1.7 \times 10^{-5}$ & $6.2 \times 10^{-5}$ \\
\hline & 7 & 3 & 4.24 & 0.45 & 0.8549 & 0.40858 & 0.027 & $2.6 \times 10^{-5}$ & $9.5 \times 10^{-5}$ \\
\hline & 8 & 3 & 4.24 & 0.45 & 0.8549 & 0.40858 & 0.051 & $5.0 \times 10^{-5}$ & $1.8 \times 10^{-4}$ \\
\hline & 9 & 3 & 4.24 & 0.09 & 0.8549 & 0.40858 & 0.015 & $2.9 \times 10^{-6}$ & $1.1 \times 10^{-5}$ \\
\hline & 10 & 3 & 4.24 & 0.045 & 0.8549 & 0.40858 & 0.01 & $9.8 \times 10^{-7}$ & $3.5 \times 10^{-6}$ \\
\hline & 11 & 3 & 4.24 & 0.22 & 0.8549 & 0.40858 & 0.019 & $9.3 \times 10^{-6}$ & $3.4 \times 10^{-5}$ \\
\hline & 12 & 2 & 3.9 & 10.67 & 1.09106 & 0.6543 & 0.016 & $4.8 \times 10^{-5}$ & $1.7 \times 10^{-4}$ \\
\hline & 13 & 3 & 4.24 & 1.34 & 0.8549 & 0.40858 & 0.039 & $1.1 \times 10^{-4}$ & $4.1 \times 10^{-4}$ \\
\hline & 14 & 3 & 4.24 & 0.67 & 0.8549 & 0.40858 & 0.072 & $1.1 \times 10^{-4}$ & $3.8 \times 10^{-4}$ \\
\hline & 15 & 1 & 5.18 & 0.67 & 0.40726 & 0.24522 & 0.014 & $5.9 \times 10^{-6}$ & $2.1 \times 10^{-5}$ \\
\hline & 16 & 3 & 4.24 & 0.27 & 0.8549 & 0.40858 & 0.018 & $1.1 \times 10^{-5}$ & $3.8 \times 10^{-5}$ \\
\hline
\end{tabular}


Table 4.2 Calculation of Type-2 dust emissions based on equation (3.3) and (3.4) (Continued)

\begin{tabular}{|c|c|c|c|c|c|c|c|c|c|}
\hline & 1 & 1 & 5.18 & 1.12 & 0.40726 & 0.24522 & 0.018 & $1.5 \times 10^{-5}$ & $5.3 \times 10^{-5}$ \\
\hline & 2 & 2 & 13.9 & 1.12 & 1.09106 & 0.6543 & 0.019 & $1.1 \times 10^{-4}$ & $4 \times 10^{-4}$ \\
\hline & 3 & 3 & 4.24 & 1.07 & 0.8549 & 0.40858 & 0.066 & $1.8 \times 10^{-4}$ & $6.5 \times 10^{-4}$ \\
\hline & 4 & 3 & 4.24 & 1.29 & 0.8549 & 0.40858 & 0.085 & $2.8 \times 10^{-4}$ & $1.0 \times 10^{-3}$ \\
\hline & 5 & 3 & 4.24 & 0.09 & 0.8549 & 0.40858 & 0.096 & $2.2 \times 10^{-5}$ & $7.9 \times 10^{-5}$ \\
\hline & 6 & 3 & 4.24 & 0.36 & 0.8549 & 0.40858 & 0.04 & $3.6 \times 10^{-5}$ & $1.3 \times 10^{-4}$ \\
\hline & 7 & 3 & 4.24 & 0.45 & 0.8549 & 0.40858 & 0.043 & $4.9 \times 10^{-5}$ & $1.8 \times 10^{-4}$ \\
\hline & 8 & 3 & 4.24 & 0.45 & 0.8549 & 0.40858 & 0.09 & $1.0 \times 10^{-4}$ & $3.7 \times 10^{-4}$ \\
\hline TSP & 9 & 3 & 4.24 & 0.09 & 0.8549 & 0.40858 & 0.032 & $7.3 \times 10^{-6}$ & $2.6 \times 10^{-5}$ \\
\hline & 10 & 3 & 4.24 & 0.045 & 0.8549 & 0.40858 & 0.026 & $3.0 \times 10^{-6}$ & $1.1 \times 10^{-5}$ \\
\hline & 11 & 3 & 4.24 & 0.22 & 0.8549 & 0.40858 & 0.038 & $2.2 \times 10^{-5}$ & $7.8 \times 10^{-5}$ \\
\hline & 12 & 2 & 3.9 & 10.67 & 1.09106 & 0.6543 & 0.018 & $6.2 \times 10^{-5}$ & $2.3 \times 10^{-4}$ \\
\hline & 13 & 3 & 4.24 & 1.34 & 0.8549 & 0.40858 & 0.069 & $2.4 \times 10^{-4}$ & $8.5 \times 10^{-4}$ \\
\hline & 14 & 3 & 4.24 & 0.67 & 0.8549 & 0.40858 & 0.118 & $2.1 \times 10^{-4}$ & $7.3 \times 10^{-4}$ \\
\hline & 15 & 1 & 5.18 & 0.67 & 0.40726 & 0.24522 & 0.016 & $7.8 \times 10^{-6}$ & $2.8 \times 10^{-5}$ \\
\hline & 16 & 3 & 4.24 & 0.27 & 0.8549 & 0.40858 & 0.115 & $7.8 \times 10^{-5}$ & $2.8 \times 10^{-4}$ \\
\hline
\end{tabular}

Table 4.3 shows the calculation of Type-2 dust emissions based on equations (3.5) and (3.7). The average concentration $\left(\chi \mathrm{in} \mathrm{mg} / \mathrm{m}^{3}\right)$ of respective particulate at a particular location is used in the calculations. The emission rate of $\mathrm{PM}_{2.5}$ using equation 3.11 at Locations 1 and 2 is $3.2 \times 10^{-5} \mathrm{~kg} / \mathrm{hr}$ and $2.2 \times 10^{-4} \mathrm{~kg} / \mathrm{hr}$, respectively. The emission rate of $\mathrm{PM}_{10}$ at Locations 1 and 2 is 
$8.1 \times 10^{-5} \mathrm{~kg} / \mathrm{hr}$ and $4.8 \times 10^{-4} \mathrm{~kg} / \mathrm{hr}$, respectively. Also, the emission rate of TSP at Locations 1 and 2 is $9.7 \times 10^{-5} \mathrm{~kg} / \mathrm{hr}$ and $6.1 \times 10^{-4} \mathrm{~kg} / \mathrm{hr}$, respectively. Among the twelve observations at Location 3 , the highest emission rate of $\mathrm{PM}_{2.5}, \mathrm{PM}_{10}$, and TSP is $1.9 \times 10^{-4} \mathrm{~kg} / \mathrm{hr}, 7.6 \times 10^{-4} \mathrm{~kg} / \mathrm{hr}$, and $1.7 \times 10^{-3}$ $\mathrm{kg} / \mathrm{hr}$, respectively. Also, the lowest emission rate of $\mathrm{PM}_{2.5}, \mathrm{PM}_{10}$, and TSP for location 3 is $2.1 \times 10^{-}$ ${ }^{6} \mathrm{~kg} / \mathrm{hr}, 5.7 \times 10^{-6} \mathrm{~kg} / \mathrm{hr}$, and $1.8 \times 10^{-5} \mathrm{~kg} / \mathrm{hr}$, respectively.

Table 4.3 Calculation of Type-2 dust emissions based on equation (3.5) and (3.7)

\begin{tabular}{|c|c|c|c|c|c|c|c|c|c|}
\hline & $\begin{array}{c}\text { Samp } \\
\text { le }\end{array}$ & $\begin{array}{c}\text { Locat } \\
\text { ion }\end{array}$ & $\mathbf{x}(\mathbf{m})$ & $\begin{array}{c}\mathbf{u} \\
(\mathbf{m} / \mathbf{s})\end{array}$ & $\begin{array}{c}\sigma_{\mathrm{y}}(\mathrm{m}) \\
(\mathrm{eqn} \\
3.5)\end{array}$ & $\begin{array}{c}\sigma_{\mathrm{z}}(\mathrm{m}) \\
(\mathbf{e q n} \\
3.7)\end{array}$ & $\begin{array}{c}\chi \\
\left(\mathbf{m g} / \mathbf{m}^{3}\right)\end{array}$ & $\begin{array}{c}\mathbf{Q}(\mathrm{g} / \mathrm{s}) \\
(\text { eqn 11) }\end{array}$ & $\begin{array}{c}\mathrm{Q} \\
(\mathrm{kg} / \mathrm{hr})\end{array}$ \\
\hline \multirow{11}{*}{$\mathbf{P M}_{2.5}$} & 1 & 1 & 5.18 & 1.12 & 0.5184 & 0.3543 & 0.006 & $9.0 \times 10^{-6}$ & $3.2 \times 10^{-5}$ \\
\hline & 2 & 2 & 13.9 & 1.12 & 1.3069 & 0.836 & 0.007 & $6.2 \times 10^{-5}$ & $2.2 \times 10^{-4}$ \\
\hline & 3 & 3 & 4.24 & 1.07 & 1.058 & 0.5575 & 0.008 & $3.7 \times 10^{-5}$ & $1.3 \times 10^{-4}$ \\
\hline & 4 & 3 & 4.24 & 1.29 & 1.058 & 0.5575 & 0.007 & $3.9 \times 10^{-5}$ & $1.4 \times 10^{-4}$ \\
\hline & 5 & 3 & 4.24 & 0.09 & 1.058 & 0.5575 & 0.006 & $2.3 \times 10^{-6}$ & $8.3 \times 10^{-6}$ \\
\hline & 6 & 3 & 4.24 & 0.36 & 1.058 & 0.5575 & 0.005 & $7.7 \times 10^{-6}$ & $2.8 \times 10^{-5}$ \\
\hline & 7 & 3 & 4.24 & 0.45 & 1.058 & 0.5575 & 0.005 & $9.6 \times 10^{-6}$ & $3.5 \times 10^{-5}$ \\
\hline & 8 & 3 & 4.24 & 0.45 & 1.058 & 0.5575 & 0.008 & $1.5 \times 10^{-5}$ & $5.5 \times 10^{-5}$ \\
\hline & 9 & 3 & 4.24 & 0.09 & 1.058 & 0.5575 & 0.004 & $1.5 \times 10^{-6}$ & $5.5 \times 10^{-6}$ \\
\hline & 10 & 3 & 4.24 & 0.045 & 1.058 & 0.5575 & 0.003 & $5.8 \times 10^{-7}$ & $2.1 \times 10^{-6}$ \\
\hline & 11 & 3 & 4.24 & 0.22 & 1.058 & 0.5575 & 0.004 & $3.6 \times 10^{-6}$ & $1.3 \times 10^{-5}$ \\
\hline
\end{tabular}


Table 4.3 Calculation of Type-2 dust emissions based on equation (3.5) and (3.7) (Continued)

\begin{tabular}{|c|c|c|c|c|c|c|c|c|c|}
\hline \multirow{5}{*}{$\mathbf{P M}_{2.5}$} & 12 & 2 & 3.9 & 10.67 & 1.3069 & 0.846 & 0.009 & $3.4 \times 10^{-5}$ & $1.2 \times 10^{-4}$ \\
\hline & 13 & 3 & 4.24 & 1.34 & 1.058 & 0.5575 & 0.008 & $5.2 \times 10^{-5}$ & $1.9 \times 10^{-4}$ \\
\hline & 14 & 3 & 4.24 & 0.67 & 1.058 & 0.5575 & 0.006 & $2.3 \times 10^{-5}$ & $8.3 \times 10^{-5}$ \\
\hline & 15 & 1 & 5.18 & 0.67 & 0.5184 & 0.3543 & 0.005 & $5.4 \times 10^{-6}$ & $1.9 \times 10^{-5}$ \\
\hline & 16 & 3 & 4.24 & 0.27 & 1.058 & 0.5575 & 0.004 & $5.8 \times 10^{-6}$ & $2.1 \times 10^{-5}$ \\
\hline \multirow{13}{*}{ PM10 } & 1 & 1 & 5.18 & 1.12 & 0.5184 & 0.3543 & 0.015 & $2.2 \times 10^{-5}$ & $8.1 \times 10^{-5}$ \\
\hline & 2 & 2 & 13.9 & 1.12 & 1.3069 & 0.836 & 0.015 & $1.3 \times 10^{-4}$ & $4.8 \times 10^{-4}$ \\
\hline & 3 & 3 & 4.24 & 1.07 & 1.058 & 0.5575 & 0.037 & $1.5 \times 10^{-4}$ & $5.3 \times 10^{-4}$ \\
\hline & 4 & 3 & 4.24 & 1.29 & 1.058 & 0.5575 & 0.044 & $2.1 \times 10^{-4}$ & $7.6 \times 10^{-4}$ \\
\hline & 5 & 3 & 4.24 & 0.09 & 1.058 & 0.5575 & 0.025 & $8.3 \times 10^{-6}$ & $3.0 \times 10^{-5}$ \\
\hline & 6 & 3 & 4.24 & 0.36 & 1.058 & 0.5575 & 0.022 & $2.9 \times 10^{-5}$ & $1.0 \times 10^{-4}$ \\
\hline & 7 & 3 & 4.24 & 0.45 & 1.058 & 0.5575 & 0.027 & $4.5 \times 10^{-5}$ & $1.6 \times 10^{-4}$ \\
\hline & 8 & 3 & 4.24 & 0.45 & 1.058 & 0.5575 & 0.051 & $8.5 \times 10^{-5}$ & $3.0 \times 10^{-4}$ \\
\hline & 9 & 3 & 4.24 & 0.09 & 1.058 & 0.5575 & 0.015 & $5.0 \times 10^{-6}$ & $1.8 \times 10^{-5}$ \\
\hline & 10 & 3 & 4.24 & 0.045 & 1.058 & 0.5575 & 0.01 & $1.7 \times 10^{-6}$ & $6.0 \times 10^{-6}$ \\
\hline & 11 & 3 & 4.24 & 0.22 & 1.058 & 0.5575 & 0.019 & $1.6 \times 10^{-5}$ & $5.7 \times 10^{-6}$ \\
\hline & 12 & 2 & 3.9 & 10.67 & 1.3069 & 0.836 & 0.016 & $7.9 \times 10^{-5}$ & $2.8 \times 10^{-4}$ \\
\hline & 13 & 3 & 4.24 & 1.34 & 1.058 & 0.5575 & 0.039 & $1.9 \times 10^{-4}$ & $7.0 \times 10^{-4}$ \\
\hline
\end{tabular}


Table 4.3 Calculation of Type-2 dust emissions based on equation (3.5) and (3.7) (Continued)

\begin{tabular}{|c|c|c|c|c|c|c|c|c|c|}
\hline \multirow{3}{*}{ PM10 } & 14 & 3 & 4.24 & 0.67 & 1.058 & 0.5575 & 0.072 & $1.8 \times 10^{-4}$ & $6.5 \times 10^{-4}$ \\
\hline & 15 & 1 & 5.18 & 0.67 & 0.5184 & 0.3543 & 0.014 & $1.1 \times 10^{-5}$ & $3.9 \times 10^{-5}$ \\
\hline & 16 & 3 & 4.24 & 0.27 & 1.058 & 0.5575 & 0.018 & $1.8 \times 10^{-5}$ & $6.4 \times 10^{-5}$ \\
\hline \multirow{16}{*}{ TSP } & 1 & 1 & 5.18 & 1.12 & 0.5184 & 0.3543 & 0.018 & $2.7 \times 10^{-5}$ & $9.7 \times 10^{-5}$ \\
\hline & 2 & 2 & 13.9 & 1.12 & 1.3069 & 0.836 & 0.019 & $1.7 \times 10^{-4}$ & $6.1 \times 10^{-4}$ \\
\hline & 3 & 3 & 4.24 & 1.07 & 1.058 & 0.5575 & 0.066 & $3.0 \times 10^{-4}$ & $1.1 \times 10^{-3}$ \\
\hline & 4 & 3 & 4.24 & 1.29 & 1.058 & 0.5575 & 0.085 & $4.7 \times 10^{-4}$ & $1.7 \times 10^{-3}$ \\
\hline & 5 & 3 & 4.24 & 0.09 & 1.058 & 0.5575 & 0.096 & $3.7 \times 10^{-5}$ & $1.3 \times 10^{-4}$ \\
\hline & 6 & 3 & 4.24 & 0.36 & 1.058 & 0.5575 & 0.04 & $6.2 \times 10^{-5}$ & $2.2 \times 10^{-4}$ \\
\hline & 7 & 3 & 4.24 & 0.45 & 1.058 & 0.5575 & 0.043 & $8.3 \times 10^{-5}$ & $3.0 \times 10^{-4}$ \\
\hline & 8 & 3 & 4.24 & 0.45 & 1.058 & 0.5575 & 009 & $1.7 \times 10^{-4}$ & $6.2 \times 10^{-4}$ \\
\hline & 9 & 3 & 4.24 & 0.09 & 1.058 & 0.5575 & 0.032 & $1.2 \times 10^{-5}$ & $4.4 \times 10^{-5}$ \\
\hline & 10 & 3 & 4.24 & 0.045 & 1.058 & 0.5575 & 0.026 & $5.0 \times 10^{-6}$ & $1.8 \times 10^{-5}$ \\
\hline & 11 & 3 & 4.24 & 0.22 & 1.058 & 0.5575 & 0.038 & $3.7 \times 10^{-5}$ & $1.3 \times 10^{-4}$ \\
\hline & 12 & 2 & 3.9 & 10.67 & 1.3069 & 0.836 & 0.018 & $1.0 \times 10^{-4}$ & $3.7 \times 10^{-4}$ \\
\hline & 13 & 3 & 4.24 & 1.34 & 1.058 & 0.5575 & 0.069 & $4.0 \times 10^{-4}$ & $1.4 \times 10^{-3}$ \\
\hline & 14 & 3 & 4.24 & 0.67 & 1.058 & 0.5575 & 0.118 & $3.4 \times 10^{-4}$ & $1.2 \times 10^{-3}$ \\
\hline & 15 & 1 & 5.18 & 0.67 & 0.5184 & 0.3543 & 0.016 & $1.4 \times 10^{-5}$ & $5.2 \times 10^{-5}$ \\
\hline & 16 & 3 & 4.24 & 0.27 & 1.058 & 0.5575 & 0.115 & $1.3 \times 10^{-4}$ & $4.8 \times 10^{-4}$ \\
\hline
\end{tabular}


Figures 4.4 and 4.5 show the comparison of $\mathrm{PM}_{2.5}$ emissions at coal train loading points using AP-42 dust emission and Type-2 dust emission using different equations. As per Figure 4.4, the AP-42 dust emissions for $\mathrm{PM}_{2.5}$ exceeds on average 4.6 times the field-based emissions determined by the Type-2 method using equation (3.3) and (3.4). As per Figure 4.5, the AP-42 dust emissions for $\mathrm{PM}_{2.5}$ exceeds on average 2.4 times the field-based emissions determined by the Type-2 method using equation (3.5) and (3.7).

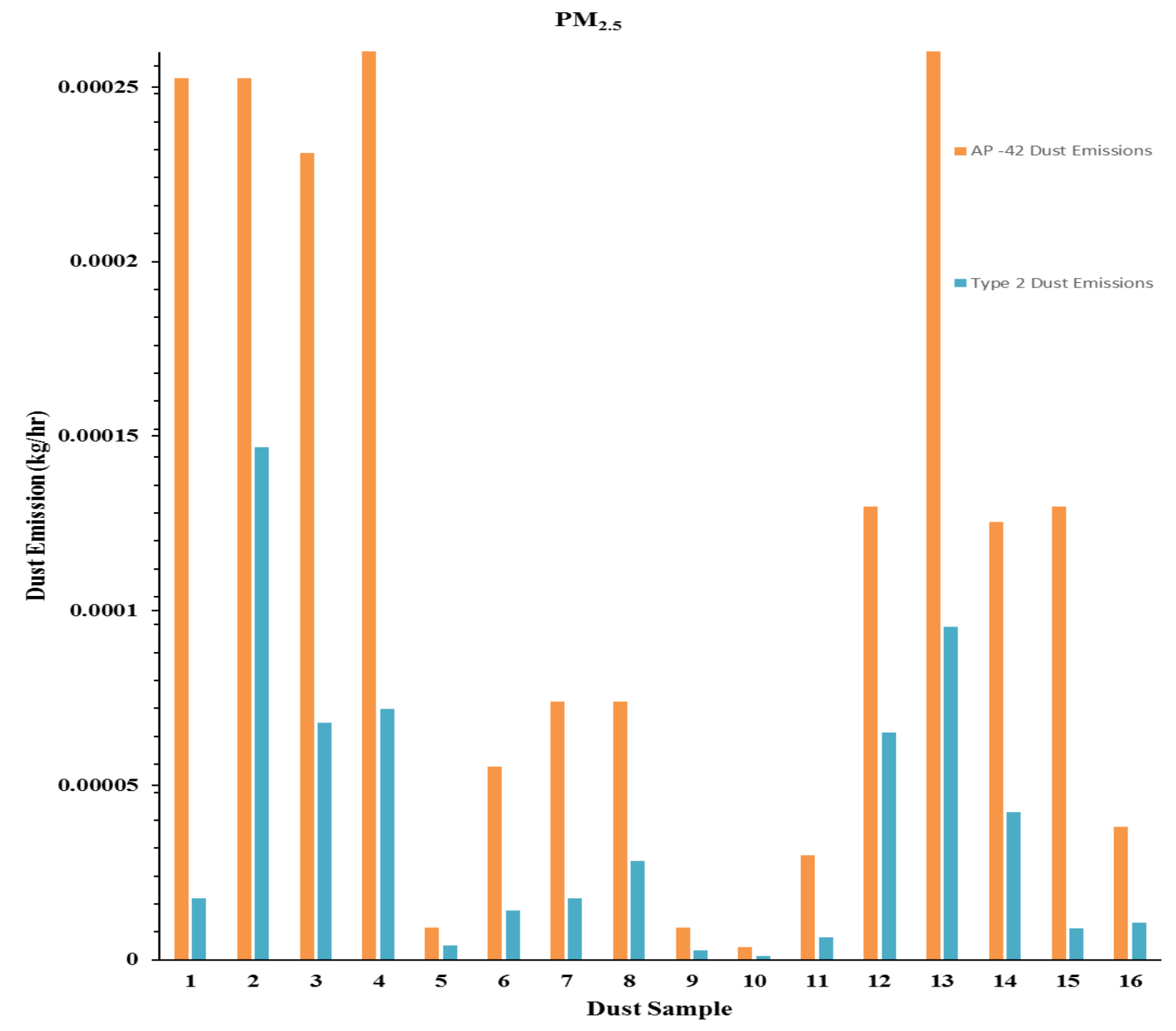

Figure 4.4 Comparison of PM2.5 emissions at coal train loading point (using equation (3.3) and (3.4)) 


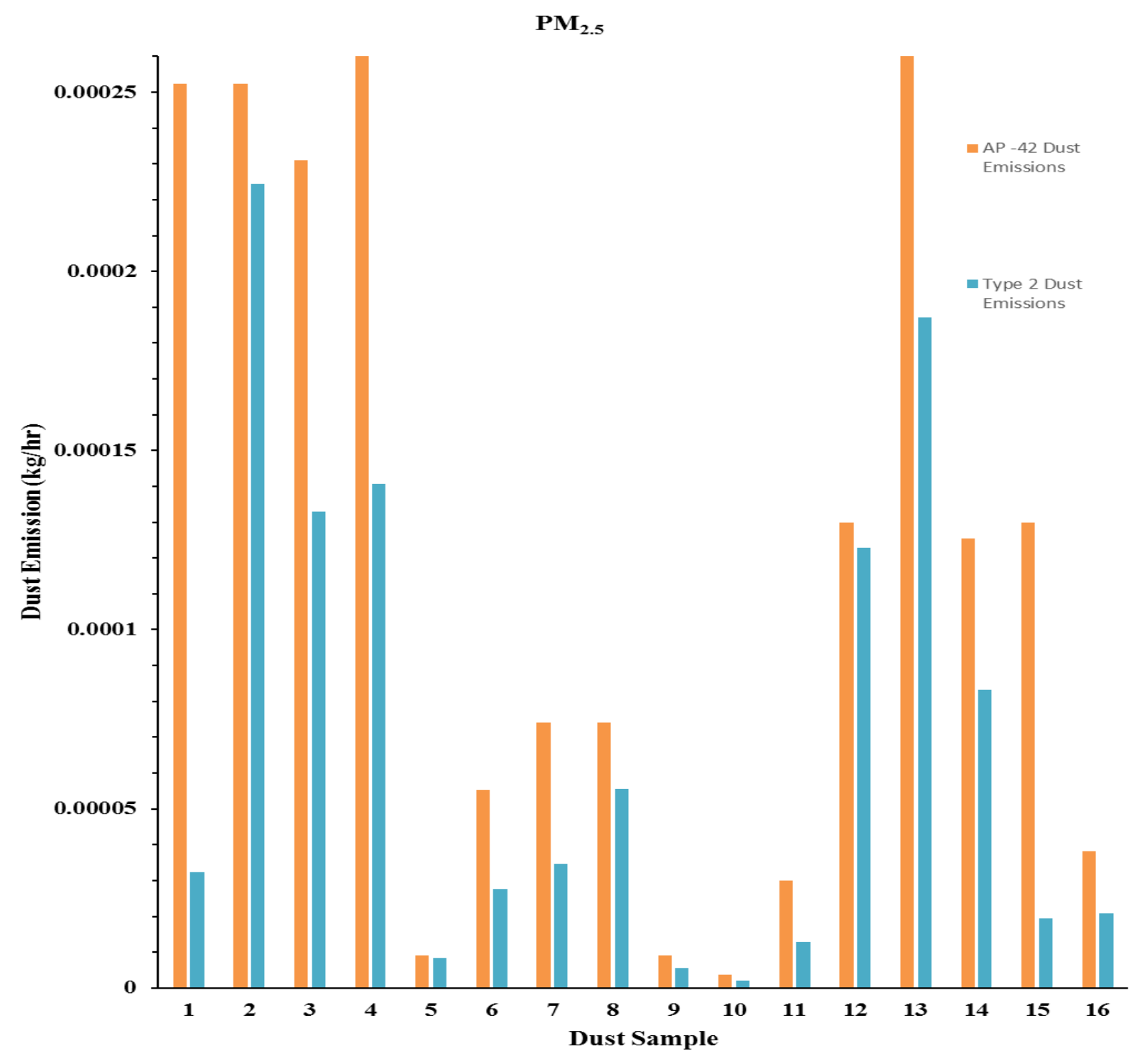

Figure 4.5 Comparison of PM2.5 emissions at coal train loading point (using equation (3.5) and (3.7))

As per Figure 4.6, the AP-42 dust emissions for $\mathrm{PM}_{10}$ exceeds on average 9 times the field-based emissions determined by the Type-2 method using equation (3.3) and (3.4). As per Figure 4.7, the AP-42 dust emissions for $\mathrm{PM}_{10}$ exceeds on average 5.2 times the field-based emissions determined by the Type-2 method using equation (3.5) and (3.7). 


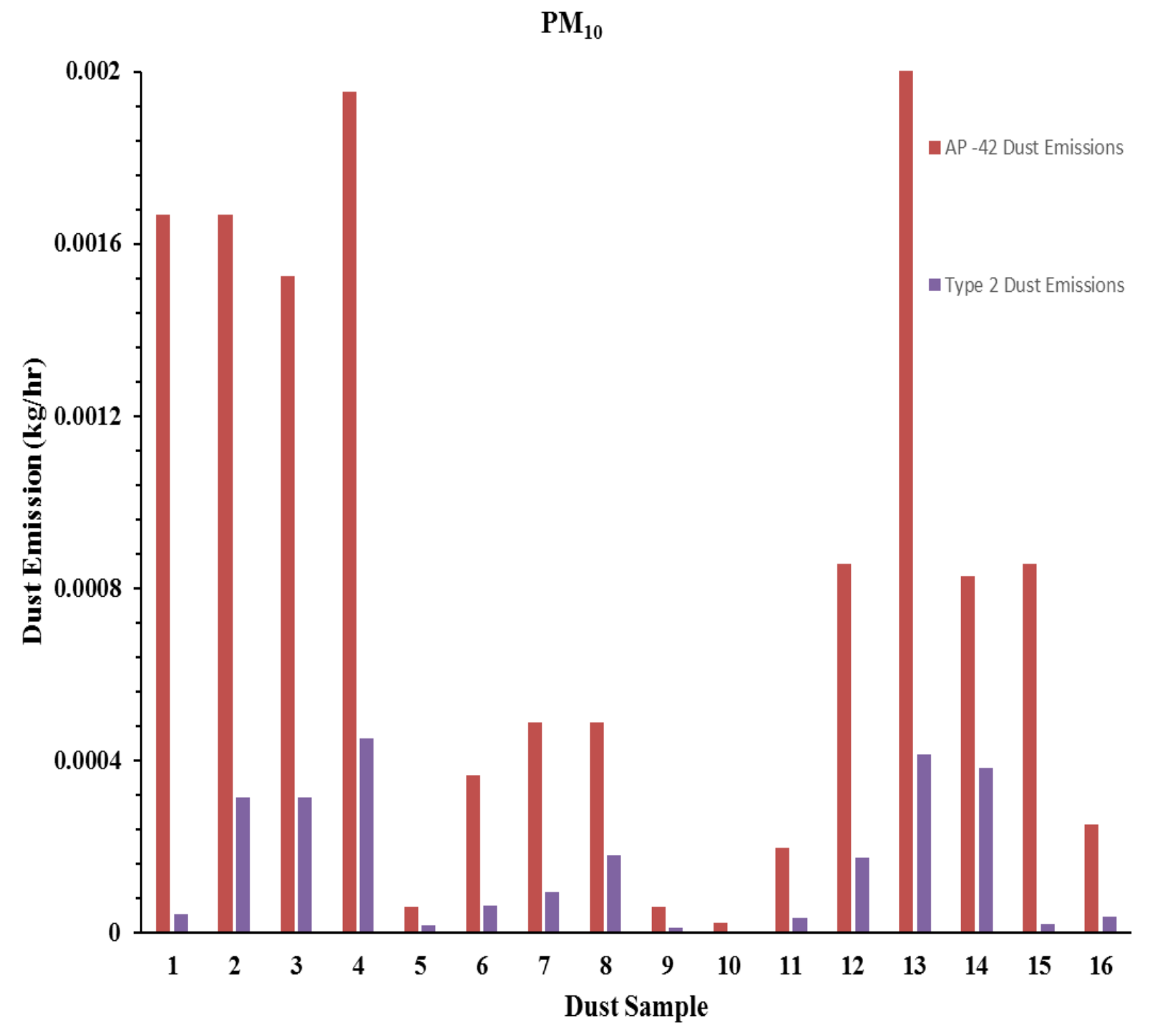

Figure 4.6 Comparison of PM10 emissions at coal train loading point (using equation (3.3) and (3.4)) 


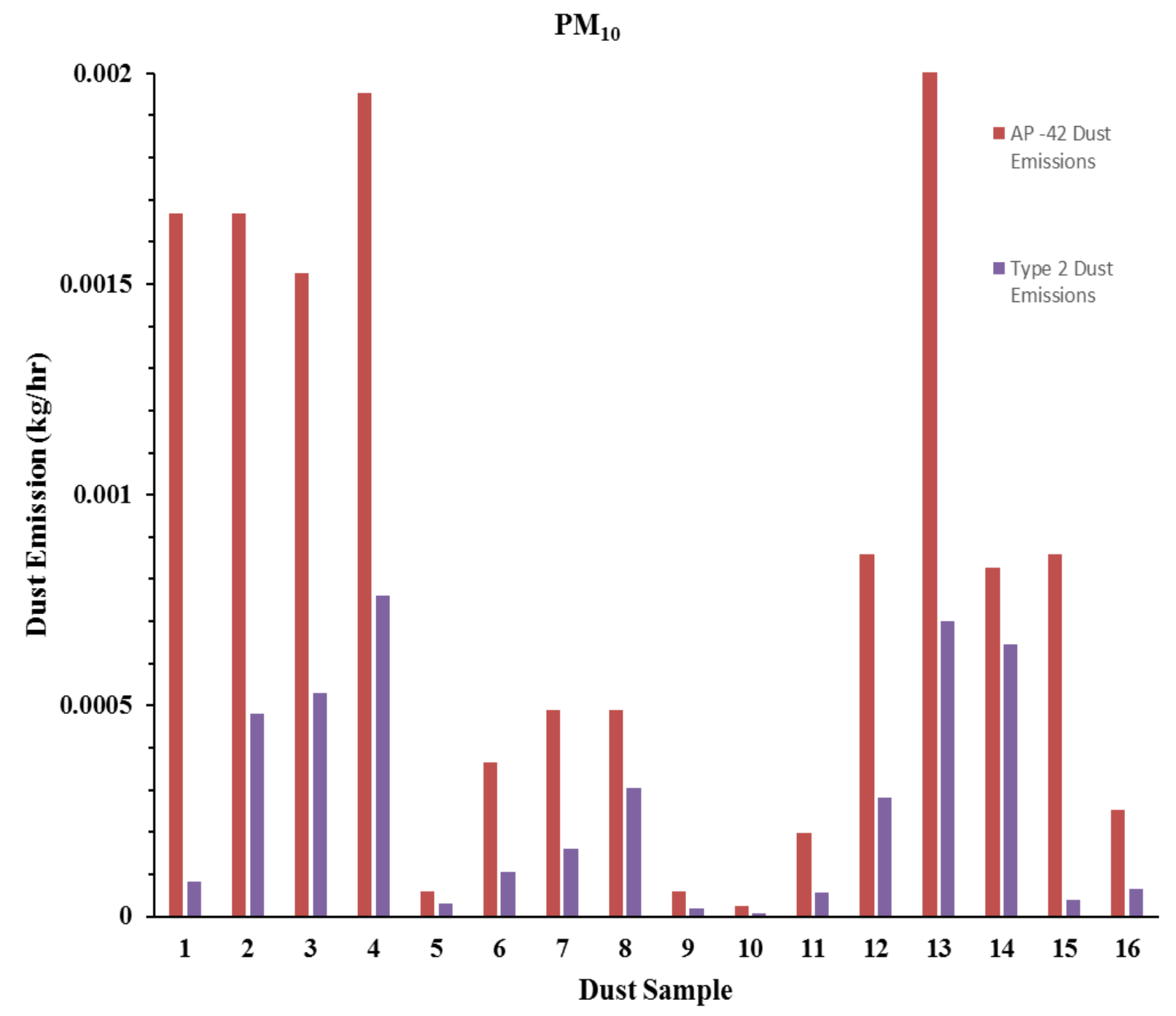

Figure 4.7 Comparison of PM10 emissions at coal train loading point (using equation (3.5) and (3.7))

Figure 4.8 indicates that the AP-42 dust emissions for TSP exceed on average 12.3 times the field-based emissions determined by the Type-2 method using equation (3.3) and (3.4). Figure 4.9 shows that the AP-42 dust emissions for TSP exceed on average 7 times the field-based emissions determined by the Type-2 method using equation (3.5) and (3.7). 


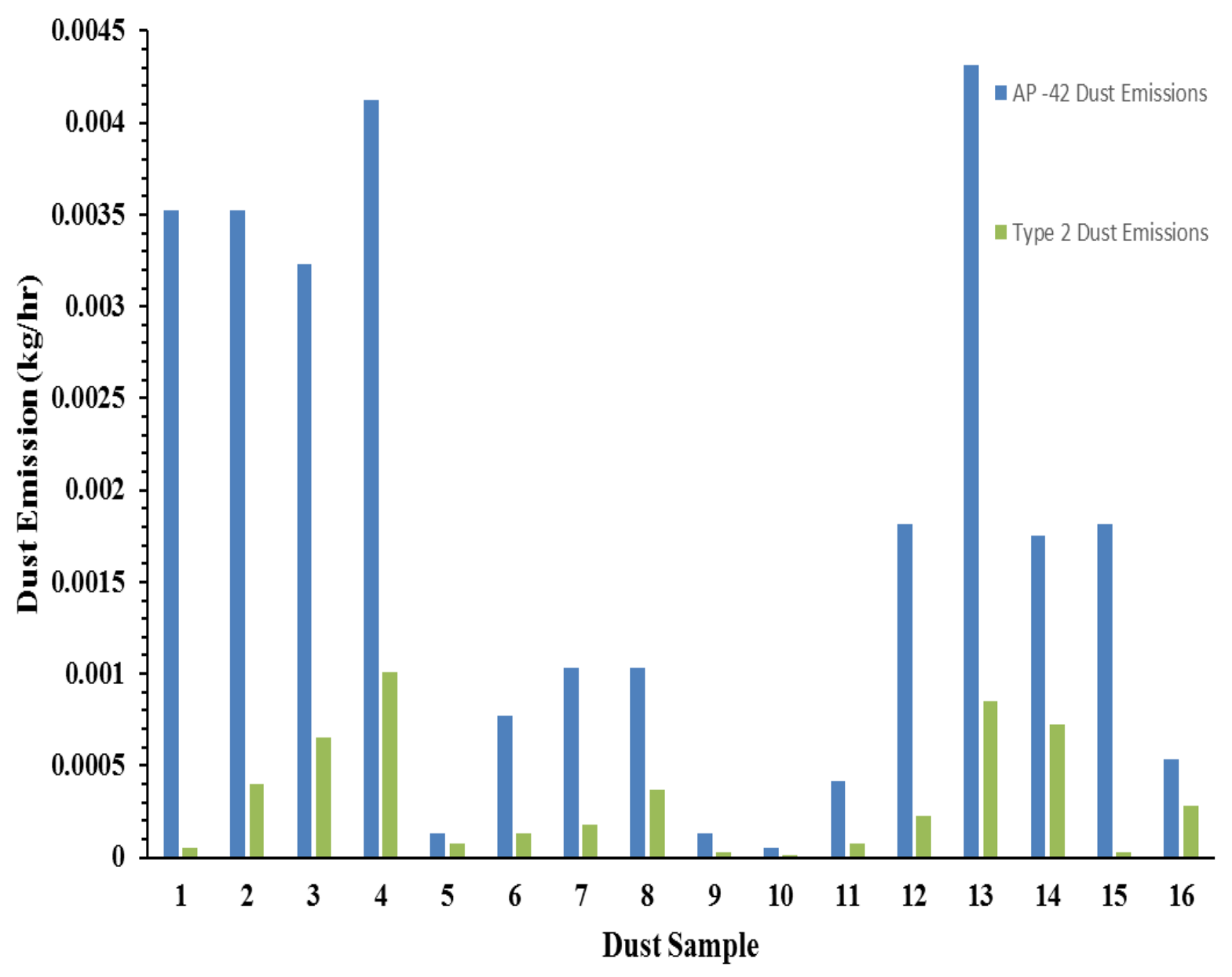

Figure 4.8 Comparison of TSP emissions at coal train loading point (using equation (3.3) and (3.4)) 


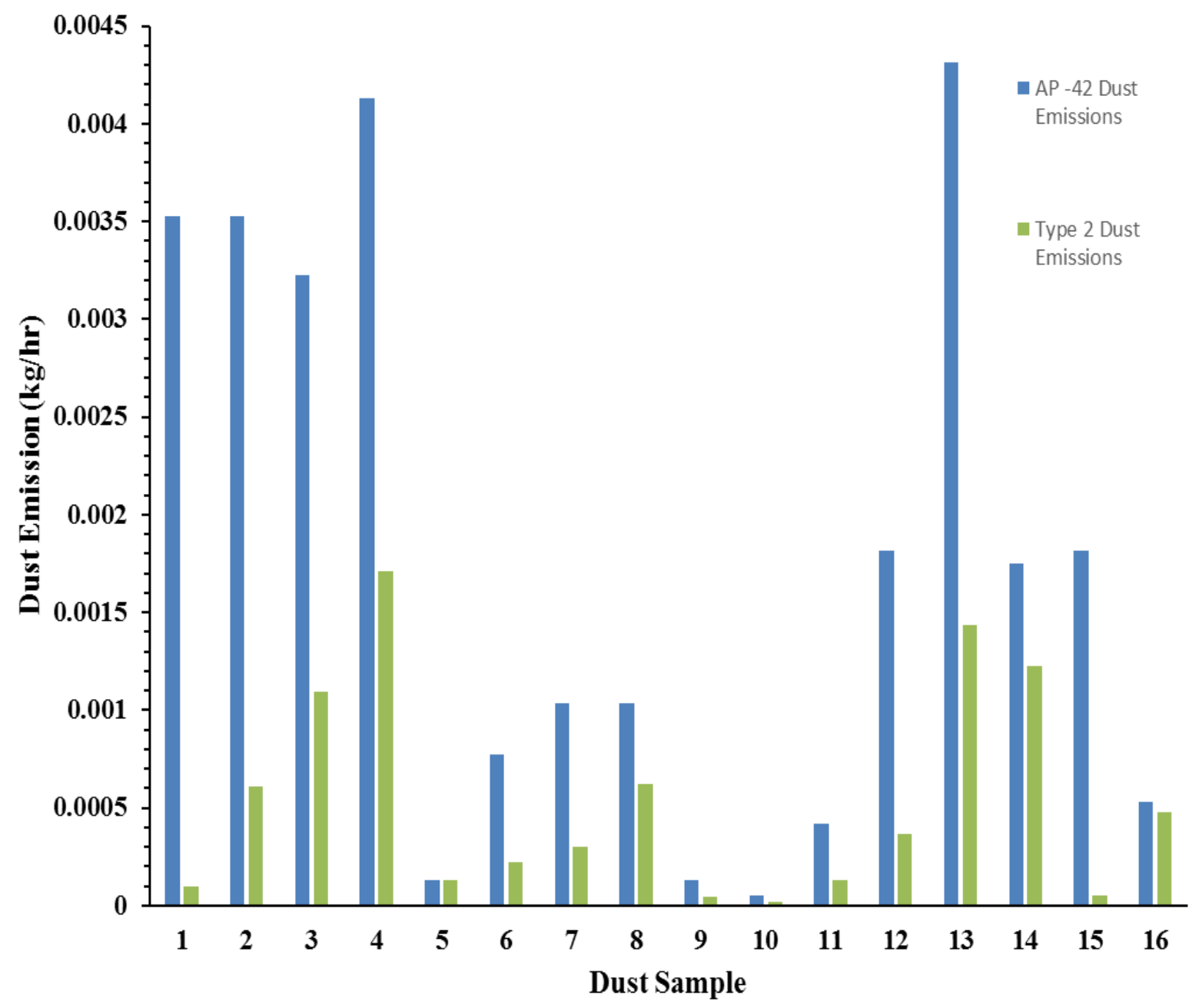

Figure 4.9 Comparison of TSP emissions at coal train loading point (using equation (3.5) and (3.7))

The results show that the AP-42 Dust Emission Estimation method overestimates the emissions from coal train loading for this particular loading facility in West Virginia. The development of the AP-42 equations based on train loading facilities in the West may not be applicable for train loading facilities in the East. Also, with the increase in particle size, the ratio of dust emissions based on the AP-42 method and the Type- 2 method increases. 


\subsection{Multiple Regression Model}

Based on the analysis of the data, reconsideration of EFs for train loading operations is suggested. A new model for estimating EF equations for train loading operations is developed based on multiple regression methods. The measured variables that are used as independent ones (regressors) and included in the model development are wind speed (S), moisture content (M), temperature $(\mathrm{T})$, and humidity $(\mathrm{H})$.

\subsubsection{Model for EF PM2.5}

Table 4.4 shows the results of the best subset regression for $\mathrm{PM}_{2.5}$. The two-variable model consists of $\log$ moisture and $\log$ wind speed. The full model containing all the variables has $\mathrm{R}^{2}(\operatorname{adj})=89.6$, which is very close to the two-variable model containing log moisture and log wind speed. Both the full model and the two-variable model have low $C_{p}$. Thus, the backward stepwise regression analysis is conducted to find the preferred model.

Table 4.4 Results of the best subset regression for EF PM2.5

\begin{tabular}{c|ccccccc}
\hline Variables & $\mathbf{R}^{\mathbf{2}}$ & $\mathbf{R}^{\mathbf{2}}(\mathbf{a d j})$ & $\mathbf{C}_{\mathbf{p}}$ & $\log \mathbf{M}$ & $\log \mathbf{S}$ & $\log \mathbf{T}$ & $\log \mathbf{H}$ \\
\hline 1 & 82.1 & 81.5 & 16.8 & & $\mathrm{X}$ & & \\
1 & 43.8 & 41.8 & 108.6 & & & $\mathrm{X}$ & \\
2 & 88.9 & 88.1 & 2.6 & $\mathrm{X}$ & $\mathrm{X}$ & & \\
2 & 85.0 & 83.9 & 11.9 & & $\mathrm{X}$ & $\mathrm{X}$ & \\
3 & 89.5 & 88.3 & 3.2 & $\mathrm{X}$ & $\mathrm{X}$ & $\mathrm{X}$ & \\
3 & 89.4 & 88.2 & 3.4 & $\mathrm{X}$ & $\mathrm{X}$ & & $\mathrm{X}$ \\
4 & 89.6 & 87.9 & 5.0 & $\mathrm{X}$ & $\mathrm{X}$ & $\mathrm{X}$ & $\mathrm{X}$ \\
\hline
\end{tabular}


Results of the multiple regression model of EF PM 2.5 are shown in Table 4.5 and Table 4.6. It can be seen from Table 4.5 that hypothesis test of the individual regression coefficients (with $\mathrm{t}$ statistic) yields p-values less than 0.005 for log moisture and $\log$ wind speed, which indicates that only these variables are statistically significant in the model. The maximum value of VIF for the model is 1.22 and indicates that multicollinearity is not an issue in this case. The coefficient of determination $\mathrm{R}^{2}$ shows that $88.91 \%$ of the variation of the $\mathrm{EF} \mathrm{PM}_{2.5}$ is explained with the variables in the model.

The analysis of variance table for the $\mathrm{EF} \mathrm{PM}_{2.5}$ is shown in Table 4.6. Analysis of variance indicates that $\mathrm{F}$ statistics are very large, and the $\mathrm{MS}_{\mathrm{E}}$ is small, which further shows that the regression line explains the most of the variability of the response variable. Comparison of SSE with Press statistics is an informal way of judging the sensitivity of the model fit. The value of the Press statistic (Table 4.5) is close to the value for sum squares of error (error adj. SS in Table 4.6), which indicates that overfitting is not the issue in this model. Moreover, the predicted $\mathrm{R}^{2}$ is reasonably close to the regular $\mathrm{R}^{2}$.

Table 4.5 Results of the multiple regression model for EF PM2.5

\begin{tabular}{c|ccccc}
\hline Term & Coef & SE Coef & T-value & P-value & VIF \\
\hline Constant & -10.599 & 0.353 & -29.99 & 0.000 & \\
Log M & -1.011 & 0.249 & -4.07 & 0.000 & 1.22 \\
Log S & 1.322 & 0.120 & 11.03 & 0.000 & 1.22 \\
Summary of & $\mathbf{R}^{\mathbf{2}=\mathbf{8 8 . 9 1 \%}}$ & $\mathbf{R}^{\mathbf{2}}(\mathbf{a d j})=$ & $\mathbf{R}^{\mathbf{2}}$ (pred) $=$ & Press $=$ & \\
Model & & $\mathbf{8 8 . 0 9 \%}$ & $\mathbf{8 7 . 1 2 \%}$ & $\mathbf{1 2 . 3 9 6 3}$ & \\
\hline
\end{tabular}


Table 4.6 Analysis of variance table for EF PM2.5

\begin{tabular}{c|ccccc}
\hline Source & DF & Adj SS & Adj MS & F-value & P-value \\
\hline Regression & 2 & 85.5533 & 42.7767 & 108.21 & 0.000 \\
Log M & 1 & 6.5360 & 6.5360 & 16.53 & 0.000 \\
Log S & 1 & 48.1103 & 48.1103 & 121.70 & 0.000 \\
Error & 27 & 10.6738 & 0.3953 & & \\
Total & 29 & 96.2272 & & & \\
\hline
\end{tabular}

The regression equation has the following form:

$$
\log \mathrm{EF}_{\mathrm{PM}} 2.5=-10.599-1.1011 \log \mathrm{M}+1.322 \log \mathrm{S}
$$

Removing log from both sides, the mathematical formulation of the model is represented by Equation 4.2.

$$
\mathrm{EF} \mathrm{PM}_{2.5}=0.0000249 \times \mathrm{M}^{-1.011} \times \mathrm{S}^{1.322}
$$

For validation of the model, data splitting was carried out. The data was divided into two separate samples in a random order. One of the samples was used in building the model, and the other sample was used for validation of the model. The MSPR was calculated when the regressed coefficients were used on the validation data set. The MSPR is 0.4033 which very close to $\mathrm{MS}_{\mathrm{E}}$ value of 0.3953 (Table 4.6). Thus, the selected model has a good predictive ability for the validation data set.

\subsubsection{Model for $\mathbf{P M}_{10}$}

Table 4.7 shows the results of the best subset regression for $\mathrm{PM}_{10}$. The two-variable model consists of $\log$ moisture and $\log$ wind speed. The full model containing all the variables has $\mathrm{R}^{2}(\operatorname{adj})=91.7$, 
which very close to the two-variable model containing log moisture and log wind speed. Both the full model and two-variable model have low $\mathrm{C}_{\mathrm{p}}$. Thus, the backward stepwise regression analysis is conducted to find the preferred model.

Table 4.7 Results of the best subset regression for EF PM10

\begin{tabular}{c|ccccccc}
\hline Variables & $\mathbf{R}^{2}$ & $\mathbf{R}^{\mathbf{2}}(\mathbf{a d j})$ & $\mathbf{C}_{\mathbf{p}}$ & $\log \mathbf{M}$ & $\log \mathbf{S}$ & $\log \mathbf{T}$ & $\log \mathbf{H}$ \\
\hline 1 & 81.3 & 80.6 & 39.5 & & $\mathrm{X}$ & & \\
1 & 47.7 & 45.9 & 157.0 & $\mathrm{X}$ & & & \\
2 & 92.6 & 92.1 & 1.8 & $\mathrm{X}$ & $\mathrm{X}$ & & \\
2 & 83.2 & 82.0 & 34.8 & & $\mathrm{X}$ & $\mathrm{X}$ & \\
3 & 92.7 & 91.9 & 3.4 & $\mathrm{X}$ & $\mathrm{X}$ & & $\mathrm{X}$ \\
3 & 92.6 & 91.8 & 3.7 & $\mathrm{X}$ & $\mathrm{X}$ & $\mathrm{X}$ & \\
4 & 92.9 & 91.7 & 5.0 & $\mathrm{X}$ & $\mathrm{X}$ & $\mathrm{X}$ & $\mathrm{X}$ \\
\hline
\end{tabular}

Results of the multiple regression model of EF PM 10 are shown in Table 4.8 and Table 4.9. It can be seen from Table 4.8 that hypothesis test of the individual regression coefficients (with $\mathrm{t}$ statistic) yields p-values less than 0.005 for log moisture and $\log$ wind speed, which indicates that only these variables are statistically significant in the model. The maximum value of VIF for the model is 1.22 and indicates that multicollinearity is not an issue in this case. The coefficient of determination $\mathrm{R}^{2}$ shows that $92.64 \%$ of the variation of the $\mathrm{EF} \mathrm{PM}_{10}$ is explained with the variables in the model.

The analysis of variance table for the $\mathrm{EF} \mathrm{PM}_{10}$ is shown in Table 4.9. Analysis of variance indicates that $\mathrm{F}$ statistics are very large, and the $\mathrm{MS}_{\mathrm{E}}$ is small, which further means that the regression line explains the most of the variability of the response variable. Comparison of SSE 
with Press statistics is an informal way of judging the sensitivity of the model fit. The value of the Press statistic (Table 4.8) is close to the value for sum squares of error (error adj. SS in Table 4.9), which indicates that overfitting is not the issue in this model. Moreover, the predicted $\mathrm{R}^{2}$ is reasonably close to the regular $\mathrm{R}^{2}$.

Table 4.8 Results of the multiple regression model for EF PM10

\begin{tabular}{c|ccccc}
\hline Term & Coef & SE Coef & T-value & P-value & VIF \\
\hline Constant & -9.114 & 0.285 & -31.92 & 0.000 & \\
Log M & -1.296 & 0.201 & -6.45 & 0.000 & 1.22 \\
Log S & 1.2427 & 0.0968 & 12.84 & 0.000 & 1.22 \\
Summary of & $\mathbf{R}^{\mathbf{2}=\mathbf{9 2 . 6 4 \%}}$ & $\mathbf{R}^{\mathbf{2}(\mathbf{a d j})=}$ & $\mathbf{R}^{\mathbf{2}}(\mathbf{p r e d})=$ & Press & \\
Model & & $\mathbf{9 2 . 0 9 \%}$ & $\mathbf{9 0 . 9 1 \%}$ & $\mathbf{= 8 . 6 0 3 9 1}$ & \\
\hline
\end{tabular}

Table 4.9 Analysis of variance table for EF PM10

\begin{tabular}{c|ccccc}
\hline Source & DF & Adj SS & Adj MS & F-value & P-value \\
Regression & 2 & 87.6389 & 43.8194 & 169.91 & 0.000 \\
Log M & 1 & 10.7411 & 10.7411 & 41.65 & 0.000 \\
Log S & 1 & 42.4953 & 42.4953 & 164.78 & 0.000 \\
Error & 27 & 6.9631 & 0.2579 & & \\
Total & 29 & 94.6020 & & & \\
\hline
\end{tabular}


The regression equation has the following form:

$$
\log \mathrm{EFPM}_{10}=-9.144-1.296 \log \mathrm{M}+1.2427 \log \mathrm{S}
$$

Removing log from both sides, the mathematical formulation of the model is represented by Equation 4.4.

$$
\mathrm{EF} \mathrm{PM}_{10}=0.00011 \times \mathrm{M}^{-1.296} \times \mathrm{S}^{1.2427}
$$

For validation of the model, data was divided into two separate samples in a random order. The MSPR was calculated when the regressed coefficients were used on the validation data set. The MSPR is 0.3116 which very close to $\mathrm{MS}_{\mathrm{E}}$ value of 0.2579 (Table 4.9). Thus, the selected model has a good predictive ability for the validation data set.

\subsubsection{Model for TSP}

Table 4.10 shows the results of the best subset regression for TSP. The two-variable model consists

of $\log$ moisture and $\log$ wind speed. The full model containing all the variables has $\mathrm{R}^{2}(\operatorname{adj})=90.7$, which is very close to the two-variable model containing log moisture and log wind speed. Both the full model and the two-variable model have low $C_{p}$. Thus, the backward stepwise regression analysis is conducted to find the preferred model. 
Table 4.10 Results of the best subset regression for TSP

\begin{tabular}{c|ccccccc}
\hline Variables & $\mathbf{R}^{2}$ & $\mathbf{R}^{\mathbf{2}}(\mathbf{a d j})$ & $\mathbf{C}_{\mathbf{p}}$ & $\log \mathbf{M}$ & $\log \mathbf{S}$ & $\log \mathbf{T}$ & $\log \mathbf{H}$ \\
\hline 1 & 76.1 & 75.3 & 48.2 & & $\mathrm{X}$ & & \\
1 & 52.8 & 51.2 & 120.5 & $\mathrm{X}$ & & & \\
2 & 91.4 & 90.7 & 2.8 & $\mathrm{X}$ & $\mathrm{X}$ & & \\
2 & 77.1 & 75.4 & 47.3 & & $\mathrm{X}$ & $\mathrm{X}$ & \\
3 & 91.9 & 91.0 & 3.1 & $\mathrm{X}$ & $\mathrm{X}$ & & $\mathrm{X}$ \\
3 & 91.7 & 90.8 & 3.8 & $\mathrm{X}$ & $\mathrm{X}$ & $\mathrm{X}$ & \\
4 & 92.0 & 90.7 & 5.0 & $\mathrm{X}$ & $\mathrm{X}$ & $\mathrm{X}$ & $\mathrm{X}$ \\
\hline
\end{tabular}

Results of the multiple regression model of EF TSP are shown in Table 4.11 and Table 4.12. It can be seen from Table 4.11 that hypothesis test of the individual regression coefficients (with $\mathrm{t}$ statistic) yields p-values less than 0.005 for $\log$ moisture and log wind speed, which indicates that only these variables are statistically significant in the model. The maximum value of VIF for the model is 1.22 and indicates that multicollinearity is not an issue in this case. The coefficient of determination $\mathrm{R}^{2}$ shows that $91.37 \%$ of the variation of the EF TSP is explained with the variables in the model.

The analysis of variance table for the EF TSP is shown in Table 4.12. Analysis of variance indicates that $\mathrm{F}$ statistics are very large, and the $\mathrm{MS}_{\mathrm{E}}$ is small, which further means that the regression line explains the most of the variability of the response variable. Comparison of SSE with Press statistics is an informal way of judging of the sensitivity of the model fit. The value of the Press statistic (Table 4.11) is close to the value for sum squares of error (error adj. SS in the 
Table 4.12), which indicates that overfitting is not the issue in this model. Moreover, the predicted $\mathrm{R}^{2}$ is reasonably close to the regular $\mathrm{R}^{2}$.

Table 4.11 Results of the multiple regression model for TSP

\begin{tabular}{c|ccccc}
\hline Term & Coef & SE Coef & T-value & P-value & VIF \\
\hline Constant & -8.240 & 0.321 & -25.67 & 0.000 & \\
Log M & -1.561 & 0.226 & -6.91 & 0.000 & 1.22 \\
Log S & 1.196 & 0.109 & 10.98 & 0.000 & 1.22 \\
Summary of & $\mathbf{R}^{\mathbf{2}=\mathbf{9 1 . 3 7 \%}}$ & $\mathbf{R}^{\mathbf{2}}(\mathbf{a d j})=$ & $\mathbf{R}^{\mathbf{2}}(\mathbf{p r e d})=$ & Press $=$ & \\
Model & & $\mathbf{9 0 . 7 3 \%}$ & $\mathbf{8 9 . 3 1 \%}$ & $\mathbf{1 0 . 9 0 8 4}$ & \\
\hline
\end{tabular}

Table 4.12 Analysis of variance table for TSP

\begin{tabular}{c|ccccc}
\hline Source & DF & Adj SS & Adj MS & F-value & P-value \\
\hline Regression & 2 & 93.249 & 46.6426 & 142.97 & 0.000 \\
Log M & 1 & 15.582 & 15.5820 & 47.78 & 0.000 \\
Log S & 1 & 39.329 & 39.3285 & 120.60 & 0.000 \\
Error & 27 & 8.805 & 0.3261 & & \\
Total & 29 & 102.054 & & & \\
\hline
\end{tabular}

The regression equation has the following form:

$$
\log \mathrm{EF} \text { TSP }=-8.24-1.561 \log \mathrm{M}+1.196 \log \mathrm{S}
$$

Removing log from both sides, the mathematical formulation of the model is represented by Equation 4.6.

$$
\mathrm{EF} \text { TSP }=0.000264 \times \mathrm{M}^{-1.561} \times \mathrm{S}^{1.196}
$$


For validation of the model, data was divided into two separate samples in a random order. The MSPR was calculated when the regressed coefficients were used on the validation data set. The MSPR is 0.3867 which very close to $\mathrm{MS}_{\mathrm{E}}$ value of 0.3261 (Table 4.12). Thus, the selected model has a good predictive ability for the validation data set. 


\section{Chapter 5}

\section{Summary, Conclusions, and Scope for Future Research}

\subsection{Summary}

No studies have been conducted relating to the estimation of dust emission for coal loading facilities since 1979. The EDS study carried out in 1978 and 1979 (Shearer et. al., 1981) to develop Particulate Matter emission factors was the most recent research in this area. Over the years many changes have taken place, particularly in the technology used in coal loading facilities. Against this backdrop, the research was undertaken to fill the void, with two objectives: (i) to conduct an analysis of dust emission for a coal train loading facility, and (ii) to develop a dust emission factors (EFs) model for train loading operations.

In the first step field studies were conducted at a train loading facility in West Virginia. The dust concentrations at different distances and locations were collected during field trips. Also, various weather parameters required for the study such as wind speed, wind direction, temperature, humidity, and atmospheric pressure were collected. The data so collected were processed and analyzed.

Dust emission for the train loading point was determined by two methods: (i) the EPA AP42 emission factor estimation equations (AP-42 Dust Emission Estimation) and (ii) the methodology used in the development of AP-42 equations (Type-2 Dust Emission Estimation). 
Based on the analysis of the data, reconsideration of EFs for train loading operations and development of improved methods for estimation of EFs was suggested. A new model for estimating EF equations for train loading operations was developed based on multiple regression analysis. The measured variables that were used as independent ones (regressors), and included in the model development were wind speed $(\mathrm{m} / \mathrm{s})$, moisture content $(\%)$, temperature $\left({ }^{\circ} \mathrm{C}\right)$, and humidity (\%). The wind speed and moisture content of coal were found to be statistically significant and were included in the final model. Though the temperature and humidity had some effect on EFs, they were excluded from the final model due to statistical insignificance.

\subsection{Conclusions}

In this study, the current EPA method for estimation of dust emission in coal loading facilities has been examined, and a comparative analysis of dust emission between AP-42 Dust Emission Estimation and Type-2 Dust Emission Estimation has been carried out for a particular loading facility in West Virginia. The comparison shows that the AP-42 Dust Emission Estimation method overestimates the emissions from loading of coal trains for this specific loading facility.

The major causes of over-prediction include the following:

i) The methodology used by EPA for calculation of the emission rates had limitations. The original AP-42 Dust Emission Estimation was developed primarily for TSP; however, later on, researchers had shifted focus to fine and inhalable particles, i.e., $\mathrm{PM}_{10}$ and $\mathrm{PM}_{2.5}$, because these elements posed the biggest environmental and health threat. Cowherd (2006) conducted studies on fine particles and found that concentration measurements used to develop EFs for $\mathrm{PM}_{2.5}$ in AP-42 were higher by a factor of two, as compared to $\mathrm{PM}_{2.5}$ measurements from EPA federal reference method (FRM) 
samplers. Currently, the ratio of $\mathrm{PM}_{2.5} / \mathrm{PM}_{10}$ in AP-42 ranges from 0.15 to 0.4 for most fugitive dust sources. However, studies showed the ratio to be in the range of 0.1 to 0.15. Based on the results of the study, EFs for $\mathrm{PM}_{2.5}$ in AP-42 were revised for the following four fugitive dust source categories: paved roads, unpaved roads (public and industrial), aggregate handling and storage piles, and industrial wind erosion.

ii) A small number of variables are considered for AP-42 emission estimation calculations, which may be inadequate.

The primary focus in developing a new model was to formulate a new EF estimation equation for dust particulate concentration at train loading operations considering the use of onsite meteorological data for that particular site. Based on the new model developed, it can be concluded that:

i) The moisture content of coal has a significant effect on the dust emission at coal train loading facilities. The moisture content increases the particle mass and surface tension, thereby reducing suspension and transport. Even after evaporation of water, the cohesion of wetted particles persists due to the formation of aggregates and surface crusts.

ii) Wind speed also plays a major role in dust emission. High wind speeds provide the energy needed to suspend loose particle from the surface, and the turbulence associated with these winds elevates particles to high altitudes where they can be transported over long distances.

iii) Temperature and humidity have some effect on emission, though their effects were statistically insignificant. Air temperature influences atmospheric stability, which in turn affects the vertical movement of particles in the atmosphere. 


\subsection{Limitations and Scope for Future Research}

The analysis of dust emission at a train loading facility in this research was based only on several data sets that were available for analysis. Also, the data collected on the same days were used also used in validation set. A collection of more data on several days would enhance the accuracy of the evaluation and give better insight into the role of different parameters on dust emission. The new data also may change the coefficients as well as increase the number of parameters in the model. Moreover, temperature and humidity may play a significant role in emissions. Also, with more data, mining, and environmental professionals could more accurately quantify dust emission at train loading facilities and develop strategies to mitigate it.

The collection of more data during the day vs. night time and also in different seasons would allow additional analysis to determine the variation between the various times as well as seasons. In that way, if the difference was significant, other strategies could be developed for particular time or season.

In future work, the Dust Emission Estimation should be based on the methodology suggested in the AERMOD model, which is the preferred dust dispersion model for regulatory applications in the estimation of dust dispersion (EPA, 2015c). EFs estimated by the AERMOD method are also based on concentration data from the mine. However, the method employed to convert concentrations to emission rates is not the same as the method used by the EPA's AP-42. The main difference between the EPA's AP-42 and the AERMOD method is the way the plume dispersion variables $\left(\sigma_{\mathrm{y}}\right.$ and $\left.\sigma_{\mathrm{z}}\right)$ are calculated. The EPA's AP-42 method uses P-G dispersion curves, whereas AERMOD uses Monin-Obukhov length to estimate plume dispersion variables. Also, a comparative analysis between AP-42 Dust Emission Estimation, Type-2 Dust Emission 
Estimation and the equations developed in the model can be carried for this particular train loading facility.

The model developed in this research can be used for estimation of dust emissions from this particular train loading facility. However, the addition of data from other train loading facilities would make the model more accurately predict dust emissions for other train loading facilities. 


\section{References}

1. ACARP, 2012, "Managing dust emissions from mine to port," (abstract of report by John Planner, Introspec Consulting). ACARP Matters. Available at: http://www.acarp.com.au/Media/ACARPMatters_24_Dust.pdf

2. AECOM, 2015, “Lower Hunter Dust Deposition Study - Interim Report," AECOM Australia Pty Ltd: Prepared for the NSW Environment Protection Authority. Available at: http://www.epa.nsw.gov.au/MediaInformation/lhddprg.htm

3. Aurecon Hatch, 2009, "Coal Leakage from Kwik-Drop Doors Coal Loss Management Project Queensland," Prepared for Queensland Rail Limited (now Aurizon)

4. Burlington Northern Santa Fe Railway Company (BNSF) and United Pacific Railroad Company (UP), 2010, "Summary of BNSF/UP Super Trial 2010," Available at: http://www.bnsf.com/customers/pdf/coal-super-trial.pdf

5. Chepil, W.S, and Woodruff, N.P., 1963, "The physics of wind erosion and its control," Advances in Agronomy, 15, 211-302.

6. Cole C.F., and Zapert J.G., 1995, “Air quality dispersion model validation at three stone quarries," Englewood, CO: TRC Environmental Corp. TRC project No. 14884 for the National Stone Association, Washington DC.

7. Colls, J., 2002, “Air Pollution,” 2nd edition, Taylor \& Francis, New York.

8. Cope, D. L., and Bhattacharyya, K.K., 2001, “A Study of Fugitive Coal Dust Emissions in Canada," Prepared for The Canadian Council of Ministers of the Environment.

9. Connell Hatch, 2008, “Environmental Evaluation of Fugitive Coal Dust Emissions from Coal Trains," Final Report, prepared for Queensland Rail Limited. Available at: 
http://www.tonguerivereis.com/documents/Coal_DustLoss_Management_Project_Enviro nmental_Evaluation.pdf

10. Cora, M.G., Hung, Y.T., 2003, "Air dispersion modeling: A tool for environmental evaluation and improvement," Environmental Quality Management, 12, 75-86.

11. Cowherd, C., 2006, "Background Document for Revisions to Fine Fraction Ratios used for AP-42 Fugitive Dust Emission Factors," Prepared by Midwest Research Institute for Western Governors Association, Western Regional Air Partnership, Denver, CO.

12.Department of Science, Information Technology, Innovation and the Arts (DSITIA), 2012, “Tennyson Dust Monitoring Investigation - September to October 2012," Queensland Government.

13. Duce, R.A., Unni, C.K., Ray, B.J., Prospero, J.M., and Merill, J.T., 1980 "Long Range atmospheric transport of soil dust from Asia to the tropical North Pacific: Temporal variability," Science, 209, 1522-1524.

14. ENVIRON, 2012, "Pollution Reduction Program (PRP) 4 - Particulate Emissions from Coal Trains," Prepared by ENVIRON Australia Pty Ltd for Australian Rail Track Corporation.

15. Environmental Protection Agency, 1994, "Modeling fugitive dust impacts from surface coal mining operations: phase II - model evaluation protocol, " Research Triangle Park, NC: U.S. Environmental Protection Agency, Office of Air Quality Planning and Standards, Technical Support Division, EPA publication No. EPA-454/ R-94-025.

16. Environmental Protection Agency, 1995a, "Modeling fugitive dust impacts from surface coal mining operations: phase III - evaluating model performance," Research Triangle Park, NC: U.S. Environmental Protection Agency, Office of Air Quality Planning and 
Standards, Emissions, Monitoring, and Analysis Division, EPA publication No. EPA454/R-96-002.

17. Environmental Protection Agency, 1995b, “User's guide for the industrial source complex (ISC3) dispersion models. Vol. II. Description of model algorithms, ” Research Triangle Park, NC: U.S. Environmental Protection Agency, Office of Air Quality Planning and Standards, Emissions, Monitoring, and Analysis Division, EPA publication No. EPA454/B-95-003b.

18. Environmental Protection Agency, 1996, "Review of the National Ambient Air Quality Standards for Particulate Matter: Policy Assessment of Scientific and Technical Information,” Office of Office of Air Quality Planning and Standards U.S. Environmental Protection Agency, EPA-452\R-96-013

19. Environmental Protection Agency, 1998, “Revision of Emission Factors for AP-42 Section 11.9 Western Surface Coal Mining," Available at: http://www3.epa.gov/ttn/chief/ap42/ch11/bgdocs/b11s09.pdf

20. Environmental Protection Agency, 2001, “Introduction to stationary point source emission inventory development, Emission inventory improvement program, Vol II, (1), ” Available at: http://www3.epa.gov/ttn/chief/eiip/techreport/volume02/ii01_may2001.pdf

21. Environmental Protection Agency, 2015a, “Emissions Factors \& AP 42, Compilation of Air Pollutant Emission Factors, ” Available at http://www3.epa.gov/ttnchie1/ap42/

22. Environmental Protection Agency, 2015b, "Emissions Factors \& AP 42, Aggregate Handling and Storage Piles, ” Available at: https://www3.epa.gov/ttn/chief/ap42/ch13/final/c13s0204.pdf 
23. Environmental Protection Agency, 2015c, “AERMOD Implementation Guide,” Available at: https://www3.epa.gov/ttn/scram/7thconf/aermod/aermod_implmtn_guide_3August2015.p $\underline{\text { df }}$

24. Ferreira A.D., Viegas D.X., and Sousa A.C.M., 2003, "Full-scale measurements for evaluation of coal dust release from train wagons with two different shelter covers," Journal of Wind Engineering and Industrial Aerodynamics, 91, 1271-1283.

25. Ferreira A.D., and Vaz P.A., 2004, "Wind tunnel study of coal dust release from train wagons, "Journal of Wind Engineering and Industrial Aerodynamics, 92, 565-577.

26. Friedlander, S. K., 1999, "Smoke, Dust, and Haze: Fundamentals of Aerosol Dynamics," Oxford University Press, Cambridge, UK.

27. Gifford, F.A., Jr. 1976, “Turbulent Diffusion - Typing Schemes: A Review,” Nuclear. Safety. 17, 68-86.

28. Gillette, D. A. and Blifford, I.H., 1971, "Composition of tropospheric aerosols as a function of altitude, "Journal of the Atmospheric Sciences, 28, 1199-1201.

29. Gillette, D. A., Blifford, I.H., Jr, and Frenster, C.R., 1972, "Measurements of aerosol size distributions and vertical fluxes of aerosols on land subject to wind erosion, " Journal of Applied Metrology and Climatology, 11, 977-987.

30. Gillette, D. A. and Hanson, K., 1989, "Spatial and temporal variability of dust production caused by wind erosion in the United States, ” Journal of Geophysical Research, 94, 1288512885.

31. Grantz, D.A, Garner, J.H.B., and Johnson, D.W., 2003, Ecological effects of particulate matter, Environment International, 29, 213-239. 
32. Green, A.E., Singhal, R.P., and Venkateswar, R., 1980, "Analytic extensions of the Gaussian plume model, " Journal of the Air Pollution Control Association, 30(7), 773-776.

33. Higginbotham, N., Ewald, B., Mozeley, F., \& Whelan, J., 2013, “Coal train pollution signature study, ” Coal Terminal Action Group Dust and Health Committee: Coal Terminal Action Group.

34. Hussein, T., Karppinen, A., Kukkonen, J., Harkonen, J., Aalto, P. P., Hameri, K., Kerminen, V., and Kulmala, V., 2006, “Meteorological dependence of size-fractionated number concentrations of urban aerosol particles, ” Atmospheric Environment, 40, 14271440.

35. International Finance Corporation (IFC), 2007, "Air emissions and ambient air quality," Environmental, health and safety guidelines. Available at http://www.ifc.org/wps/wcm/connect/532ff4804886583ab4d6f66a6515bb18/11\%2BAir\%2BEmissions\%2Band\%2BAmbient\%2BAir\%2BQuality.pdf?MOD=AJPERE $\underline{\mathrm{S}}$

36. International Standard Organization (ISO), 2004, “ISO 20905:2004, Coal Preparation: Determination of dust/moisture relationship for coal," Available at: http://www.iso.org/iso/iso_catalogue/catalogue_tc/catalogue_detail.htm?csnumber=3431 $\underline{3}$

37. Inyang, H.I., and Bae, S., 2006, “Impacts of dust on environmental systems and human health, ” Hazardous Materials, 132, v-vi.

38. Jaffe, D., Putz, J., Hof, G., Hee, J., Lommers-Johnson, D.A., Gabela, F., Fry, J.L., Ayres, B., Kelp, M. and Minsk, M., 2015, “Diesel particulate matter and coal dust from trains in 
the Columbia River Gorge," Washington State, USA. Atmospheric Pollution Research, 6(6), 946-952.

39. Kane, M., 2015, "Health Hazard in our suburbs: Particulate pollution along the SouthEast Queensland coal dust corridor," Prepared for Clean Air Queensland.

40. Katestone Environmental Pty Ltd., 2012, "Duralie Extension Project, Study of Dust Emissions from Rail Transport, ” Prepared for Duralie Coal Pty Ltd.

41. Katestone Environmental Pty Ltd., 2014, “Literature Review of Coal Train Dust Management Practices, " Report to NSW Environment Protection Authority.

42. Kotchenruther, R., 2013, "Fugitive dust from coal trains: factors effecting emissions \& estimating PM $2.5 \quad$ NW-AIRQUEST,,$\quad$ Available at: $\underline{\text { http://lar.wsu.edu/nw- }}$ airquest/docs/201306_meeting/20130606_Kotchenruther_coal_trains.pdf

43. Kutner, M. H., Nachtsheim, C.J., and Neter, J., 2004, “Applied Linear Regression Models, " Fourth Edition, McGraw-Hill/Irvin, Inc., New York, USA

44. Lashgari, A., and Kecojevic, V. 2015, “Comparative Analysis of Dust Emission of Digging and Loading Equipment in Surface Coal Mining," International Journal of Mining, Reclamation and Environment. Taylor \& Francis. DOI: 10.1080/17480930.2015.1028516.

45. Montgomery, D.C. and Runger, G.C., 2003, "Applied Statistics and Probability for Engineers, ” Third Edition, John Wiley and Sons Inc., New York, USA.

46. Moore D.S. and McCabe George P., 2006, “Introduction to the practice of statistics, ” Fifth Edition, W. H. Freeman and Company, New York, USA.

47. National Institute for Occupational Safety (NIOSH), 1995, “Criteria for a recommended standard, occupational exposure to respirable coal mine dust," Available at http://www.cdc.gov/niosh/docs/95-106/pdfs/95-106.pdf 
48. National Pollutant Inventory. 2012, "Emission Estimation Technique Manual for Mining. Version 3.1," Available at: http://www.npi.gov.au/system/files/resources/7e04163a-12ba6864-d19a-f57d960aae58/files/mining.pdf

49. New South Wales Environmental Protection Agency (NSW EPA), 2014, “Compliance audit of coal train loading and unloading facilities," Environment Compliance report. Available at http://www.epa.nsw.gov.au/resources/epa/148597-comp-audit-coal-train.pdf

50. Occupational Safety and Health Administration (OSHA), 2015, "Chemical Sampling Information," Available at: https://www.osha.gov/dts/chemicalsampling/data/CH_266740.html

51. Prospero, J.M., Bonatti, E., Schubert, C. and Carlson, T.N., 1970, "Dust in the Caribbean atmosphere traced to an African dust storm, " Earth and Planetary Science Letters, 9, 287293.

52. Prospero, J.M. and Carlson, T.N., 1972, "Vertical and aerial distribution of Saharan dust over the western equatorial North Atlantic Ocean, Journal of Geophysical Research," 77, $5255-5265$

53. Reed W.R., Westman E.C., and Haycocks C., 2001, “An improved model for estimating particulate emissions from surface mining operations in the eastern United States, " In: Securing the Future - Proceedings of the International Conference on Mining and the Environment (Skellefteå, Sweden, June 25-July 1, 2001). Stockholm, Sweden: Swedish Mining Association, 693-702.

54. Reed W.R., 2003, "An improved model for prediction of PM10 from surface mining operations," Dissertation. Blacksburg, VA: Virginia Polytechnic Institute and State University, Department of Mining and Minerals Engineering. 
55. Reed, W. R., 2004, "Performance evaluation of a dust-dispersion model for haul trucks," SME Transaction, 316, pp. 163-171.

56. Reed, W.R., 2005, “Significant Dust Dispersion Models for Mining Operations, ” Report for National Institute for Occupational Safety and Health, Research Laboratory, Pittsburgh, IC 9478 information circular/2005.

57. Ryan, L., and Wand, Mo., 2014, "Re-analysis of ARTC data on Particulate Emissions from Coal Trains," accessUTS Pty Limited, NSW, Australia, Project Number 2013001693. Available at: http://www.epa.nsw.gov.au/resources/air/ARTCreanalysisFeb2014.pdf

58. Ryan, L., and Malecki, A., 2015, “Additional analysis of ARTC data on Particulate Emissions from Coal Trains," accessUTS Pty Limited, NSW, Australia, Project Number 2015000889. Available at: http://www.epa.nsw.gov.au/resources/air/artc-dust-ryanreport.pdf

59. Schnelle, Karl B., and Partha R. Dey. 2000, “Atmospheric dispersion modeling compliance guide,” New York: McGraw-Hill

60. Sehmel, G. A., 1980, “Particle resuspension: A review,” Environment International, 4, $107-127$

61. Shearer, D. L., Dougherty, R.A., and Easterbrook, C.C., 1981, “Coal Mining Emission Factor Development and Modeling Study," TRC Environmental Consultants Inc. Project No. \#0908-D1045.

62. Slinn, W. G. N, 1982, 'Predictions for particle deposition to vegetative canopies," Atmospheric Environment, 16, 1785-1794.

63. Szabo. M.F., 1978, “Environmental assessment of coal transportation,” Environmental Protection Agency, Cincinnati, Ohio. 
64. Todorski, A. 2012, "Particulate matter best management practice pollution reduction program-Ashton Coal Operations Pty Ltd," Job Number 12050093.

65. Turner, D.B., 1970, “Workbook of Atmospheric Dispersion Estimates,” PHS Publication No. 999-AP-26. U.S. Department of Health, Education and Welfare, National Air Pollution Control Administration, Cincinnati, Ohio.

66. Zoras, S., Triantafyllou, A.G. and Deligiorgi, D., 2006, "Atmospheric stability and $P M_{10}$ concentrations at far distance from elevated point sources in complex terrain: Worst-case episode study," Environmental Management 80, 295-302. 